
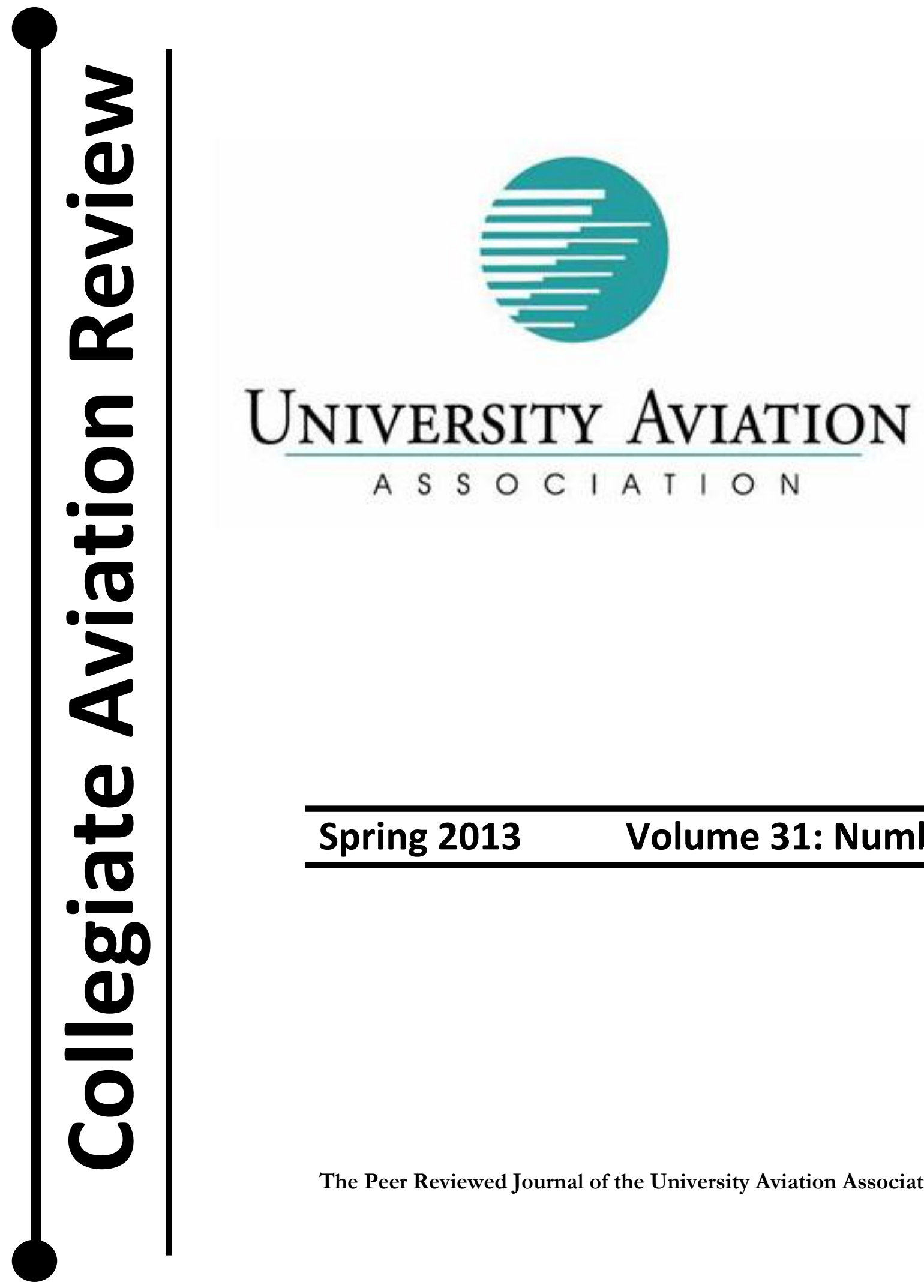

A S S O C I A T I O N

Spring $2013 \quad$ Volume 31: Number 1

The Peer Reviewed Journal of the University Aviation Association 


\section{UNIVERSITY AVIATION ASSOCIATION}

\section{COLLEGIATE AVIATION REVIEW}

David C. Ison, Ph.D., Editor

Wendy S. Beckman, Ed.D., Associate Editor 
The Collegiate Aviation Review (CAR)

Spring 2013, Volume 31, Number 1

David C. Ison, Editor

Copyright (C 2013 University Aviation Association

All correspondence and inquiries should be directed to:

University Aviation Association

3410 Skyway Drive

Auburn, AL 36830

Telephone: 334-844-2434

Email: uaa@uaa.aero

ISSN Number: 1523-5955 


\section{Editorial Board of the \\ Collegiate Aviation Review}

David C. Ison, Embry-Riddle Aeronautical University, Editor

Wendy S. Beckman, Middle Tennessee State University, Associate Editor

$\begin{array}{ll}\text { Timm Bliss } & \text { Oklahoma State University } \\ \text { Thomas Carney } & \text { Purdue University } \\ \text { Gerald Chubb } & \text { The Ohio State University } \\ \text { Richard Fanjoy } & \text { Purdue University } \\ \text { Mavis Green } & \text { Utah Valley University } \\ \text { Ramon Gonzalez } & \text { Farmingdale State College } \\ \text { Todd Hubbard } & \text { Oklahoma State University } \\ \text { Merrill Karp } & \text { Arizona State University } \\ \text { Suzanne Kearns } & \text { University of Western Ontario } \\ \text { Jacqueline Luedtke } & \text { Embry-Riddle Aeronautical University } \\ \text { David NewMyer } & \text { Southern Illinois University at Carbondale } \\ \text { Gary Northam } & \text { Embry-Riddle Aeronautical University } \\ \text { Jeanne Radigan } & \text { Farmingdale State College } \\ \text { Lorelei Ruiz } & \text { Southern Illinois University at Carbondale } \\ \text { Mark Sherman } & \text { New York State University - Farmingdale } \\ \text { James Simmons } & \text { Metropolitan State University of Denver }\end{array}$




\section{ACKNOWLEDGEMENTS}

No juried publication can excel, unless experts in the field serve as anonymous reviewers. Indeed, the ultimate guarantors of quality and appropriateness of scholarly materials for a professional journal are the knowledge, integrity, and thoroughness of those who serve in this capacity. The thoughtful, careful, and timely work of the Editorial Board and each of the following professionals added substantively to the quality of the journal, and made the editor's task much easier. Thanks are extended to each reviewer for performing this critically important work. In addition to the members of the Editorial Board, the other reviewers for this issue include:

Troy Allen
Ken Barnard
Elizabeth Bjerke
Tim Brady
Carmen Burrows
Paul Craig
Ronald Ferrara
Terry Gibbs
Cass Howell
Robert Kaps
Kitty Laird
Jeffrey LaPoint
Kent Lovelace
Chien Tsung Lu
Maxine Lubner
Michaela Lucas
Joel McKinzie
John Mott
Michael O'Toole
Manoj Patankar
Stephen Quilty
David Robertson
Gregory Schwab
James Simmons
Teresa Sloan
Alan Stolzer
Mary Ann Turney
Joe Vacek
Dale Watson
Linda Weiland
David Worrells
Bernard Wulle
John Young

\author{
Indiana State University \\ Kansas State University \\ University of North Dakota \\ Embry-Riddle Aeronautical University \\ Thomas Nelson Community College \\ Middle Tennessee State University \\ Middle Tennessee State University \\ University of Nebraska, Kearney \\ Embry-Riddle Aeronautical University \\ Southern Illinois University - Carbondale \\ Purdue University \\ Embry-Riddle Aeronautical University \\ University of North Dakota \\ Purdue University \\ Vaughn College of Aeronautics \\ University of Nebraska - Omaha \\ Minnesota State University - Mankato \\ Purdue University \\ Embry-Riddle Aeronautical University \\ Saint Louis University \\ SMQ Airport Services \\ Embry-Riddle Aeronautical University \\ Indiana State University \\ Metro State University of Denver \\ Central Washington State University \\ Embry-Riddle Aeronautical University \\ Arizona State University \\ University of North Dakota \\ Auburn University \\ Embry-Riddle Aeronautical University \\ Embry-Riddle Aeronautical University \\ Purdue University \\ Purdue University
}




\section{STATEMENT OF OBJECTIVES}

The Collegiate Aviation Review is published semi-annually by the University Aviation Association. Papers published in this volume were selected from submissions that were subjected to a blind peer review process, for presentation at the 2013 Fall Education Conference of the Association.

The University Aviation Association is the only professional organization representing all levels of the non-engineering/technology element in collegiate aviation education. Working through its officers, trustees, committees and professional staff, the University Aviation Association plays a vital role in collegiate aviation and in the aviation industry.

The University Aviation Association accomplishes its goals through a number of objectives:

To encourage and promote the attainment of the highest standards in aviation education at the college level.

To provide a means of developing a cadre of aviation experts who make themselves available for such activities as consultation, aviation program evaluation, speaking assignments, and other professional contributions that stimulate and develop aviation education.

To furnish a national vehicle for the dissemination of knowledge relative to aviation among institutions of higher education and governmental and industrial organizations in the aviation/aerospace field.

To foster the interchange of information among institutions that offer non-engineering oriented aviation programs including business technology, transportation, and education.

To actively support aviation/aerospace-oriented teacher education with particular emphasis on the presentation of educational workshops and the development of educational materials in the aviation and aerospace fields.

\section{University Aviation Association}

3410 Skyway Drive

Auburn, AL 36830

Telephone: (334) 844-2434

Email: uaa@auburn.edu 


\section{Call for Papers}

The Collegiate Aviation Review (CAR) is the refereed journal of the University Aviation Association (UAA). Both qualitative and quantitative research manuscripts relevant to aviation are acceptable. The CAR review process incorporates a blind peer review by a panel of individuals who are active in the focus area of each manuscript. Additional recommendations are also provided by the editors of the CAR. A list of all reviewers is published in each edition of the CAR and is available from the CAR editor.

Authors should e-mail their manuscript, in Microsoft Word format, to the editor at CARjournal@uaa.aero no later than July 1 (Fall 2013 issue) or December 31 (Spring 2014 issue).

Previous editions of the CAR should also be consulted for formatting guidance. Manuscripts must conform to the guidelines contained in the Publication Manual of the American Psychological Association, 6th edition. Specifically, this means that submissions should follow the formatting found in the manual, e.g. proper use of the headings, seriation, and in-text citations. The references section must be complete and in proper APA format. Submissions that include tables and figures should use the guidelines outlined in the APA manual. In order to better align the CAR with the general research community, submissions using quantitative analysis should take into account the recommendations of the APA Task Force on Statistical Inference. Papers that do not meet these expectations will be returned to the author for reformatting.

All submissions must be accompanied by a statement that the manuscript has not been previously published and is not under consideration for publication elsewhere. Further, all submissions will be evaluated with plagiarism detection software. Instances of selfplagiarism will be considered the same as traditional plagiarism. Submissions that include plagiarized passages will not be considered for publication.

If the manuscript is accepted for publication, the author(s) will be required to submit a final version of the manuscript via e-mail, in "camera-ready" Microsoft Word format, by the prescribed deadline. All authors will be required to sign a "Transfer of Copyright and Agreement to Present" statement in which (1) the copyright to any submitted paper which is subsequently published in the CAR will be assigned to the UAA and in which (2) the authors agree to present any accepted paper at a UAA conference to be selected by the UAA, if requested. Students are encouraged to submit manuscripts to the CAR. A travel stipend for conference attendance up to $\$ 500$ may be available for successful student submissions. Please contact the editor or UAA for additional information.

Questions regarding the submission or publication process may be directed to the editor at (727) 403-9903, or may be sent by email to: CARjournal@uaa.aero. 


\section{Editor's Commentary}

"If you want change, you have to make it. If we want progress we have to drive it." Susan Rice

There have been many changes that have taken place at the $C A R$ since I began my tenure as editor. Some aspects have been met with resistance - others with praise and support.

"Be a yardstick of quality. Some people aren't used to an environment where excellence is expected." - Steve Jobs

I stand by my dedication to making the $C A R$ the aviation academic journal with the highest regard among the industry. With this comes a commitment to ensuring that the work that appears in the journal is original, quality research that adds to the exigent body of knowledge. I believe that this edition shows how far the $C A R$ has come. We had a record number of submissions and this edition is one of the largest we have published. Submissions for the Fall edition are already beginning to be submitted. It appears that the $C A R$ is quite healthy and receiving numerous, excellent studies for consideration for publication. The publication rate for this issue was $83 \%$, rather high for an academic journal. However, I believe that the editorial staff and the reviewers did an excellent job of considering the submissions and insuring only quality work was accepted. I would like to say a special thank you for all who have dedicated their time and effort in service of the journal.

I will again challenge all of you to go out and perform research in pursuit of publication in the $C A R$. I will even make more interesting. If you have never been published in the $C A R$, submit an article for the Fall edition, and it is selected for publication, I will host a dinner for you in Puerto Rico (and if you can't make it I will send you a gift card so you can have a nice meal with friends or family). I'll call this the Editor's Challenge. I hope we will be sharing some mofongo or other Puerto Rican specialty in the Fall.

As a reminder, the $C A R$ now accepts book reviews (non-peer reviewed), methodological papers, reviews of statistical analysis, pilot studies, and more - basically, we are now more flexible about submissions. Please send me a query about any ideas you have for submission. We can chat about what works and what doesn't.

Lastly, thank you to all who support the transition of the $C A R$ into an even more prestigious publication. Cheers - David Ison, $\mathrm{PhD}$, Editor

"Associate with men of good quality if you esteem your own reputation; for it is better to be alone than in bad company." - George Washington 


\section{TABLE OF CONTENTS}

Public Law 111-216: Effects of New Legislation on Collegiate Aviation Flight Training Programs

Chad L. Depperschmidt

Learning Styles of Australian Aviation Students: An Assessment of the Impact of Culture

Yi Gao, Kai Tai Stephen Au, Hyuk Joo Kwon, and Eu Wing Leong.....

Participation in Instrumental Music as a Predictor of Success in a Collegiate Level Aviation Flight Course

Tyson G. Jaquez.

Carbon Estimation and Offsets for U.S. University Aviation Programs

Mary E. Johnson, Alan Gonzalez, Brian Kozak, and Lauren Sperlak

Bioavailable Lead in Topsoil Collected from General Aviation Airports

Jerry H. Kavouras, Randal J. DeMik, and Allison C. Hopkins. ..

Snap-Courses: An Instructional Design Strategy for Aviation Mobile Learning

Suzanne K. Kearns.

Automatic Dependent Surveillance-Broadcast Training: Does it exist in Collegiate Aviation?

Andrew Leonard.

Promotion and Tenure Perceptions of University Aviation Association (UAA)

Collegiate A viation Administrators and Faculty:

Administration Perceptions versus Faculty Perceptions

Samuel R. Pavel and Bryan T. Harrison.

Leadership Effectiveness of Collegiate Aviation Program Leaders: A Four-frame Analysis

Ryan S. Phillips and Mark A. Baron

Economic Modeling to Improve Estimates of the Benefits of Safety Management Systems

Kelly Whealan George

Implementing Jet Aircraft Training in a University Setting:

Instructor Perceptions and Lessons Learned

Scott R. Winter, Jennifer E. Kirschner, Steven M. Leib, and Richard O. Fanjoy.... 


\title{
Public Law 111-216: Effects of New Legislation on Collegiate Aviation Flight Training Programs
}

\author{
Chad L. Depperschmidt \\ Oklahoma State University
}

\begin{abstract}
In response to the Colgan Air Flight 3407 crash, new legislation has been enacted. Among this new legislation is Public Law 111-216 (PL 111-216) that will require newly hired airline pilots to have acquired an Airline Transport Pilot (ATP) Certificate. This new requirement will affect aspiring pilots and training institutions. Collegiate flight training institutions have been particularly concerned with the implementation of PL 111216. To explore the potential effects of this new legislation and the perceptions of the survey respondents, this study surveyed collegiate flight training institutions. Results indicate collegiate aviation training institution respondents concerned that as a result of PL 111-216, programmatic and training costs will increase, recruitment and retention of student pilots will be adversely affected, and overall, the law will be detrimental to collegiate aviation flight training programs.
\end{abstract}

\section{Introduction}

On February 12, 2009, a Continental Connection flight operating as Colgan Air Flight 3407 crashed in Buffalo, New York, resulting in the deaths of 50 individuals (49 passengers and crew and one individual on the ground) (Pasztor, 2009). Colgan Air Flight 3407 was a regularly scheduled flight from Newark, New Jersey to Buffalo, New York. The aircraft operated for Flight 3407 was a 74 seat Bombardier Dash 8 Q400 aircraft. Colgan Air Flight 3407 was in its final stages of flight on an instrument approach approximately five minutes before the flight was scheduled to land at Buffalo Niagara International Airport when it crashed (Watch, 2009). On February 13, 2009, the National Transportation Safety Board (NTSB) sent a team of 14 investigators to the crash site. Both flight recorders, the Cockpit Voice Recorder and the Flight Data Recorder, were retrieved for analysis (Karp, 2012). Less than one year following the crash, the NTSB released its final Aircraft Accident Report. This report concluded the cause of the accident was pilot error (Trumbull, 2010). More specifically, the NTSB accident report concluded the probable cause for the crash of Colgan Air Flight 3407 was:

the captain's inappropriate response to the activation of the stick shaker, which led to an aerodynamic stall from which the airplane did not recover. Contributing to the accident were (1) the flight crew's failure to monitor airspeed in relation to the rising position of the lowspeed cue, (2) the flight crew's failure to adhere to sterile cockpit procedures, (3) the captain's failure to effectively manage the flight, and (4) Colgan Air's inadequate procedures for airspeed selection and management during approaches in icing conditions. (National Transportation Safety Board, 2009, p. 155) 
Immediately after the crash of Colgan Air Flight 3407, a great amount of interest and concern from many different groups closely followed developments and information from the pending investigation. These groups included the victims' families, aviation industry insiders, and the flying public. Soon after the events of Flight 3407, many concerns were quickly identified that were related to this accident. These areas of concern included airline code-sharing transparency, pilot training, issues of fatigue, and minimum pilot qualifications (Levin, 2012). These concerns were particularly important to the victims' families who organized and lobbied for a multitude of safety improvements. These items included flight and duty time limits, safety management systems, crew member training, crew member screening and qualifications, Air Transport Pilot (ATP) certificate requirement for all Part 121 flight crew members, mentoring and professional development, stall recognition and recovery, and remedial training programs (PL 111-216 Has Been Signed Into Law, 2010).

Due to the efforts of the victims' families and in an effort to address the multiple issues that the NTSB identified as potential contributing factors to the crash of Flight 3407, several rule changes have been proposed or implemented by the Federal Aviation Administration (FAA). The most significant of these rule changes is The Airline Safety and Federal Aviation Administration Extension Act of 2010, also known as Public Law 111-216 (PL 111-216 Has Been Signed Into Law, 2010). This legislation indicates its purpose is to; "amend the Internal Revenue Code of 1986 to extend the funding and expenditure authority of the Airport and Airway Trust Fund, to amend title 49, United States Code, to extend airport improvement program project grant authority and to improve airline safety, and for other purposes" (H.R. 5900, 2010 para.1). Among other things, this new legislation re-defines minimum qualification standards for pilots of commercial airlines. This change in standards is particularly important to aspiring pilots and pilot training organizations. As one of the largest and most unified entities of pilot training, collegiate flight training institutions have expressed a great deal of concern with this new legislation and its effects on training procedures and aspiring professional pilots (Everett, 2012; NewMyer, 2010).

While there are many different emphases within Public Law 111-216, this study focuses only on Section 217 - Flight Crewmember Screening and Qualifications. Within Section 217, the legislation indicates that after August 2013, all flight crewmembers of Part 121 operators will be required to have obtained an Airline Transport Pilot (ATP) Certificate. Before enactment of this legislation, airlines would hire pilots without an ATP Certificate, allowing them to earn their ATP as they gained flight time and experience as a first officer with the company. Regulations previously required these newly hired first officers to have an instrument rating and commercial pilot certificate that required 250 flight hours (Karp, 2012).

When this new legislation is enacted, regulations will require pilots to have a minimum of 1,500 flight hours to be eligible for an ATP Certificate. By requiring new pilots to earn an ATP Certificate, this legislation will require aspiring airline pilots to achieve more flight hours and additional certificates before they are eligible for employment with the airlines. The increase in flight time to 1,500 represents an approximate 700 hour increase in flight hours over airline hiring minimums prior to 
implementation of this new legislation (Airline Transport Professionals, 2012; Wald \& Negroni, 2010). While the intent of this legislation may be to enhance the level of safety by increasing the minimum qualification levels of new airline pilots, opponents argue this new requirement may have negative effects on aspiring pilots by significantly increasing the amount of hours required for employment by airlines. By requiring an ATP Certificate for new airline pilot candidates, these regulatory changes may inadvertently discourage aspiring airline pilots. Pilot training organizations, specifically collegiate flight training institutions, have voiced concern that by increasing minimum qualification standards pilots will be forced to acquire many more flight hours beyond the amount typically included within collegiate academic programs (University Aviation Association, 2012a).

Currently, flight students often will spend four or more years to obtain a collegiate flight training degree at considerable expense. In a recent document, the University Aviation Association (2012a) indicated that the average college debt of newly graduated flight instructors is more than $\$ 73,000$. Unfortunately, regional airline first officer position salaries are surprisingly low, making it difficult to offset the high cost of education and training. Rebecca Shaw, the first officer of Colgan Air Flight 3407, earned an annual salary of $\$ 16,200$. This low salary is not uncommon as hourly wages for regional pilots start at $\$ 12.50$ per hour (Fox News, 2009). Considering cost of education or training compared to the starting salaries, opponents to PL 111-216 express concern that adding additional requirements to earn an ATP Certificate will further exacerbate the required costs and discourage individuals from pursuing a career as an air carrier pilot (University Aviation Association, 2012a).

Before the passage of PL 111-216, many collegiate flight training institutions expressed hope that they may be allowed consideration in final enforcement of this law if their flight training degree program was accredited by the Aviation Accreditation Board International (AABI). Wording within the PL 111-216 legislation states "the Administrator may allow such credit based on a determination by the Administrator that allowing a pilot to take specific academic training courses will enhance safety more than requiring the pilot to fully comply with the flight hour requirement" (Congress, 2010, p. 22).

Institutions felt consideration may be given to pilots by allowing credit towards flight hours from academic training courses completed with institutions that have their flight training programs accredited by AABI. With history tracing back to 1974, "AABI accreditation has three fundamental purposes: to ensure the quality of the institution or program, to assist in the improvement of the institution or program, and to maintain relevance of education with the industry it serves" (Aviation Accreditation Board International, 2012a, para. 2). At the time of this study, there are 28 flight training programs that have earned AABI accreditation for their flight training program (Aviation Accreditation Board International, 2012b). AABI has also been active in offering feedback, concerns, and responses in assistance and support to the authoring and development of PL 111-216. 


\section{Methodology}

Exploratory in nature, this study was designed to elicit collegiate flight training institution information and perceptions related to PL 111-216 and its effect on collegiate aviation flight training institutions.

To guide this study the following research questions were created:

1. How will PL 111-216 affect collegiate aviation flight training programs?

2. In response to PL 111-216, do collegiate aviation flight training programs find Aviation Accreditation Board International accreditation of their flight training programs necessary?

\section{Research Population}

The research instrument was electronically administered to University Aviation Association (UAA) member collegiate flight training institutions that offer flight training for academic credit. "The UAA is the voice of collegiate aviation to its members, industry, government and the general public" (University Aviation Association, 2012b, para. 1). With a history dating back to 1947 , "the UAA currently has more than 525 members that include 105 accredited college or universities" (University Aviation Association, 2012b, para. 2). The author used the 2011 Institutional Membership list of the UAA to identify potential participant collegiate flight training institutions. From this list, each institution's website was reviewed for evidence of an active flight training program for academic credit. Only institutions within the U.S. were included for consideration in this study.

Of the U.S. institutions on the membership list, 85 institutions had active flight training programs for academic credit. Each of these institutions was then sent a solicitation email asking them to voluntarily participate in this study by completing the on-line research instrument. Emails were sent to the institutional membership representative's email address as indicated on the membership list. Of the 85 institutions solicited, 59 completed the research instrument (response rate of 69.4\%), 18 did not respond to the solicitation or chose the option to not complete the research instrument within the electronic survey, and 8 partially completed the research instrument. To standardize data results, partially completed results were excluded from analysis. Permission to perform this research study involving UAA member flight training institutions was approved by the Institutional Review Board at Oklahoma State University.

\section{Research Instrument}

The research instrument, developed by the author, was formulated to identify demographic information related to the participating collegiate flight training institutions and to seek the perceptions of these institutions related to the effects of PL 111-216. The survey instrument of this study consisted of three parts: demographic information, Likert- 
scale statements, and open-ended personal comment questions. The first part of the research instrument solicited demographic information regarding each participating institution. The Likert-scale statement section of the research instrument offered respondents an ordinal measurement pattern that included options ranging from: Strongly Agree, Agree, Disagree, and Strongly Disagree. The participants were required to respond to three statements by choosing one of the Likert-scale options described above. These statements were designed to identify the perceptions of the institutions regarding direct and indirect effects of PL 111-216 to their flight training program. The final part of the research instrument asked participants open-ended questions offering them an open text box to author their unique response.

\section{Statistical Measures}

For statistical analysis, this study applied descriptive statistics to analyze the data. Analysis of data included measure of variability (standard deviation) (Fraenkel \& Wallen, 2006). Standard deviation statistical measures are indicated as SD in the results section of this study.

\section{Internal Consistency Measurement}

Cronbach's $\alpha$ reliability test was applied to test internal consistency of Likert-scale statements. Cronbach's $\alpha$ is a general formula for estimating internal consistency based on a determination of how all items on a test are related to all other items and to the total test (Gay, Mills, \& Airasian, 2006). The following Chonbach's $\alpha$ acceptance scale has been established by George and Mallery (2003): " $\geq .9-$ Excellent, $\geq .8-$ Good, $\geq .7-$ Acceptable, $\geq .6$ - Questionable, $\geq .5$ - Poor, and $\geq .5$ - Unacceptable" (p. 231). For analysis, all Likert-scale statement data were entered into a Microsoft Excel spreadsheet and exported into SPSS version 19.0. These data resulted in an overall $\alpha$ of .776. Based on the established acceptance scale, .776 represents an acceptable level of internal consistency.

\section{Results}

Participating collegiate flight training institutions were asked to identify how many undergraduate students were enrolled in their professional pilot/flight training program. The research instrument had six available enrollment sub-groups for which respondents could choose, defined in increments of 50 students. Table 1 indicates the majority of participants (80\%) had fewer than 150 enrolled flight training students.

The number of training aircraft of each participating institution is indicated in Table 2. Each sub group was defined by increments of 5 aircraft. The majority of institutions (78\%) possess between 1-25 training aircraft. The most common sub group was 6-10 training aircraft receiving $26 \%$ of responses. 
Table 1

\begin{tabular}{l|l|l}
\multicolumn{2}{l}{ Institution's Flight Training Enrolled Students } \\
Enrolled Students & Responses & $\begin{array}{l}\text { Percentage of } \\
\text { Responses }\end{array}$ \\
\hline $1-50$ & 17 & $29 \%$ \\
$51-100$ & 23 & $39 \%$ \\
$101-150$ & 7 & $12 \%$ \\
$151-200$ & 3 & $5 \%$ \\
$201-250$ & 3 & $5 \%$ \\
250 or More & 6 & $10 \%$ \\
\hline Total & 59 & $100 \%$
\end{tabular}

Table 2

Institution's Flight Training Aircraft Fleet Size

\begin{tabular}{l|l|l}
$\begin{array}{l}\text { Number of } \\
\text { Training Aircraft }\end{array}$ & Responses & $\begin{array}{l}\text { Percentage of } \\
\text { Responses }\end{array}$ \\
\hline $1-5$ & 6 & $10 \%$ \\
$6-10$ & 15 & $26 \%$ \\
$11-15$ & 8 & $14 \%$ \\
$16-20$ & 12 & $20 \%$ \\
$21-25$ & 6 & $10 \%$ \\
$26-30$ & 0 & $0 \%$ \\
$31-35$ & 2 & $3 \%$ \\
$36-40$ & 6 & $10 \%$ \\
$41-45$ & 1 & $2 \%$ \\
46 or More & 3 & $5 \%$ \\
\hline Total & 59 & $100 \%$
\end{tabular}

Table 3

Institutions Flight Training Degree Program AABI Accreditation Status

\begin{tabular}{|c|c|c|}
\hline $\begin{array}{l}\text { Is Program } \\
\text { AABI Accredited }\end{array}$ & Responses & $\begin{array}{l}\text { Percentage of } \\
\text { Responses }\end{array}$ \\
\hline Yes & 24 & $41 \%$ \\
\hline No & 35 & $59 \%$ \\
\hline Total & 59 & $100 \%$ \\
\hline
\end{tabular}


The next four research instrument questions were related to AABI, and how responding institutions regarded AABI accreditation in relationship to PL 111-216. Of responding institutions, $24(41 \%)$ had flight training degree programs that were accredited by AABI, whereas 35 (59\%) did not have flight training degree programs with AABI accreditation.

Responding institutions that did not have $\mathrm{AABI}$ accreditation for their flight training degree programs were further asked if they were considering or pursuing AABI accreditation. Table 4 indicates that $8 \%$ of respondents are pursuing AABI accreditation. However, $41 \%$ of respondents chose the option Not Applicable, indicating they have earned AABI accreditation. Considering this, of the 35 respondents whose flight training programs are not accredited by AABI, $30(85.7 \%)$ are not pursuing accreditation.

Table 5 details the number of institutions that do not have AABI accreditation and are considering accreditation for their flight training degree programs. Respondents indicated that $27(45 \%)$ are considering AABI accreditation. However, $41 \%$ of respondents chose the option Not Applicable, indicating they have earned AABI accreditation. Considering this, of the 35 respondents that do not have flight training programs that are AABI accredited, 27 (77.1\%) are considering AABI accreditation.

Table 4

Institutions that are Pursuing AABI Accreditation

\begin{tabular}{l|l|l}
$\begin{array}{l}\text { Pursuing AABI } \\
\text { Accreditation }\end{array}$ & Responses & $\begin{array}{l}\text { Percentage of } \\
\text { Responses }\end{array}$ \\
\hline Yes & 5 & $8 \%$ \\
No & 30 & $51 \%$ \\
Not Applicable & 24 & $41 \%$ \\
\hline Total & 59 & $100 \%$
\end{tabular}

A follow up question asked responding institutions if they were considering AABI accreditation for their flight training degree programs in response to PL 111-216. Institutions indicated that $22(37 \%)$ were considering accreditation in response to PL 111216 as detailed in Table 6. However, $41 \%$ of respondents chose the option Not Applicable, indicating they have already earned AABI accreditation. Considering this, of the 35 respondents that do not have flight training programs that are AABI accredited, 22 (62.8\%) are considering accreditation in response to PL 111-216.

To explore how PL 111-216 will affect flight training degree program expenses, participants were asked how program expenses will be affected in response to PL 111216. Table 7 details that 31 (53\%) of responding institutions expect expenses to increase, $28(47 \%)$ expect expenses to decrease, and $0(0 \%)$ expect expenses to remain at the same approximate level.

Likert-scale statements that examine the perception of flight training institutions in regards to PL 111-216 effects are presented in Table 8. Fifty eight percent of respondents 
Table 5

Institutions that are Considering AABI Accreditation

\begin{tabular}{l|l|l}
$\begin{array}{l}\text { Considering AABI } \\
\text { Accreditation }\end{array}$ & Responses & $\begin{array}{l}\text { Percentage of } \\
\text { Responses }\end{array}$ \\
\hline Yes & 27 & $45 \%$ \\
No & 8 & $14 \%$ \\
Not Applicable & 24 & $41 \%$ \\
\hline Total & 59 & $100 \%$
\end{tabular}

Table 6

Institutions that are Considering AABI Accreditation in Response to PL 111-216

\begin{tabular}{l|l|l}
$\begin{array}{l}\text { Considering } \\
\text { Accreditation in }\end{array}$ & \\
Response to PL 111-216 & Responses & $\begin{array}{l}\text { Percentage of } \\
\text { Responses }\end{array}$ \\
\hline Yes & 22 & $37 \%$ \\
No & 13 & $22 \%$ \\
Not Applicable & 24 & $41 \%$ \\
\hline Total & 59 & $100 \%$
\end{tabular}

Table 7

Institution's Expectation of Program Expenses

\begin{tabular}{l|l|l} 
Program Expenses & Responses & $\begin{array}{l}\text { Percentage of } \\
\text { Responses }\end{array}$ \\
\hline Increase & 31 & $53 \%$ \\
Decrease & 28 & $47 \%$ \\
Stay Approximately the Same & 0 & $0 \%$ \\
\hline Total & 59 & $100 \%$
\end{tabular}

disagreed or strongly disagreed, compared with $42 \%$ that agreed or strongly agreed with the statement: PL 111-216, section 217, will create additional opportunity for collegiate aviation flight training programs. A majority of responding institutions (67\%) agreed or strongly agreed with the statement: PL 111-216, section 217, is detrimental to collegiate aviation flight training programs. The remaining 33\% either disagreed or strongly disagreed with this statement. When asked to respond to the statement: Collegiate aviation programs will be more likely to pursue $A A B I$ accreditation as a result of $P L$ 111-216, section 217, the majority of respondents (85\%) agreed or strongly agreed, whereas $15 \%$ of respondents disagreed or strongly disagreed. 
Table 8

Institution's Perceptions Related to PL 111-216

\begin{tabular}{|c|c|c|c|c|c|}
\hline Likert-Scale Statement & $\begin{array}{l}\text { Strongly } \\
\text { Agree }\end{array}$ & Agree & Disagree & $\begin{array}{l}\text { Strongly } \\
\text { Disagree }\end{array}$ & $\begin{array}{l}\text { Statistical } \\
\text { Measures }\end{array}$ \\
\hline $\begin{array}{l}\text { PL } 111-216 \text {, section } 217 \text {, will } \\
\text { create additional opportunity for } \\
\text { collegiate aviation flight training } \\
\text { programs. }\end{array}$ & $\begin{array}{c}6 \\
(10 \%)\end{array}$ & $\begin{array}{c}19 \\
(32 \%)\end{array}$ & $\begin{array}{c}25 \\
(42 \%)\end{array}$ & $\begin{array}{c}9 \\
(16 \%)\end{array}$ & SD: 0.87 \\
\hline $\begin{array}{l}\text { PL } 111-216 \text {, section } 217 \text {, is } \\
\text { detrimental to collegiate aviation } \\
\text { flight training programs. }\end{array}$ & $\begin{array}{c}15 \\
(25 \%)\end{array}$ & $\begin{array}{c}25 \\
(42 \%)\end{array}$ & $\begin{array}{c}15 \\
(25 \%)\end{array}$ & $\begin{array}{c}4 \\
(8 \%)\end{array}$ & SD: 0.88 \\
\hline $\begin{array}{l}\text { Collegiate aviation programs will } \\
\text { be more likely to pursue AABI } \\
\text { accreditation as a result of PL } 111 \text { - } \\
216 \text {, section } 217 \text {. }\end{array}$ & $\begin{array}{c}22 \\
(38 \%)\end{array}$ & $\begin{array}{c}28 \\
(47 \%)\end{array}$ & $\begin{array}{c}7 \\
(12 \%)\end{array}$ & $\begin{array}{c}2 \\
(3 \%)\end{array}$ & SD: 0.78 \\
\hline
\end{tabular}

The research instrument also asked respondents to answer three different open-ended questions related to PL 111-216. To respond to these questions, participants authored their own unique responses in an open text box. The research instrument asked respondents to answer the following three questions: 1), What are your most significant concerns regarding PL 111-216, section 217?, 2)What effects do you perceive PL 211216, section 217 will have on collegiate aviation flight programs?, and 3)Please indicate any additional comments you may have. Fortunately, respondents were very willing to offer comments in this section of the research instrument. Not all respondents replied to each question and some respondents identified multiple concerns or effects for each question. Results of the participant responses identified common concerns or effects regarding PL 111-216. These common concerns or effects have been identified and sorted by common themes and indicated in Tables 9, 10, and 11.

Samples from responses that represent these common concerns are indicated below.

- Once prospective students realize how limited their employment opportunities will be without an ATP, I believe there will be so few students pursuing a degree in professional piloting that most schools will have to close their programs down. Furthermore, enrolled students may decide to switch majors.

- PL111-216 ties pilot quality and safety to flight hour experience, which is a false premise. It is the quality of that instruction and the richness of the experience that leads to improved proficiency and safety.

- My greatest concern about this legislation is that it will further centralize flight training. My fear is that if only AABI schools can compete, then only accredited or accreditation-eligible schools will continue to operate. Centralizing flight training within fewer providers will likely drive up prices and decrease options for potential students. 
Table 9

Responses to the question: What are your most significant concerns regarding PL 111216, section 217 ?

\section{Concerns}

Costs (student)

Student recruitment and/or retention

Final details of law

Ability of students to meet requirements of law

Costs (institution)

The law favors or gives advantage to AABI accredited schools

Other (bill is not realistic, does not meet need of industry, none)

Quality of training versus quantity of hours

\begin{tabular}{|c|c} 
Responses & Percentage \\
8 & $23 \%$ \\
8 & $23 \%$ \\
4 & $11 \%$ \\
4 & $11 \%$ \\
3 & $9 \%$ \\
3 & $9 \%$ \\
2 & $9 \%$ \\
& $5 \%$
\end{tabular}

Table 10

Responses to the question: What effects do you perceive PL 211-216, section 217 will have on collegiate aviation flight programs?

\begin{tabular}{l|c|c} 
Effects & Responses & Percentage \\
\hline Reduction in enrollment & 17 & $41 \%$ \\
Increase in institutional costs & 7 & $17 \%$ \\
To be determined (depends on the final implementation of law) & 6 & $15 \%$ \\
Increase in enrollment & 4 & $10 \%$ \\
Reduction in overall number of collegiate flight programs & 4 & $10 \%$ \\
Little or minimal effect & 2 & $5 \%$ \\
Collegiate flight programs will adjust how they offer training & 1 & $2 \%$
\end{tabular}

Table 11

Responses to the question: Please indicate any additional comments you may have

\begin{tabular}{l|c|c} 
Comments & Responses & Percentage \\
\hline PL-111-216 was a knee-jerk/ineffective/inappropriate response & 7 & $39 \%$ \\
Other (none, N/A, interesting subject/study, etc.) & 5 & $28 \%$ \\
Final law details/implementation need to be known & 3 & $17 \%$ \\
Concern regarding increased costs & 2 & $11 \%$ \\
Safety will be impacted & 1 & $5 \%$
\end{tabular}


Samples from responses that represent these common concerns continued:

- This bill is not driven by factual data and needs.

- Due to the cost of flight training, it is very difficult to get students to complete. This could be another roadblock to getting a job with an airline and may result in students not choosing to be a pilot.

- In my opinion, the law makes the pursuit of a professional piloting degree (and the career field in general) less desirable and less practical.

- Impact on smaller, less well-financed collegiate aviation programs (especially at some community colleges and smaller four year schools) and their inability to respond to what might be the more expensive aspects of preparing students for an airline flight career.

- If colleges are required to purchase equipment (jet sims, for example) the impact will be significant. Smaller schools can't effectively utilize such equipment to make it cost effective.

- It could limit the amount of students that would consider piloting as a career choice.

- Recruitment and retention in collegiate aviation flight programs will suffer.

- Many training institutions, including smaller collegiate programs, will be unable to bear the costs of new requirements and will go out of business.

- More expense for the student will decrease the attractiveness of a collegiate pilot training program.

- Decreased student enrollment, reduction in the number of students considering professional pilot as a career.

- Costs will increase for both the school and the students.

- Flight hours by boring holes into the sky vs real training.

- It will take the average student pilot much longer to make it to the regional airlines.

- It may leave the two year schools with nowhere to go unless they have agreements with the 4 year schools to accept their students.

Samples from responses that represent these common effects are indicated below.

- Numerous (non-AABI) collegiate flight programs will die, some will get stronger and increase student enrollments, but we will experience a substantially smaller number of strong collegiate aviation programs in existence within the United States before 2018.

- For two year programs, it is my opinion it will hurt student enrollment because the costs for students to get that job will be greater.

- I can't imagine colleges can afford to re-tool to add too many more capital assets to provide additional training unless the economy deals them a windfall of some sort.

- The result will be that many potentially great aviators will not enter the profession and regional carriers will have an even smaller pool of first officer applicants.

- Students will be forced to pursue flight training at collegiate providers opposed to $\mathrm{GA} / \mathrm{FBO}$ private providers. 
- It will make things much more expensive.

- Many of the smaller schools will suffer low enrollment.

- Increased flight hours and instruction requirements will stress smaller collegiate programs and possibly force them out of business.

- Probably good for them (collegiate aviation flight training) in the sense of driving students to them. The FBO world will suffer.

- Fewer students will be able to see the light at the end of the tunnel or any way to cope with the crushing burden of student loans while trying to make a living flying.

- It will result in minimal effects for collegiate aviation.

- For the GA route of becoming an ATP, we believe collegiate aviation will be the only viable solution for most people.

- More costs of training simply cannot be absorbed by the student pilot or the university. Debt is simply too high already. The industry will need to step in to help with training requirements.

- PL 111-216 was a knee-jerk reaction to a human factors problem. More flight time does not necessarily translate into safer operations.

- Safety will be impacted as future work force tries to find cheap ways to build time.

- Congress screwed up in a big way by fixing something that wasn't broken just so they could beat their chest and show they'd by God done something.

- The requirement for second officers to hold ATP is ridiculous. Congress didn't do their homework. There is no scientific or statistical data base that suggests this action was needed.

- I do not feel that this measure will have an appreciable effect on airline safety. To gain the additional hours, students are likely to repeat the "same flight hour" a few hundred more times. "Real experience" is not gained until you are out of the practice area. A genuine and relevant mentoring program, established by the airlines, might be a better means to achieve a measurable increase in safety. Subsequently, the industry, especially at the entry level, will have to undergo some major revisions.

- Flight training programs may have to support their training curriculum with expensive FTD/simulator equipment in order to compete with other flight training programs with extensive alumni and collegiate financial support.

- The Colgan Air disaster was tragic and avoidable. Both pilots involved had well over the 1,500 flight hours required for an ATP and the depth of their experience, or lack of same, did not serve to prevent the accident. The challenges imposed by PL111-216 will have a profound affect across the aviation industry from the FAA to the smallest teaching FBO. It will only be through a coordinated joint effort by all stake holders that we will avert severely adverse consequences across the industry.

\section{Discussion}

The development and anticipated enforcement of PL111-216 has been a highly charged issue since its inception, especially within collegiate aviation flight training 
institutions. Individual institutions and institutions collectively, through the UAA, have expressed multiple concerns and have been instrumental in offering advice and feedback during development of PL 111-216. Many of these concerns expressed both formally and informally, are echoed in the results of this study.

In response to the first research question, how will PL 111-216 affect collegiate flight training programs, the majority of respondents indicated that PL 111-216 will cause program expenses and flight training costs to increase. While only a small majority of respondents $(53 \%)$ indicated overall program expenses would increase, many respondent comments expressed concern for increases in flight training costs. As a result of an anticipated increase in flight training costs, many respondents expressed concern for a negative effect on collegiate flight training program recruitment and retention of students. The prospect of significant increases in training time and student costs that will be required before employment by a Part 121 operation may discourage prospective professional pilots from pursuing a career as an airline pilot. Furthermore, this issue is exacerbated when considering the low level of pay for newly hired or low experienced Part 121 pilots. Overall, respondents indicated that PL 111-216 would have a negative effect on collegiate aviation flight training institutions. In their responses, $67 \%$ of participants agreed or strongly agreed with the statement: PL 111-216, section 217, is detrimental to collegiate aviation flight training programs. Additionally, $58 \%$ of respondents disagreed or strongly disagreed with the statement: PL 111-216, section 217, will create additional opportunity for collegiate aviation flight training programs.

In response to the second research question; in response to PL 111-216, do collegiate flight training programs find Aviation Accreditation Board International accreditation of their flight training programs necessary, respondents indicated that AABI accreditation is necessary. Of the 59 responding institutions, $24(41 \%)$ had been granted AABI accreditation for their flight training degree programs while $35(59 \%)$ had not. Of these 35 institutions, five were currently pursuing AABI accreditation and 27 were considering AABI accreditation. When asked if they were considering pursuing AABI accreditation in response to PL 111-216, 22 respondents indicated yes. This indicates that of the 27 institutions pursuing AABI accreditation, 81\% are doing so in response to PL 111-216. Furthermore when responding to the Likert statement: collegiate aviation programs are more likely to pursue AABI accreditation as a result of PL 111-216, 85\% of respondents agreed or strongly agreed.

Additional concerns expressed from respondents included the concern for future vitality of smaller collegiate flight programs (small four-year and two-year institutions) after implementation of PL 111-216. Respondents indicated concern for these programs to compete with larger institutions and their inability to afford significant increases in costs (both in updating training capabilities and possible AABI accreditation costs).

Additionally, respondents indicated that the resulting legislation of PL 111-216 is not an effective improvement in quality or safety. Respondents indicated PL 111-216 is based on the false assumption that there is a correlation between number pilot flight hours and quality of pilot skill. As one respondent stated; "Both pilots involved had well over the 1,500 flight hours required for an ATP and the depth of their experience, or lack of 
same, did not serve to prevent the accident." Another respondent added; "To gain the additional hours, students are likely to repeat the "same flight hour" a few hundred more times. Real experience is not gained until you are out of the practice area. A genuine and relevant mentoring program, established by the airlines, might be a better means to achieve a measurable increase in safety."

Overall, the majority of collegiate aviation flight training institutions indicated concern with PL 111-216 and its eventual effect on collegiate flight training and potential future for aspiring Part 121 pilots. Since the tragic flight of Colgan Air 3407, there has been many adjustments and evolutions involved with the eventual creation of PL 111216. Before its final implementation date of August 2013, there is likely to be additional refinement or interpretation. Therefore, its final effect on collegiate aviation training institutions may not yet be fully understood. As one survey respondent indicated, "the devil may be in the details." 


\section{References}

Aviation Accreditation Board International. (2012a). Rationale. Retrieved from http://www.aabi.aero/rationale.html

Aviation Accreditation Board International. (2012b). Accredited programs. Retrieved from http://www.aabi.aero/programs.html

Airline Transport Professionals. (2012). Aspiring professional pilots, proposal regs bring more opportunity. Retrieved from http://www.atpflightschool.com/airline_training_programs/1500-hour-rule/

Congress, 1. (2010). Public Law 111-216. U.S. Congress. families of continental flight 3407 . Retrieved from http://www.3407memorial.com/index.php

Everett, M. (2012). Aviation schools online. Retrieved from http://www.aviation schoolsonline.com/faqs/new-requirements-for-pilots.php

Fox News. (2009, May 13). Low pay one of many difficulties facing regional pilots. Retrieved from http://www.foxnews.com/story/0,2933,520097,00.html

Fraenkel, J. R., \& Wallen, N. E. (2006). How to design and evaluate research in education. New York, NY: McGraw Hill.

Gay, L.R., Mills, G.E., \& Airasian, P. (2006). Educational Research: Competencies for Analysis and Applications ( $8^{\text {th }}$ Ed.). Upper Saddle River, New Jersey: Pearson Prentice Hall.

George, D., \& Mallery, P. (2003). SPSS for Windows step by step: A simple guide and reference. 11.0 update ( $4^{\text {th }}$ ed.). Boston: Allyn \& Bacon.

H.R. 5900, 2.-2., 111th Cong. (2010). Retrieved from http://www.govtrack.us/congress/bills/111/hr5900/text

Karp, A. (2012, March 1). FAA proposes 1,500 flight hr. requirement for pilots. Air Transport World. Retrieved from http://atwonline.com/international-aviationregulation/news/faa-proposes-1500-flight-hr-requirement-pilots-0229

Levin, A. (2012, Feb. 27). Pilots would need more experience under U.S. proposal. Bloomberg. Retrieved from www.bloomberg.com/news/print/2012-02-27/pilotswould-need-more-experience-under-proposal.html 
NewMyer, D. A. (2010, April 8). National Training Aircraft Symposium. Response from the university aviation association to FAA 2010. Retrieved from http://ntas.erau.edu/ proceedings/ downloads/2011/NTAS-2011-University Aviation-Association-ANPRM-Response.pdf

National Transportation Safety Board (2009). Loss of Control on Approach Colgan Air, Inc. Flight 3407 Accident Report NTSB/AAR-10/01, PB2010-910401. Washington D.C. National Transportation Safety Board.

Pasztor, A. (2009, May 11). Captain's training faulted in air crash that killed 50. Retrieved from http://online.wsj.com/article/SB124200193256505099.html

PL 111-216 Has Been Signed Into Law. (2010). Families of Continental Flight 3407. Retrieved from http://www.3407memorial.com/index.php?view=article\&id =132: pl-111-216-has-been-signed-into-law \&format=pdf

Trumbull, M. (2010, February 2). Probe blames pilot errors for Colgan Air's Buffalo crash. Christian Science Monitor. Retrieved from http://www.csmonitor.com/USA/2010/0202/ Probe-blames-pilot-errors-for-Colgan-Air-s-Buffalo-crash

University Aviation Association. (2012a). Response to Docket Number FAA2010-0100. Auburn, AL: Author.

University Aviation Association. (2012b). Retrieved from http://www.uaa.aero/default.aspx?cid=iFyWBFTaBRc=

Wald, M., \& Negroni, C. (2010, January 31) Errors cited in 09 crash could persist, F.A.A. Says. Retrieved from http://www.nytimes.com/2010/02 /01/nyregion/01colgan.html

Watch, M. (2009, February 13). Plane crash near Buffalo kills 50. Retrieved from http://articles.marketwatch.com/2009-02-13/news/30761324_1_ plane-crash-tedlopatkiewicz-ntsb 


\title{
Learning Styles of Australian Aviation Students: An Assessment of the Impact of Culture
}

\author{
Yi Gao, Kai Tai Stephen Au, Hyuk Joo Kwon, and Eu Wing Leong \\ Swinburne University of Technology
}

\begin{abstract}
Australia has a rich history in aviation and has the tradition of being a pilot training provider for many decades. Students from all over the world are being attracted to Australia every year with the ambition of becoming a commercial pilot. An understanding of the impact of national cultures on the learning styles of student pilots from different culture backgrounds will be beneficial to the overall quality of pilot education in Australia. In this study, students enrolled in the aviation (pilot) program of Swinburne University of Technology were surveyed using Kolb's Learning Style Inventory, and subsequent analysis was performed to the survey data. It was found that a predominant percentage of aviation students were adopting converging and assimilating styles. When comparing findings of this project with previous studies using samples from China and the United States, Australian students' preference of abstract conceptualization was found to be quite similar to that of American students and different from Chinese students, which is an indication of the impact of national culture on learning style preference. This newfound knowledge of Australian aviation students will help raise the understanding how aviation students of different cultural backgrounds learn piloting skills and provide insightful information for flight training academies and researchers.
\end{abstract}

\section{Introduction}

Australia is one of the leading countries to provide quality flight training to future aspiring pilots around the world. Cathay Pacific Airways, Qantas Airways, Jetstar, Vietnam Airlines, and Singapore Airlines are examples of companies that have agreements with various Australian flight-training providers. With this agreements, responsibility is entrusted onto these training providers for a professional quality of training that will ensure a high level of safety, efficiency and professionalism will be attained by these aspiring pilots.

Understanding how these students acquire both ground theory and practical piloting skills will help flight training providers adjust their training curriculum and more importantly, the instruction style, to cater to the need of students to improve the training outcome. This in turn will be beneficial to flight schools as they recruit international students. Students themselves will also benefit from knowing their own learning style, as they will be able to develop a more efficient way of learning with the assistance of learning style theory. 
The study of learning styles has been a topic of interest, and several methods have been employed to determine preferred learning styles. For example, McCall, Klein, Piterman and Lam (2005) conducted a study on Hong Kong general practitioners by employing the Honey and Mumford's Model of Learning Style and found the predominant learning style to be reflective. Mitsis and Foley (2004) found that teacherdriven learning style characteristics are associated with countries that have high masculinity, high Confucian, high uncertainty avoidance and high collectivism ratings. More specifically in aviation, Kanske (2001) conducted a survey on United States Air Force pilots using the Kolb's Learning Style Inventory (KLSI) and found that the majority of students' learning styles to be of converging. Recently, Fanjoy and Gao (2011) studied the learning style of Chinese students enrolled in the aviation program of the Civil Aviation University of China and found a shift of learning style preference from being assimilating and converging in lower year groups to diverging and assimilating when they progressed in the aviation program. The difference of learning style preference between American students and Chinese students suggests a possible effect of national culture on learning styles.

According to Joy and Kolb (2009), culture does have an influence on an individual's learning style preference, though the influence is only marginal. By examining the influence of individual culture dimensions on learning style preference, Joy and Kolb concluded that students from culture backgrounds that are high in in-group collectivism, institutional collectivism, uncertainty avoidance, future orientation and gender egalitarianism are more likely to adopt an abstract learning style, whereas individuals from countries that are high in in-group collectivism, uncertainty avoidance and assertiveness may have a more reflective learning style.

The findings of several studies concurred with Joy and Kolb that cultural difference correlates with learning style preference (Berry, 1996; Claxton, 1990; Creason, 1992; Henderson \& Washington, 1975; Lee \& Carrasquillo, 2006; Kennedy, 2002; Nelson, 1995). Nelson (1995) and Ramirez III (1989) advocated that socialization and cultural background shape children's learning styles through their early experiences. Singleton (in Finkelstein, Imamura \& Tobin, 1991) further acknowledged that learning style is developed at a very early age through sharing culturally based patterns of behavior. Not only that, the cultural pattern also guides the educational curriculum.

In spite of culture being in some way related to learning style, it does not mean that a group of students from the same cultural background share similar characteristics in learning. Many other factors may affect the preference of one's learning style, such as gender, age, religion, family structure, native language, work history, socioeconomic class, area of specialization, etc. (Kolb \& Kolb, 2005). Dunn (1997, p. 74-75) asserted, "there is no single or dual learning style for the members of any culture, national, racial, or religious group," and diversity exists not just between cultures, but also within a single culture.

Hofstede (1996) defined five cultural dimensions, which are Power Distance Index (PDI), Individualism (IDV), Masculinity (MAS), Uncertainty Avoidance Index (UAI) and Long-Term Orientation (LTO) to describe and compare national cultures. There are 
other studies regarding national culture in the past, such as value orientation framework (Kluckhohn \& Strodtdbeck, 1961), Trompenaars' Relationship Dimensions (Trompenaars \& Hampden-Turner, 1997), Hall's Cultural Factors (Hall, 1966). However, none of them has as wide or diverse coverage of the population of countries as Hofstede's study. See Figure 1 for a comparison of national culture among Australia, China, and the United States using Hofstede's culture dimensions. It can be noted in the figure the similarity between American and Australian culture and the distinction between these two cultures and the Chinese culture.

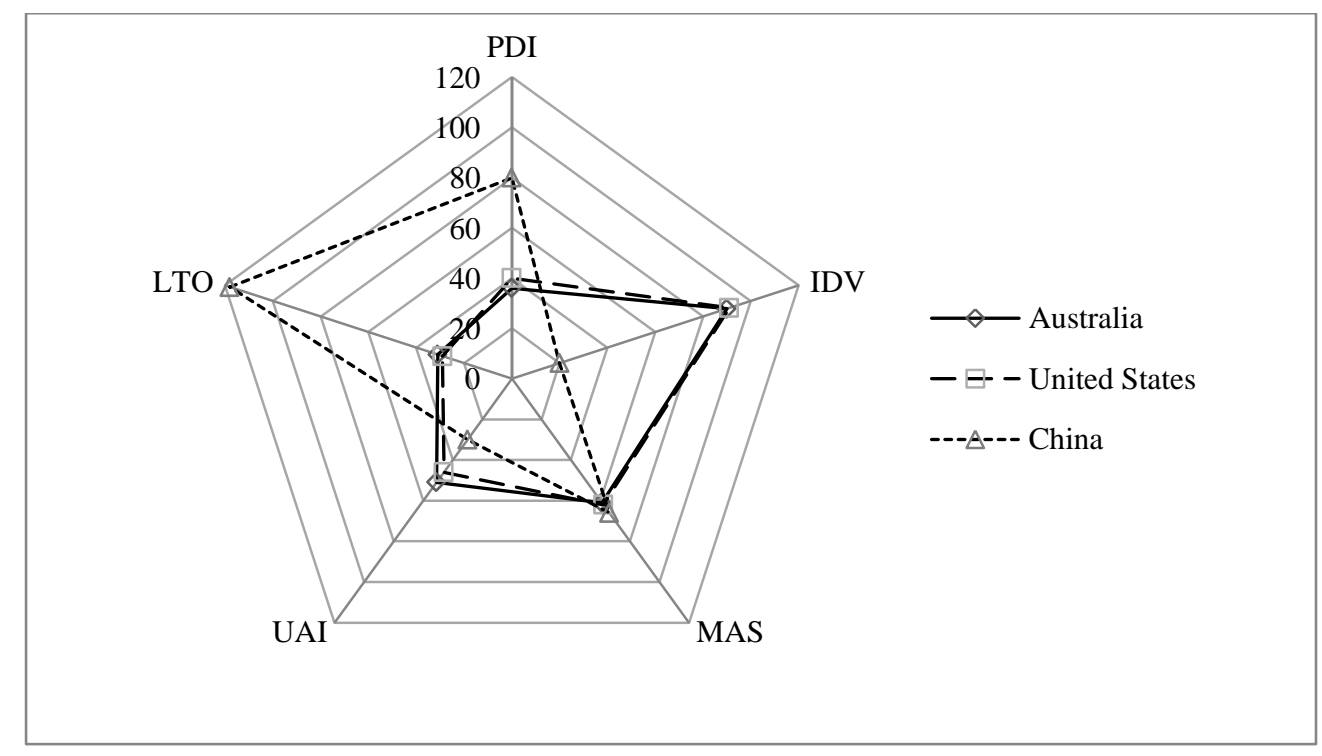

Figure 1. A comparison of national cultural dimensions (Hofstede, 1996).

At the moment, studies regarding learning and teaching of aviation students in Australia are limited. Therefore this study mainly aims to investigate the learning style preference of students enrolled in the aviation program of Swinburne University of Technology using Kolb's Learning Style Inventory. Results of the investigation will be used to compare prior studies in nations of other culture background to assess the impact of culture on learning style preference.

\section{Method}

The subjects of this study were students enrolled in the Bachelor of Aviation course or Bachelor of Aviation/Commerce double degree course at Swinburne University of Technology (SUT) in 2011. For students undertaking the aviation course at SUT, flight training was conducted by what was then Oxford Aviation Academy, now known as CAE Oxford Aviation Academy (COAA). These students, ranging from Year One to Year Four in their course of study, were at different stages of their flight training, including Private Pilot's Licence (PPL), Commercial Pilot's Licence (CPL) and the theory part of Civil Aviation Safety Authority (CASA) Air Transport Pilot Licence (ATPL). In 2011, the total number of students enrolled in the aviation course of SUT was 223, out of which 76 students were in year one, 70 were in year two, 74 were in year three, and three were in Year four. The age of students ranged from 18 to 28. 
This project used the method of survey to investigate learning styles of students being trained at SUT/COAA. The survey instrument consisted of demographic questions and the Kolb Learning Style Inventory (KLSI), which was authorized by the Hay Group to be used in this study. The demographic part asked questions to identify students' age, gender, country of residence in the past 10 years, flight experiences in hours, licence qualification and current year of study.

KLSI is a popular instrument widely adopted to analyse learning styles in various fields, and has been frequently used by researchers in previous similar studies (Fanjoy \& Gao, 2011; Kanske, 2001; Kanske \& Brewer, 2001). KLSI is helpful in providing a framework to discuss the learning process where students could better their learning experiences. At the same time, Kolb (1976) himself and other researchers (Loo, 1997; Ruble \& Stout, 1992) found that scores of test and re-test using earlier versions of KLSI lacked consistence. Kolb then had made changes to KLSI to improve the test-retest reliability, the improvement of which was confirmed by several studies (Romero, Tepper \& Tetrault, 1992; Veres III, Sims \& Locklear, 1991). By using the same survey instrument, a constructive comparison can be made between this study and results from previous studies to assess the impact of national culture.

The Human Research Ethics Committee of Swinburne University of Technology approved the project, allowing the survey to be carried out in COAA. Hard copies of the survey questionnaire were distributed to students attending ground theory lectures at COAA, which is located in Moorabbin Airport, Victoria, Australia. Before taking the survey, participants were informed in advance that the completion of survey was completely voluntary and that they would remain anonymous throughout and after the study. Students were then asked to fill the questionnaire while researchers were present, and to return filled questionnaires back to researchers after completion.

Data collected from the student sample were analysed with a rubric obtained from the Hay Group to yield a grid score on the Abstract Conceptualisation/Concrete Experience (AC-CE) axis and Active Experimentation/Reflective Observation (AE-RO) axis respectively. The coordination of the grid scores identified learning style of individuals as accommodating, diverging, assimilating, or converging. See Figure 2 for the LearningStyle Type Grid.

Besides the determination of learning styles of the student sample, this study also compared student pilots of SUT, representing Australian aviation students, with student pilots of other nations to assess the impact culture in shaping students' cognitive styles. Therefore, statistical analysis was used to compare learning styles of aviation student samples from Australia, China, and the USA. 


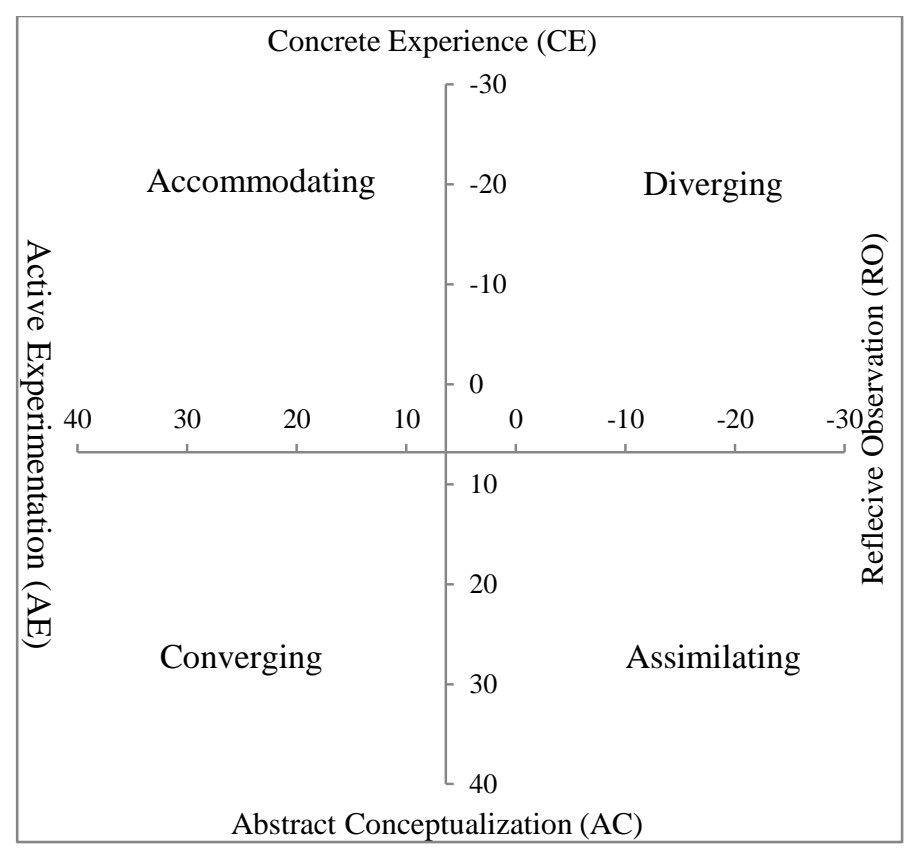

Figure 2. Kolb's Learning-Style type grid (Kolb \& Kolb, 2005).

In this study, it was assumed that students in the aviation course of SUT/COAA who had resided in Australia for longer than ten years at the time of the survey were good representatives of Australian student pilots body and the Australian culture so that a comparison with students from other nations could be made to assess the impact of culture. All survey participants were assumed to answer survey questions truthfully according to their learning habits therefore the result is an accurate indication of their learning style preference.

\section{Results}

In total 91 survey questionnaires were distributed and three of them were not retrieved, giving a response rate of 96.7 per cent. Seven of the collected questionnaires were inappropriately answered, and consequently, were not included in the following analysis. The number of valid responses covers $36.3 \%$ of all the aviation students enrolled in the aviation program as of Semester 2, 2011.

The 81 valid responses consisted of 29 Year one students (36\%), 26 Year two students (32\%), and 26 Year three students (32\%). In Australian Tertiary education system, an undergraduate program usually consists of three years of full time study. Therefore, Year four, which only had three students enrolled at the time of the survey, was not represented by the sample of this study. Among these 81 subjects, four of them were international students (4.9\%), and the rest of students had resided in Australia for longer than ten years. The participation of the survey once again confirmed that aviation is a male-dominant industry with 74 out of 81 subjects being male. 
Using the KLSI rubric provided by the Hay group, the scores of AC-CE and AE-RO were calculated for each filled questionnaire, and the corresponding learning style of each student was determined using the LSI type grid. In the sample of 81 students, 30 were found to adopt converging style (37.0\%), 27 were assimilating (33.3\%), 17 were diverging $(21.0 \%)$, and 7 were accommodating (8.7\%). Figure 3 depicts the distribution of learning styles of the respondents.

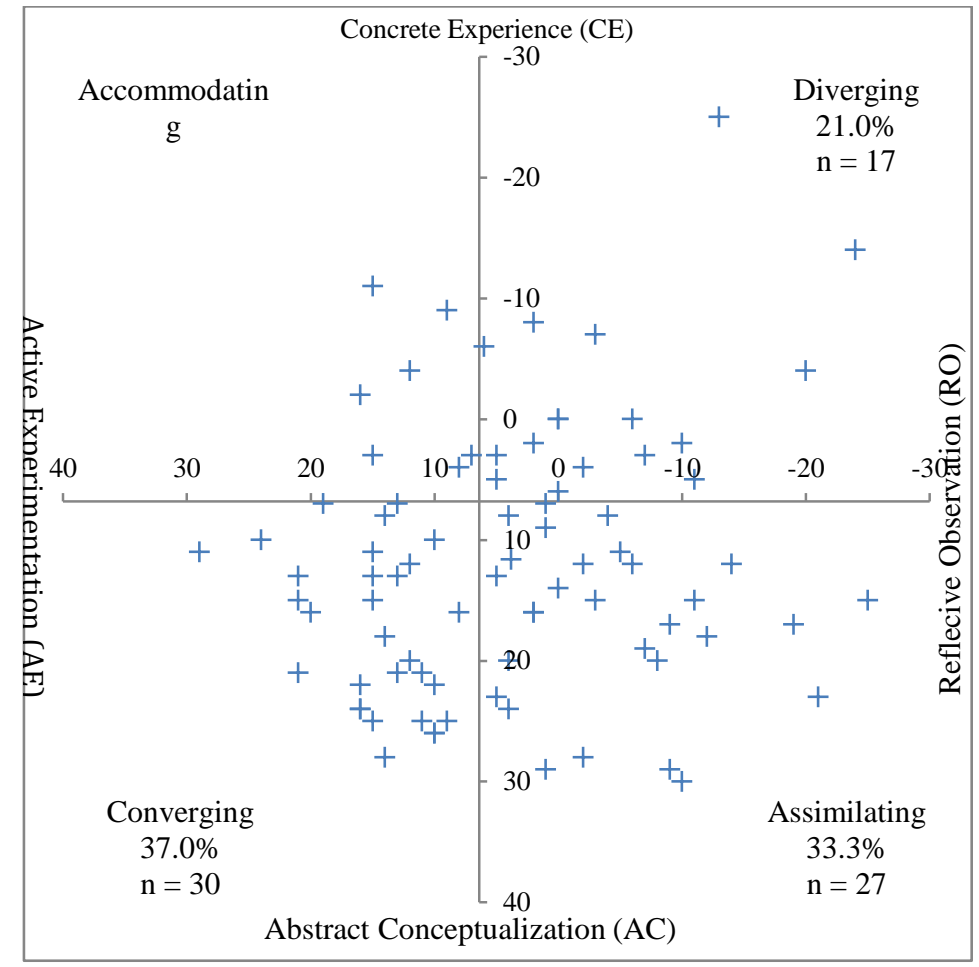

Figure 3. Distribution of students' learning styles on KLSI type grid.

The sample means for AC-CE and AE-RO are 11.63 and 3.83, and the $95 \%$ confidence internals for both means are $(9.15,14.11)$ and $(1.21,6.44)$ respectively. The KLSI rubric uses the $\mathrm{AC}-\mathrm{CE}=6.8$ and $\mathrm{AE}-\mathrm{RO}=6.4$ as reference values to determine learning style preference. It can be noted that the sample demonstrated a statistically significant preference of Abstract Conceptualisation (AC) over Concrete Experience (CE), though no significance could be found on Active Experimentation (AE) over Reflective Observation (RO). The preference of Abstract Conceptualisation over Concrete Experience can also be viewed from Figure 3, where a majority of respondents, or 57 out of $81(70.4 \%)$ to be exact, were found to have a learning style of either Converging or Assimilating. And the rest 24 (29.6\%) respondents were categorized as Accommodating or Diverging.

A breakdown of learning styles preferences by students of different year groups can be seen in Table 1. Because the sample size for each year group was relatively small, this study did not compare learning styles of different year groups. 
Table 1. Learning Style Preference by Year Group

\begin{tabular}{llll}
\hline & \multicolumn{1}{c}{ Year 1 } & \multicolumn{1}{c}{ Year 2 } & \multicolumn{1}{c}{ Year 3 } \\
\hline Converging & $13(44.8 \%)$ & $10(38.5 \%)$ & $7(26.9 \%)$ \\
Diverging & $2(6.9 \%)$ & $9(34.6 \%)$ & $6(23.1 \%)$ \\
Assimilating & $10(34.5 \%)$ & $7(26.9 \%)$ & $10(38.5 \%)$ \\
Accommodating & $4(13.8 \%)$ & $0(0 \%)$ & $3(11.5 \%)$ \\
\hline
\end{tabular}

In addition to exploring the learning style preference of the Australian sample, another objective of this study was to compare the current sample from Australia with prior studies in China (Fanjoy \& Gao, 2011) and USA (Kanske, 2001). Table 2 provides statistics of students' learning style preference of three different samples. In terms of AC$\mathrm{CE}$, similar to the Australian sample, the American sample demonstrated a skewed preference toward Abstract Conceptualization, though the preference is marginal. By contrast, the Chinese sample displays a more balanced preference between Abstract Conceptualisation and Concrete Experience.

In terms of AE-RO, the Chinese sample shows a significant preference of Reflective Observation over Active Experimentation. The Australian sample also displays a marginal preference towards Active Experimentation. The American sample, on the other hand, is more balanced and does not show noticeable preference to Reflective Observation or Active Experimentation.

Table 2. Comparison of learning style preference among different samples

\begin{tabular}{lcrccrrr}
\hline & \multirow{2}{*}{ Sample Size } & \multicolumn{3}{c}{ AC-CE $($ reference=6.8) } & \multicolumn{3}{c}{ AE-RO (reference=6.4) } \\
\cline { 3 - 8 } & & Mean & S.D. & 95\% C.I. & Mean & \multicolumn{1}{c}{ S.D. } & 95\% C.I. \\
\hline Australia & 81 & 11.63 & 11.22 & $(9.15,14.11)$ & 3.83 & 11.83 & $(1.21,6.44)$ \\
China & 293 & 6.70 & 10.30 & $(5.52,7.89)$ & 3.12 & 9.02 & $(2.08,4.16)$ \\
U.S.A. & 233 & 8.39 & 14.86 & $(6.78,10.00)$ & 5.93 & 12.41 & $(4.59,7.27)$ \\
\hline
\end{tabular}

\section{Conclusion}

The study found that the predominant learning styles of the SUT/COAA aviation students were converging and assimilating, which together accounted for $70.3 \%$ of the sample. A major of the students preferred Abstract Conceptualization over Concrete Experience when they learn. The preference of Abstract Conceptualization and the dominance of converging and assimilating among the Australian sample are similar to previous studies completed by Kanske (2001) and Kanske, Brewster and Fanjoy (2003) on American aviation students. In terms of modes of transforming experience (AE vs. $\mathrm{RO}$ ), the Australian sample demonstrated a more balanced preference, compared with Chinese students who preferred Reflective Observation over Active Experimentation.

Results of this study suggest the possible impact of national culture on the preference of learning styles. Australian and American aviation students' preference for Abstract Conceptualization and Chinese students' preference for Reflective Observation can be explained by Yamazaki's (2005) meta-analysis of learning style studies on samples from different cultural backgrounds. Yamazaki (2005) found that people from cultures of low- 
context, M-type organization, independent-self, and field-independent, typical characteristics of western countries such as the U.S.A and Australia, preferred Abstract Conceptualization, and people from cultures of strong uncertainty avoidance, interdependent-self, and guilt culture, such as Japan and China, would prefer Reflective Observation.

The preference of Abstract Conceptualization means that pilot students are willing to use systematic planning and theory to solve problems. Although pilot skills, in the traditional sense, mostly means the operation of aircraft, which comes from repetitive practice, findings of the present study indicates that most SUT students understand the importance of theory, such as aerodynamics, and prefer to use theoretical learning to guide their practical flight training. Therefore, while most flight schools deploy a larger percent of their resource on flight training, they should also value ground theory instruction, pre-flight planning and post-flight debriefing to reinforce training outcomes.

While the study by Joy and Kolb (2009) found that culture had a significant impact on the preference between Abstract Conceptualization and Concrete Experience and a marginal impact on the preference between Active Experimentation and Reflective Observation, the impact of culture was found to be lower than that of area of specialization. Aviation, as a highly specialized area, usually requires trainees with certain psychomotor skills and mandates rigorous flight-training syllabus. If mean values of AC-CE and AE-RO of samples are used to determine the representative learning style of a particular group, then the representative learning style of aviation students from Australia, China and the U.S.A will all be assimilating. Compared with samples from diverse areas of specialization (Yamazaki, 2005), learning style preference of aviation students from different cultures showed a certain level of similarity.

It has to be noted that the sample size in this study is not large enough to conduct a statistical analysis to compare learning styles of students from different year groups. Therefore, we were unable to test if the study in the aviation program has any effect on the evolution of students' learning styles. Students in the sample of this study were extracted from a single aviation program. And due to the possible variation among students and the training syllabi of different states, the sample of this study may not well represent the aviation students of Australia as a whole.

Future studies could include more aviation programs all across Australia. Besides the tertiary education sector, students learning how to fly in aviation clubs around Australia should be also included, which would broaden the scope of the study and provide a more representative result. With an expanded scope of study, the impact of national culture on learning styles could also be more accurately assessed. 


\section{References}

Berry, J. W. (1966). Temne and Eskimo perceptual skills. International Journal of Psychology, 1(3), 207-229.

Claxton, C. (1990). Learning styles, minority students, and effective education. Journal of Development Education, 14(1), 6-8.

Creason, P. (1992). Changing demographics and the importance of culture in student learning style. Retrieved from Education Resources Information Centre: http://www.eric.ed.gov/PDFS/ED361270.pdf

Dunn, R. (1997). The goals and track record of multicultrual education. Educational Leadership, 54(7), 74-77.

Fanjoy, R., \& Gao, Y. (2011). Learning Styles of Chinese aviation students. International Journal of Applied Aviation Studies, 11(1), 57-65.

Hall, E. (1966). The Hidden Dimension. New York: Doubleday.

Henderson, D., \& Washington, A. (1975). Cultural difference and the education of black children: An alternative model for program development. Journal of Negro Education, 44(3), 353-360.

Hofstede, G. (1996). Cultures and oragnizations, software of the mind: Intercultural cooperation and its importance for survival. New York: McGraw-Hill.

Joy, S., \& Kolb, D. (2009). Are there cultural differences in learning style? International Journal of Intercultrual Relations, 33(1), 69-85.

Kanske, C. (2001). Learning styles of pilots currently qualified in United States Air Force aircraft. Journal of Air Transportation World Wide, 6(2), 33-46.

Kanske, C., \& Brewster, L. (2001). The learning styles of college aviation students. Collegiate Aviation Review, 19(1), 62-70.

Kanske, C., Brewster, L., \& Fanjoy, R. (2003). A longitudinal study of the learning styles of college aviation students. International Journal of Applied Aviation Studies, $3(1), 79-89$.

Kennedy, P. (2002). Learning cultures and learning styles: Myth-understandings about adult (Hong Kong) Chinese learners. International Journal of Lifelong Education, 21(5), 430-445.

Kluckhohn, F., \& Strodbeck, F. L. (1973). Variations in Value Orientations. London: Greenwood Press. 
Kolb, A., \& Kolb, D. (2005). The Kolb Learning Style Inventory-Version 3.12005 Technical Specifications. Boston, MA: Hay Group Transforming Learning.

Lee, K. S., \& Carrasquillo, A. (2006). Korean college students in united states:

Perceptions of professors and students. College Student Journal, 40(2), 442-456.

Loo, R. (1997). Evaluating change and stability in learning style scores: A methodological concern. Educational Psychology, 17(1-2), 95-100.

McCall, L., Klein, B., Piterman, L., \& Lam, T.P. (2005). Learning style preferences for Hong Kong GPs recruited in a distance-learning course. Hong Kong Practitioner, 27(7), 261-267.

Mitsis, A., \& Foley, P. (2004). The effect of students' cultural values on the teacherdriven learning style preference. Proceedings of the 18th Australian and New Zealand Academy of Management Conference (ANZAM). Dunedin: Australian and New Zealand Academy of Management.

Nelson, G. L. (1995). Cultural differences in learning styles. In J. Reid (Ed.), Learning styles in the ESL/EFL classroom (pp. 3-18). Boston, MA: Heinle \& Heinle.

Ramirez III, M. (1989). A bicognitive-multicultural model for a pluralistic education. Early Child Development and Care, 51(1), 129-136.

Romero, J. E., Tepper, B. J., \& Tetrault, L. A. (1992). Development and validation of new scales to measure Kolb's (1985) Learning Style dimensions. Educational and Psychological Measurement, 52(1), 171-180.

Ruble, T. L., \& Stout, D. E. (1992). Changes in learning-style preferences: Comments on Geiger and Pinto. Psychological Reports, 70(3), 697-698.

Singleton, J. (1991). The spirit of gamburu. In B. Finkelstein, A. E. Imamura, \& J. J. Tobin (Ed.), Transcending Stereotypes: Discovering Japanese Culture and Education (pp. 120-125). Yarmouth, ME: Intercultural Press.

Trompenaars, F., \& Hampden-Turner, C. (1997). Riding The Waves of Culture: Understanding Diversity in Global Business (2nd ed.). New York: McGraw-Hill.

Veres III, J. G., Sims, R. R., \& Locklear, T. S. (1991). Improving the reliability of Kolb's revised Learning Style Inventory . Educational and Psychological Measurement, 51(1), 143-150. 


\title{
Participation in Instrumental Music as a Predictor of Success in a Collegiate Level Aviation Flight Course
}

\author{
Tyson G. Jaquez \\ University of North Dakota
}

\begin{abstract}
Many different studies have been conducted that examine the effect that participation in instrumental music may have on the cognitive abilities and development of children and young adults. Many of these studies indicate that participating in instrumental music can enhance certain cognitive abilities. This study took those theories and applied them to collegiate flight training in an FAA FAR Part 141 training environment. Participants in the study were questioned about the extent of their participation in instrumental music. These results were then paired with their flight and academic records from their collegiate level private pilot flight course. Using varying statistical comparisons, specific measures of success in the private pilot course were measured against differing measures of participation in instrumental music. These tests revealed that, for most of the areas explored, there was not a significant difference between participants with experience in instrumental music and those that did not have any musical experience. However, statistical significance was found to correlate general participation in instrumental music and a reduction in the number of flight hours that were necessary to successfully complete the private pilot course $(t[66]=2.24, p<.05)$. In support of this finding, participants that had experience playing specifically the piano, demonstrated a significant reduction in the number of flight hours needed to successfully complete the private pilot course $(F[1,66]=4.158, p<.05)$. There appears to be some effect from participating in instrumental music on students in a collegiate level flight course; however, more study is warranted to discover the extent of these effects.
\end{abstract}

\section{Introduction}

Music education and the benefits that students who participate in it may gain have been a topic of debate in various educational forums within the United States. These benefits have been researched, debated, extolled, and denied. Many advocacy groups, such as the National Association for Music Education (NAFME), provide statistics and anecdotes that support the benefits of an educational program that includes music as a fundamental element (NAFME, 2012). However, these data only focus on how well students are prepared for college entrance exams such as the SAT. This study sought to take these anecdotal data a step further and find if there was a connection between participation in instrumental music and success in the real world application of aviation, specifically a university level private pilot course.

The argument about music has even worked its way into the current education debate on whether keeping music and arts in the public schools is important or not. Petress (2005) cites that music is beneficial to students by creating success in society, school, and developing intelligence as well as helping students to succeed in life. One of the most important questions that researchers ask today is "does music make you smarter?" 
Schellenberg (2005) answers "yes" to this question. While he states that music is not a fast solution for educational problems, it has been demonstrated that just listening to music can slightly enhance cognitive functioning over a short period of time.

Music has been linked to many different subjects in education. Participation in band (wind and percussion instruments) or orchestra (stringed instruments) has been shown to significantly increase students' scores on math proficiency tests, especially for low socioeconomic status (SES) students (Caterall, Chapleau, \& Iwanaga, 2009). Moreno (2009) discovered that that sensorimotor-auditory training, like that involved in learning an instrument, involves malleability, or brain plasticity within the auditory cortex. Moreno was also able to demonstrate that just six months of musical training was enough to modify behavior and brain function.

An instrumental music education has been demonstrated to have different effects on people based on the age at which they are exposed to it. Caufield (1999) posits that exposing young children to music, even before birth, may have the possibility of helping to create neural pathways in the auditory cortex of the brain. Creating these extra links has the possibility of setting children up for future cognitive benefits. Črnčec, Wilson, \& Prior (2006) discovered that participating in music lessons produced a small to medium effect on the spatiotemporal ability of younger children. Again, although these effects are small, they may lead to future gains in cognitive development.

In search of evidence that music does have an effect on cognitive development, scientists have begun to look at the brain itself. Hyde et al., (2009) demonstrated that there is a possible link between music and the development of the brain. The study shows that only fifteen months of musical training for children near the age of six created observable changes in their brains. Students that participated in music had significantly different brain deformation changes from those that did not participate in music. In addition, the study also found that students who participated in music for this same amount of time also showed a significant and near significant improvement in both the right and left hand fine motor skills, respectively.

In addition to the numerous studies demonstrating help in specific skills, it has also been demonstrated that participation in instrumental music can also help increase academic performance. Johnson and Memmott, in their 2006 study, found that students at the elementary school level that participated in "exemplary" music programs tended to score higher on both the English and Math portions of standardized tests. Schellenberg (2004) was also able to link IQ with participation in music. It was found that students who studied both the keyboard and voice lessons had small increases in their IQ over those that took drama lessons or did not participate in arts. In a 2009 study, Caterall, Chapleau and Iwanaga demonstrated that secondary school students who were highly involved in either band or orchestra outperformed their peers on math proficiency tests. In addition, Fitzpatrick (2006) demonstrated that, despite the differences found in test scores due to low socioeconomic status (SES), students that participated in, again, either band or orchestra performed better on standardized tests than peers not involved in music. 
Pilot selection has always been an important area of study throughout the history of aviation (Hunter \& Burke, 2002). Many different ways of determining the likelihood of success as a pilot have been used such as personality (Luuk, Luuk, and Aluoja, 2009), training scenarios (Bartram \& Baxter, 1996), and various other tests that examine motor skills and comprehension (Burke, Hobson, \& Linksy, 1997). Many of these methods focus on areas that music may help to enhance. Music has been shown to enhance not only cognitive development and abilities, but may also help to increase fine motor skills, which may eventually lead to better pilots.

\section{Research Methodology}

The author of this study conducted this research at the University of North Dakota (UND) in Grand Forks, ND. The John D. Odegard School of Aerospace Sciences at UND offers several degrees in aviation, with the Bachelor of Commercial Aviation focusing on flight training in a FAR Part 141 flight school. This program includes both collegiate courses and FAA approved flight and ground courses.

Due to the lack of research correlating music and successful pilot training, this study was exploratory in nature and sought to establish a possible connection between participation in instrumental music and success in a private pilot course which may then lead to further research.

The following research questions were used in the study to provide a general framework:

1. Is there a relationship between participation in instrumental music during elementary/secondary school and success in a collegiate level private pilot course?

2. Is there a relationship between the amount of time spent studying instrumental music during elementary/secondary school and success in a collegiate level private pilot course?

3. Is there a relationship between the age at which the study of instrumental music began and success in a collegiate level private pilot course?

4. Is there a relationship between current participation in instrumental music and success in a collegiate level private pilot course?

5. Is there a relationship between studying and performing in a specific group of musical instruments and success in a collegiate level private pilot course?

\section{Participant Selection}

Participants in this study were all students enrolled in the Commercial Aviation program advanced flight courses at the University of North Dakota. The private pilot course is a prerequisite for each of these courses which are listed in Table 1. 
Table 1

Flight Courses Used in the Study

\begin{tabular}{cc}
\hline Course Number & Course Title \\
\hline Avit 325 & Multi-Engine Systems and Procedures \\
Avit 414 & CFI* Certification \\
Avit 415 & Instrument Flight Instructor \\
Avit 480 & Advanced Aircraft Operations \\
\hline
\end{tabular}

*Certified Flight Instructor

\section{Data Collection}

Permission was sought by the researcher to enter the classrooms of the professors that were teaching the ground portion of each of the above-mentioned classes. Once permission was obtained, the research project was presented to the students in the class who were then asked to voluntarily participate in the study.

Data collection consisted of two steps. In the first step of data collection, a survey covering the participant's history, or lack of history, of instrumental music participation in elementary school, secondary school, and university was created and used. This survey was reviewed by experts in both the aviation and music education fields to ensure proper validity. A comparable survey was not found during the initial literature review. The second step of data collection involved matching the participants' academic records for their private pilot course with their survey. This was done by using their student ID number to match the records with the survey. Once the data were matched, the student ID was removed to de-identify all data.

\section{Limits and Assumptions}

This study was conducted under many assumptions and limitations. It focused on the relationship between participation in instrumental music and success in a private pilot course at one university. Therefore, these results may not be generalizable to a wider population without further study. In addition, the researcher only examined students that were majoring in Commercial Aviation, excluding other majors to avoid any confounding factors. This study also looks at students who are seeking a four year degree toward a professional career in flight, so the results may differ from general aviation (GA) pilots.

During the study, the researcher assumed that the instruction received by each participant was equal in nature. All flight instructors at UND follow a prescribed syllabus as described by the university's FAA approved Training Course Outline. The researcher also assumed that weather and other various acts of nature out of human control will likely have affected students in a similar manner. Therefore, these areas were assumed to not have a significant effect on the results gained in this study. 


\section{Results}

Several different measures were used in the study to determine success in a private pilot course. These measures include the number of flight hours required to complete the private pilot course, the pass rate for each of the different stage checks, the grade that was received in the ground course, and the overall pass rate of the private pilot course. Each of these measures was selected because it measured a different area of measurable success or failure within the private pilot course.

The first measure, the number of flight hours the participants required to successfully complete the private pilot course, and thus earn a private pilot certificate, was selected to measure the actual number of hours that a student spent in flight. In this study, a lower number of flight hours needed to pass the FAA exam at the end of the course is considered more successful. Table 2 outlines the statistics of the flight hours for all participants in the study.

Table 2

Flight Hours Descriptive Statistics, $N=68$

\begin{tabular}{cc}
\hline Descriptive & Flight Hours \\
\hline Range & 45.7 \\
Minimum & 38.7 \\
Maximum & 84.4 \\
Mean & 58.3 \\
Standard Deviation & 10.5 \\
\hline
\end{tabular}

The second of the measures used to determine success in the private pilot course was the rate at which the participants passed the various stage checks on the first attempt. According to the UND flight syllabus, there are three different stage checks, or flight exams, the last of which is the FAA private pilot check ride. Each stage check is comprised of two parts: the oral examination and the flight portion or practical examination. Each stage check must be passed in order to continue with the private pilot course. Passing the stage check on the first attempt is seen as more successful than a participant that needed to do the stage check two or more times in order to pass. The pass rate of each stage check is displayed in Table 3.

The third measure used in determining the success in the private pilot course was the grade that the participant earned in the ground portion of the private pilot course. An " $\mathrm{A}$ " was considered the most successful while an "F" was considered not successful. This measure was selected to analyze the relationship to classroom learning and provide a different view of success in the course. These grades are displayed in Table 4.

The fourth and final measure used in this study to determine the success within a private pilot course was if the participant had to retake the full private pilot course in order to successfully complete it. This measure was chosen in order to view the effect 
that music has on the overall success in the course, not just specific areas of the course. These data are shown in Table 5.

Table 3

Stage Check Pass Rate

\begin{tabular}{ccc}
\hline Stage Check & Number Passed on First Attempt & Percent of Students \\
\hline Stage 13 Oral & 75 & 96.2 \\
Stage 13 Flight & 58 & 74.4 \\
Stage 24 Oral & 53 & 67.9 \\
Stage 24 Flight & 50 & 64.1 \\
Stage 28 Oral & 72 & 92.3 \\
Stage 28 Flight & 59 & 75.6 \\
\hline
\end{tabular}

Table 4

Grades Received in the Ground Course

\begin{tabular}{ccc}
\hline Grade & N & Percent of Students \\
\hline A & 28 & 35.9 \\
B & 27 & 34.6 \\
C & 17 & 21.8 \\
D & 1 & 1.3 \\
F & 5 & 6.4 \\
\hline Total & 78 & 100 \\
\hline
\end{tabular}

Table 5

Number of Re-Takes to Complete Private Pilot Course

\begin{tabular}{ccc}
\hline Needed to Retake & N & Percent of Students \\
\hline No & 71 & 91.0 \\
Yes & 7 & 9.0 \\
\hline Total & 78 & 100
\end{tabular}

The results of the study are broken down here by research question and then by the measure used to test that question. Each statistical test was selected based upon the nature of the variables that were being tested for correlations and the nature of the data. Pearson's $r$ correlations and Spearman's Rho correlations were used frequently when the data did not meet parametric assumptions for the normal tests that were indicated by the variables. All tests used a $p$ value of .05 to indicate significance. 
The first research question examined the relationship between participation in instrumental music and success in the private pilot course. It was found that the number of flight hours was significantly lower for those participants that had participated in instrumental music when compared to participants who were not involved in music. The results for the first research question are displayed in Table 6.

Table 6

Summary of Results for Question 1 - Involvement in Instrumental Music

\begin{tabular}{cccc}
\hline Dependent Variable & Test Used & Test Statistic & Value of $p$ \\
\hline Flight Hours & Independent t-test & $t(66)=2.24$ & $.021^{*}$ \\
Stage Check Failures & Pearson's $r$ & $r=-.17$ & .152 \\
Ground Course Grade & Pearson's $r$ & $r=.21$ & .069 \\
Retake of Course & Chi Square & $x^{2}(1)=1.33$ & .249 \\
\hline
\end{tabular}

* Results are significant at

the 05 level

The second research question examined the relationship between the amount of time, in years, spent studying instrumental music and the relationship this had to success in the private pilot course. No significant differences were noted for this question. The results are summarized in Table 7 . The third research question explored the relationship between the age at which the study of instrumental music began and the success that participants had in the private pilot course. As in the second research question, there were no significant results found during the analysis. Table 8 summarizes these results.

Table 7

Summary of Results for Question 2 - Number of Years Studying Music

\begin{tabular}{clcc}
\hline Dependent Variable & Test Used & Test Statistic & Value of $p$ \\
\hline Flight Hours & Spearman's Rho & $r_{s}=-.09$ & .448 \\
Stage Check Failures & Spearman's Rho & $r_{s}=-.11$ & .344 \\
Ground Course Grade & Spearman's Rho & $r_{s}=.10$ & .404 \\
Retake of Course & Spearman's Rho & $r_{s}=-.10$ & .378 \\
\hline
\end{tabular}

Table 8

Summary of Results for Question 3 - Age at Which Study of Music Began

\begin{tabular}{cccc}
\hline Dependent Variable & Test Used & Test Statistic & Value of $p$ \\
\hline Flight Hours & Spearman's Rho & $r_{s}=-.11$ & .456 \\
Stage Check Failures & Spearman's Rho & $r_{s}=-.08$ & .534 \\
Ground Course Grade & Spearman's Rho & $r_{s}=.06$ & .661 \\
Retake of Course & Spearman's Rho & $r_{s}=-.09$ & .516 \\
\hline
\end{tabular}


The relationship between participation in instrumental music and participation in instrumental music during the private pilot course was examined in the fourth research question. As in the previous two questions, no significant results were noted during the analysis. The results of the fourth research question are displayed in Table 9.

Table 9

Summary of Results for Question 4 - Concurrent Participation in Instrumental Music

\begin{tabular}{cccc}
\hline Dependent Variable & Test Used & Test Statistic & Value of $p$ \\
\hline Flight Hours & Independent t-test & $t(76)=.16$ & .877 \\
Stage Check Failures & Spearman's Rho & $r_{s}=-.13$ & .246 \\
Ground Course Grade & Spearman's Rho & $r_{s}=.02$ & .856 \\
Retake of Course & Independent t-test & $t(76)=-.89$ & .379 \\
\hline
\end{tabular}

The fifth research question explored the relationship between learning specific groups of instruments and success in the private pilot course. The various instruments learned by the participants were divided into Band instruments (all wind and percussion instruments), Piano, and Other instruments which covered the string family as well as various other instruments. It was discovered that participants who had learned the piano required significantly fewer hours to complete the private pilot course (see Table 11). All other groups were non-significant at the .05 level. However, the measure of the Ground Course Grade approached significance in the Band group, indicating a trend. These results are summarized in Tables 10, 11, and 12.

\section{Conclusions}

\section{Significant Results}

Two sets of results in the study were found to be significant. It was discovered that participants who were involved in instrumental music, for any amount of time, required significantly fewer flight hours to complete the private pilot course than participants who were never involved in music. This result demonstrates that there is a possible connection between learning music and success in a private pilot course. In addition, when the instruments were divided into groups, results revealed that participants who had learned the piano, specifically, required significantly fewer flight hours to complete the private pilot course than participants who either played other instruments or never participated in music.

These significant results seem to indicate that participation in instrumental music may indeed have effects on learning and thus on success in a private pilot course. Hyde et. al. (2009) indicated that music may enhance fine motor skills. It is possible that this transfers from musical instruments, particularly the piano, into the aircraft during flight 
training. It is also possible that the added brain plasticity, indicated by Moreno (2009), allows flight students who have participated in instrumental music to more easily absorb and understand the difficult concepts that are required during the flight portion of the private pilot course.

Table 10

Summary of Results for Question 5 - Band

\begin{tabular}{cccc}
\hline Dependent Variable & Test Used & Test Statistic & Value of $p$ \\
\hline \multicolumn{1}{c}{ Flight Hours } & One Way Independent & $\mathrm{F}(1,66)=2.192$ & .143 \\
& ANOVA & & \\
Stage Check Failures & Spearman's Rho & $r s=-.15$ & .191 \\
Ground Course Grade & Spearman's Rho & $r s=.22$ & .054 \\
\hline
\end{tabular}

Table 11

Summary of Results for Question 5 - Piano

\begin{tabular}{cccc}
\hline Dependent Variable & Test Used & Test Statistic & Value of $p$ \\
\hline Flight Hours & One Way Independent & $\mathrm{F}(1,66)=4.158$ & $.045^{*}$ \\
& ANOVA & & \\
Stage Check Failures & Spearman's Rho & $r s=-.81$ & .481 \\
Ground Course Grade & Spearman's Rho & $r s=.17$ & .133 \\
\hline
\end{tabular}

* Results are

significant at the 05

level

Table 12

Summary of Results for Question 5 - Other

\begin{tabular}{cccc}
\hline Dependent Variable & Test Used & Test Statistic & Value of $p$ \\
\hline Flight Hours & $\begin{array}{c}\text { One Way Independent } \\
\text { ANOVA }\end{array}$ & $\mathrm{F}(1,66)=.450$ & .505 \\
Stage Check Failures & Spearman's Rho & $r s=.15$ & .188 \\
Ground Course Grade & Spearman's Rho & $r s=.004$ & .971 \\
\hline
\end{tabular}

While these results indicate that there is some correlation between instrumental music training and success in a private pilot course, it is extremely difficult to see exactly where the correlation is. As mentioned above, the enhancements could come from increased practice of hand/eye coordination or from brain plasticity that leads to better learning. It would also appear that the piano is the instrument that is best suited to aviation students. However, at this time, it is not possible to tell why the piano seems to be the best instrument for these students. While these significant results are promising, more study 
is needed to find which activities and brain processes are enhanced or affected by participation in instrumental music.

\section{Non-Significant Results}

Although not statistically significant, the other results from this study lead to more questions in this area of research. When the ground course grade was compared to involvement in instrumental music, a positive correlation was discovered. Although this result was not found to be significant, it does appear that a small trend may be present in the data. It is possible that future studies may find significance with a different and larger sample.

The other areas examined in the first research question displayed very low correlations between participation in instrumental music and the stage check pass rate, and the need to retake the course. This seems to indicate that there is not a noticeable connection between these areas and succeeding in a private pilot course. This result was rather surprising, considering much of the research done with music education shows that music enhances grades and performance in school and on standardized tests.

The lack of significance in any of the measurements for the second research question bring up some interesting questions. It can be expected that the longer a person studies music, the larger the benefits they may receive from that study. However, this does not appear to be the case when it comes to taking a private pilot course. On the other hand, these results tend to support the theory that music either does not have the effects on mental ability that some studies claim (Črnčec, Wilson, and Prior, 2006) or, if there are benefits gained, they are short lived and do not carry on beyond the time of study (CostaGiomi, 1999). A future study may look at a possible correlation between the length of time that passes between the completion of music study and the beginning of the private pilot course for any clues into these surprising data.

The third research question also demonstrated non-significant results for all measurements of success in a private pilot course. Studies such as the one conducted by Rauscher et al. (1997) indicate that the younger a person is when they begin to study music, the more pronounced the effects of the music on brain plasticity. However, the non-significant results from this section indicate that this is not the case, at least in the field of aviation. It is possible that any benefits that are gained from music may come from practice that is not age dependent, indicating that the study of music can begin at any age, and that there is not an optimal age at which to begin.

The fourth research question also demonstrated non-significant results. Within this fourth area of research, it may have been surmised that if past participation benefited the participant, then someone who was still participating in music might have larger benefits. This was not the case, however, based upon the results that were derived from this area. Again, these non-significant results point to the fact that there seems to be a limit to the amount of help that a person can glean from their music education. 
The fifth research question, with the exception of the piano group, again showed nonsignificant results. This demonstrates that people who play piano may have an advantage over those that play other instruments when it comes to aviation. However, it was surprising to find that only one group, the piano players, may gain any benefits in aviation from their participation in instrumental music. Many different instrument groups must use coordination, in different forms, to perform music on their instruments. However, the significant and non-significant results from this study would seem to indicate that playing the piano has the best correlation to the types of coordination that are needed on the flight deck. Future studies may be completed to study the exact correlations and their possible ramifications on future pilots.

Overall, it can be concluded from this research that instrumental music does have some positive effects on students who are in a collegiate level aviation flight course. However, from the abundance of non-significant results, it also appears that participation in instrumental music does not have the large effect that would be expected based on the studies done of the effects of music on standardized tests and the studies conducted in actual classrooms. For the group tested in this research, it appears that piano players are reaping the greatest benefits of their instrumental music education.

There are many areas this study has opened for further research, and indeed more research is warranted. This study was limited to a small group of students at only one university flight school. A broader study that included many more students and university flight programs across the country would help to create a clearer picture of the effects that an instrumental music education has on students enrolled in collegiate flight programs. Another area that could be examined is different groups or kinds of music. An example of this would be to include vocal music participation in the study. This study focused solely on instrumental music. Also, a larger sample might yield more variety of instruments. With this, a broader comparison between types of instruments could be made to more clearly answer the fifth research question.

The results of this study have shown that there are some interesting connections between instrumental music and success in a collegiate level aviation flight course. However, the study also opened up many areas for future research and created more questions than it answered. Most of the results that were expected were not found to be true for the UND private pilot students; however, other places and groups may show different results. This study has hopefully created a starting place for future research with music education and its relation to the field of aviation. It also opens the question of whether there are any unrelated fields that may have a positive impact on aviation education, and therefore may be a benefit to future aviation students. The boundaries and connections have been tested. Some were broken, and others were not. However, it is the question that leads points to the potential for further research. 


\section{References}

Bartram, D., \& Baxter, P. (1996). Validation of the Cathay Pacific Airways pilot selection program. International Journal of Aviation Psychology, 6(2), 149.

Burke, E., Hobson, C., \& Linsky, C. (1997). Large sample validations of three general predictors of pilot training success. International Journal of Aviation Psychology, $7(3), 225$.

Caterall, J. S., Chapleau, R., \& Iwanaga, J. (1999). Involvement in the arts and human development: General involvement in intensive involvement in music and theatre arts. The Imagination Project at UCLA. University of California at Los Angeles. Retrieved from: http://www.newschool.ie/_fileupload/Image/artsinvolvement.pdf

Caufield, R. (1999). Mozart effect: Sound beginnings? Early Childhood Education Journal, 27(2), 119-121.

Costa-Giomi, E. (1999). The effects of three years of piano instruction on children's cognitive development. Journal of Research in Music Education, 47, 198-212. doi: $10.2307 / 3345779$

Črnčec, R., Wilson, S., \& Prior, M. (2006). The cognitive and academic benefits of music to children: Facts and fiction. Educational Psychology, 26(4), 579-594. doi:10.1080/01443410500342542

Fitzpatrick, K. R. (2006). The effect of instrumental music participation and socioeconomic status on Ohio fourth-, sixth-, and ninth-grade proficiency test performance. Journal of Research in Music Education, 54(1), 73-84.

Hunter, D. R., \& Burke, E. F. (1994). Predicting aircraft pilot- training success: A metaanalysis of published research. International Journal of Aviation Psychology, 4(4), 297.

Hyde, K. L., Lerch, J., Norton, A., Forgeard, M., Winner, E., Evans, A. C., \& Schlaug, G. (2009). Musical training shapes structural brain development. The Journal of Neuroscience, 29(10), 3019-3025. doi:10.1523/JNEUROSCI.5118-08.2009

Johnson, C. M., \& Memmott, J. E. (2006). Examination of relationships between participation in school music programs of differing quality and standardized test results. Journal of Research in Music Education, 54(4), 293-307.

Luuk, K., Luuk, A., \& Aluoja, A. (2009). Predicting professional success of air traffic control personnel from their personality profile at admission to ab initio training. International Journal of Aviation Psychology, 19(3), 235-251. doi:10.1080/10508410902983896 
Moreno, S. (2009). Can music influence language and cognition? Contemporary Music Review, 28(3), 329-345. doi:10.1080/07494460903404410

National Association for Music Education. (2012). Support music: Make your case. Retrieved from www.nafme.org/supportmusic_cases. Reston, VA.

Petress, K. (2005). The importance of music education. Education, 126(1), 112-115.

Rauscher, F. H., Shaw, G. L., Levine, L. J., Wright, E. L., Dennis, W. R., Newcomb, R. L. (1997). Music training causes long-term enhancement of preschool children's spatial-temporal reasoning. Neurological Research, 19, 2-8.

Schellenberg, E. G. (2004). Music lessons enhance IQ. Psychological Science (WileyBlackwell), 15(8), 511-514. doi:10.1111/j.0956-7976.2004.00711.x

Schellenberg, E. G. (2005). Music and cognitive abilities. Current Directions in Psychological Science (Wiley-Blackwell), 14(6), 317-320. doi:10.1111/j.09637214.2005.00389.x 


\title{
Carbon Estimation and Offsets for U.S. University Aviation Programs
}

\author{
Mary E. Johnson, Alan Gonzalez, Brian Kozak, and Lauren Sperlak
}

Purdue University

\begin{abstract}
Aviation activities produce carbon. The International Civil Aviation Organization has included a carbon calculator on its website as a way to estimate a passenger's carbon footprint. United Airlines, Delta Airlines and British Airways are three airlines that offer customers ways to offset the carbon emissions generated by their air travel. University flight programs also generate carbon emissions. While not required in the United States at this time, forward-thinking companies and universities are looking for ways to reduce their carbon footprint by reducing or offsetting emissions created by combustion of fuels. This paper discusses aviation fuel emissions, examines the carbon footprint of a university flight program, identifies ways to offset the carbon, and explores the use of trees to offset the carbon generated by flight operations. In addition, this paper presents a methodology for estimating the carbon footprint for the fuel used in a university flight training program and for estimating the number of trees to offset aviation emissions.
\end{abstract}

\section{Introduction}

The combustion of aviation gasoline and jet fuel results in carbon emissions. The Environmental Protection Agency (EPA) and the European Environmental Agency agree that carbon emissions have detrimental effects on the environment (EPA, 2012; European Environment Agency, 2012). This paper presents a method for estimating carbon emissions generated by a university flight program and introduces the possible use of trees as a method for offsetting the carbon.

Carbon offsets and caps have not been established in the United States as of 2012, but the European Union (EU) has implemented the Emissions Trading Scheme (ETS) for commercial aviation beginning in January 2012. The U.S. Government submitted the Aviation Greenhouse Gas Emissions Reduction Plan to International Civil Aviation Organization (ICAO) in June 2012 (FAA, 2012). This plan states that the U.S. has a “...goal of achieving carbon-neutral growth for U.S. commercial aviation by 2020 , using 2005 emissions as a baseline" (FAA, 2012, p.1).

While not required in the U.S. at this time, forward-thinking companies and universities are looking for ways to reduce their carbon footprint. United Airlines, Delta Airlines and British Airways are just three airlines that offer customers ways to offset the carbon emissions generated by their air travel. In addition, CalAir Aviation, LLC, a commercially operated flight school located at the Torrance Airport in California, has begun offering carbon offsets and uses donations to carbonfund.org to offset pilot and student flights (Kelly, 2011; CalAir Aviation, LLC,2010). This paper discusses aviation emissions estimation, emission reduction methods, carbon credit and offset methods, and certification. In addition, this paper presents a methodology for estimating the carbon 
footprint for the fuel used in a university flight training program and for estimating the number of trees to offset aviation emissions.

\section{Literature Review}

Air transportation is essential for the quick, safe and cost effective movement of both people and cargo around the world. Aviation activities such as flight, ground operations, brake dust, and terminal operations generate carbon emissions. While this paper focuses on flight operations, the methods described may be used to better understand the offset of carbon generated by other activities on and off airports. Carbon dioxide $\left(\mathrm{CO}_{2}\right)$ is identified as a greenhouse gas (GHG) that has adverse effects on the earth's environment (EPA, 2012; European Environment Agency, 2012). The combustion of currently available aviation fuels, such as Jet A and aviation gasoline, generate carbon emissions. The EU has established the ETS as a way to encourage the reduction of carbon emissions. As previously state, starting in January 2012, flights to or from EU cities have been subject to the ETS, even when the flight originates or ends outside the EU (European Commission, 2012a). While aviation activities within the U.S. are not currently under an ETS, the ICAO is working on a global version of an ETS (ICAO, 2011). This literature review covers aviation emissions, carbon calculation for flight, carbon markets, aviation carbon emissions and offsets, and carbon certification.

\section{Aviation Emissions}

When aviation fuels are combusted in engines, both gaseous and particulate emissions are produced. These emissions include $\mathrm{CO}_{2}$, nitrogen oxides $\left(\mathrm{NO}_{\mathrm{x}}\right)$, sulfur oxides $\left(\mathrm{SO}_{\mathrm{x}}\right)$, carbon monoxide (CO), water vapor, volatile organic compounds (VOC), particulate matter (PM), and other trace gases (see Figure 1). In carbon calculations for emissions trading and offsets, emissions are converted to $\mathrm{CO}_{2}$ equivalents using a global warming potential (GWP) factor that represents the relative amount of warming effect on the atmosphere (International Panel on Climate Change, 2006). In GWP, the emissions are converted using $\mathrm{CO}_{2}$ as the base, and other emissions as a factor of the base. For instance, methane $\left(\mathrm{CH}_{4}\right)$ has a GWP factor of 21 , which means that methane as a GHG is 21 times more capable of trapping heat in the atmosphere than $\mathrm{CO}_{2}$ (EPA, 2011). Aviation programs in the U.S. primarily use aviation gasoline (avgas) powered aircraft, and others use a combination of avgas and jet fuel powered aircraft.

Jet A is a kerosene-based fuel, similar to diesel fuel, which is used in turbine engines. Lead is not added to Jet A; therefore, Jet A emissions do not contain lead. Jet A does, however, contain trace amounts of sulfur which results in $\mathrm{SO}_{\mathrm{x}}$ (Air Transport Action Group, 2011). In comparison, air consists of $79 \%$ nitrogen, $21 \%$ oxygen and less than $1 \%$ other gases (EPA, 2010. The oxygen in the atmosphere is used in combustion. The combustion of Jet A inside a turbine engine with air yields a large amount of energy and emissions consisting of approximately $70 \% \mathrm{CO}_{2}, 25 \%$ water vapor, and less than $5 \%$ of $\mathrm{NO}_{\mathrm{x}}, \mathrm{CO}, \mathrm{VOC}, \mathrm{PM}$ and $\mathrm{SO}_{\mathrm{x}}(\mathrm{FAA}, 2005)$ as summarized in Figure 1. Jet $\mathrm{A}$ is the primary jet fuel used in the United States. However, Jet A-1, which is predominately used outside of the U.S., has similar emissions to Jet A, and is therefore treated as such. 


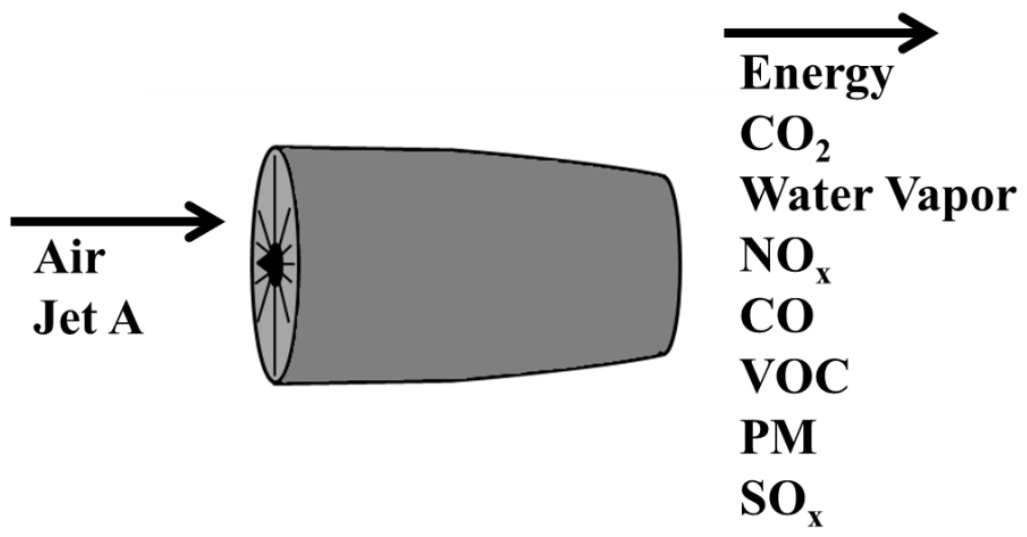

Figure 1. Typical emissions for an aircraft turbine engine.

Aviation gasoline in the U.S. is 100 low lead, which is similar to high-octane automotive gasoline. Unlike jet fuel, lead is added during the petroleum refining process for avgas, therefore lead is in the emissions. The combustion of avgas in aircraft piston engines produces approximately the mixture and percentages of emissions as turbine engines, except for the addition of lead (FAA, 2005).

\section{Carbon Calculation for Flight}

The EU ETS seeks to reduce carbon emissions through a carbon allocation and offset system based on the cap and trade principle (European Commission, 2012b). While applicable to EU heavy industries since 2005, the EU ETS began covering aviation activities beginning in January 2012 (European Commission, 2012a). The EU has delayed the implementation of the ETS for non-EU airlines until next year; however, the ETS is still in effect for airlines within the EU. Each metric ton $(1,000 \mathrm{~kg})$ of carbon dioxide is equivalent to one carbon credit. Simply put, the EU ETS method estimates the amount of carbon based on the amount of fuel consumed on flights in to and out of the EU (European Commission, 2012a). The legality of the EU ETS was upheld in the European courts in December 2011 (European Commission, 2012a). However, the legality of the EU ETS is being challenged by countries and airlines across the globe such as the U.S., China and India (Buyck, 2011; Trauvetter, 2012; Moores, 2012). The EU has made estimation of carbon simple by basing it on the amount of fuel consumed (European Commission, 2010b). In the EU ETS, carbon may be calculated by multiplying the kilograms of fuel consumed by the emissions factor of $3.15 \mathrm{~kg}-\mathrm{CO}_{2} / \mathrm{kg}$ fuel for Jet A/A-1 and by the emissions factor of $3.10 \mathrm{~kg}-\mathrm{CO}_{2} / \mathrm{kg}$-fuel for aviation gasoline as described in Chapters 1 and 3 of the IPCC Guidelines for National Greenhouse Gas Inventories (International Panel on Climate Change, 2006). The U.S. Environmental Protection Agency publishes emission factors for aviation gasoline as $8.31 \mathrm{lb}-\mathrm{CO}_{2} /$ gallon and for jet fuel as $9.75 \mathrm{lb}-\mathrm{CO}_{2} /$ gallon (EPA, 2011).

The ICAO publishes a Carbon Emissions Calculator that provides an estimate of the carbon footprint or carbon emissions per traveler on specific air routes throughout the world, and uses factors such as aircraft types, cabin class seating, and load factor. By identifying the cabin class seating, number of passengers, one-way or round trip, and city 
pairs, the calculator estimates the kilograms of $\mathrm{CO}_{2}$ per passenger, and shows the typical aircraft types on the route, average kilograms of fuel consumed, and average number of seats per flight. The full ICAO methodology for calculating carbon footprint is available (ICAO, 2012b). For instance, one passenger flying round trip with an economy class ticket from New York (JFK) to Frankfurt, Germany (FRA) results in $821.86 \mathrm{~kg}$ of $\mathrm{CO}_{2}$ estimated using the ICAO carbon calculator on the website (ICAO, 2012a). The ICAO calculator uses the jet fuel emission factor of $3.157 \mathrm{~kg}-\mathrm{CO}_{2} / \mathrm{kg}$-fuel and is intended for use by jet aircraft travelers in carbon offset programs (ICAO, 2012b). The ICAO calculator is not the only calculator used by airlines. International Air Transport Association (IATA) reported that 32 member airlines have carbon calculators to offset emissions from flight using projects of varying qualities (Schneider, 2012).

\section{Carbon Markets}

The United Nations Framework Convention on Climate Change (UNFCCC) was created in 1992 to evaluate solutions against climate change; and in 1997 the Kyoto Protocol was adopted by the UNFCCC to reinforce inadequate resolutions from the first Convention (UNFCCC, 2012). In the Kyoto Protocol, targets were established for GHG emissions for 37 countries and the European Union. These nations are obligated to reduce their GHG emissions, and the developed nations must reduce GHG at a proportionally higher rate than developing nations (UNFCCC, 2012a).

To help achieve emission targets, the Kyoto Protocol created three market-based mechanisms, resulting in a regulated carbon market: Emissions Trading System (ETS), the Clean Development Mechanism (CDM), and Joint Implementation (JI) (UNFCCC, $2012 \mathrm{~b}$ ). The biggest carbon markets around the world such as the European Union use the ETS (Brohe, Eyre, \& Howarth, 2009). Emission Trading Systems work under a cap and trade or a baseline and credit (Brohe, et al., 2009). The carbon market is a key tool for reducing emissions worldwide; it was worth 30 billion U.S. dollars in 2006 and is growing (UNFCCC, 2012b). As of October 2012, the United States has not ratified the Kyoto Protocol that it signed in December 11, 1998 (UNFCCC, 2006). This means any projects to offset U.S. aviation emissions will fall into the voluntary carbon markets.

In the voluntary offsetting carbon markets, an institution estimates their GHG emissions and proposes to offset emissions from a different institution at a certain price per metric ton (Brohe, et al., 2009). The offset provider sets a price to offset emissions at a certain price per metric ton or carbon credit. Offset prices for credits are dependent on which of fiver project types are used: "forestry, renewable energy, destruction of fluorinated gases, and energy efficient projects related to waste management or recovery of methane" (Brohe, et al., 2009, p 275). The voluntary carbon market may be of interest to university aviation programs. This paper focuses on university-based aviation programs located in the United States. The authors believe that the EU ETS is not expected to affect U.S.-based university aviation operations. 


\section{Aviation Carbon Reduction and Offset Methods}

Current technology for commercial air travel and university-based flight training programs requires the use of fuel that emits carbon, most commonly avgas and Jet A. Decreasing fuel consumption is one way to decrease carbon emissions. In addition, the U.S. government has identified five other ways to reduce carbon emissions: technological improvement of engines and aircraft, improvements in operations, alternative fuels, scientific modeling and analysis, and policies, standards and measures that support carbon neutral growth (FAA, 2012). Operational changes may include routing considerations (Johnson \& Gonzalez, in press), approach paths, single engine taxi, or other changes. The carbon emitted by air transportation may be offset. Aviation businesses are offering ways for customers to offset their carbon footprint. First, airline offset programs are introduced, and then a commercial flight school offset program is described.

Airlines around the world are currently participating in voluntary and carbon offset programs approved by the UNFCCC. IATA's program for TAP, a Portuguese airline, has begun replacing fossil fuel-based electricity generators with hydropower electricity generators with an expected GHG reduction of nearly 15,000 metric tons of $\mathrm{CO}_{2}$ equivalent each year (IATA, 2012). Airlines are also offering ways for travelers to offset their carbon through voluntary aviation emissions offset programs. Of the 30 airlines offering carbon offsets (ICAO, 2010), three airline examples are discussed: Delta, United, and British Airways. Delta Airlines claims being the first airline to offer a carbon offset option for purchasers of air tickets beginning in 2007 (Delta Airlines, 2012). Using Delta's online emissions calculator, travelers may purchase carbon offsets that currently support a Nature Conservancy forestry management project in Belize (Delta Airlines, 2012). The Nature Conservancy has a carbon footprint calculator available on its website that uses a $\$ 15$ gifts to offset one metric ton of $\mathrm{CO}_{2}$ (Nature Conservancy, 2012). Using the Nature Conservancy calculator, one roundtrip flight of over 300 miles each way is estimated to have an impact of 2.2 metric tons and costs $\$ 30$ to offset.

United Airlines has a carbon offset program titled eco-skies that offers carbon offsets for $\$ 5$ per 0.5 metric ton or donation to a specific carbon project (United Airlines, 2012). Using the United Airlines calculator for a round trip flight from New York (JFK) to Paris (CDG) in October, the estimated carbon footprint was 1.5 metric tons. The two programs offered on the United Airlines website were a $\$ 30.30$ donation to a forest conservation project in California or a $\$ 15.15$ donation to a wind power project in Texas (United Airlines, 2012). For British Airways, passengers may choose to donate money to the One Destination Carbon Fund that supports projects in the United Kingdom (British Airways, 2012). A carbon offset calculator was not found on the British Airways website.

At least one commercial flight school is offering a program to offset the carbon footprint of flight training. The school makes contributions to a carbon offset program based on fuel consumption during pilot training (CalAir Aviation, LLC, 2012; Kelly, 2011). The chosen offset program is carbonfund.org (Kelly, 2011) which uses donations of approximately $\$ 10$ per metric ton to support third-party offset projects. 


\section{Carbon Certification}

Certification of carbon offset programs is a concern. The IATA has voiced concerns regarding validation and certification of offset programs. These concerns include setting and ensuring standards are met, accurate emissions calculations, and transparency of auditable offsets (Schneider, 2012, p. 15). With an offset market of nearly $\$ 400$ million dollars in 2011, fraudulent carbon offsets and credits is a real threat, with several occurrences already (Struck, 2010; Collinson, 2012; \& Russell, 2012). There are certification programs from organizations such as carbonfund.org and carbon neutral plane (Carbonfund.org, n.d.a \& Carbon Neutral Plane, 2012). An international standards body, the International Organization of Standardization, has developed a series of standards under ISO 14000 to address environmental management systems. For instance, there are ISO standards for GHG inventory and reporting, validation and verification of GHG assertions, and accreditation of validation and verification bodies. Table 1 summarizes a portion of the ISO 14000 series standards related to GHG inventories. ISO 14064-3 addresses GHG validation and verification of GHG claims while ISO 14065 contains principles and requirements that bodies seeking validation or verification should be able to conform to (ISO, 2006b).

Table 1

Summary of Selected ISO 14000 Standards

\begin{tabular}{lcl} 
ISO Standard & \multicolumn{1}{c}{ Focus } & \multicolumn{1}{c}{ Purpose } \\
\hline 14001 & Organization & Environmental Management Systems \\
$14064-1$ & Organization & GHG Inventory \& Reporting of Emissions \\
$14064-2$ & Project & GHG Quantification \& Reporting of Emissions \\
$14064-3$ & Claims/Assertion & Validation \& Verification of GHG Assertions \\
14065 & Verification Body & Accreditation of GHG Validation \& Verification \\
14066 & Verification Body & Competence Requirements for GHG Validation \\
& & \& Verification Bodies
\end{tabular}

Note. ( ISO 2006a)(ISO 2006b)

\section{Methodology}

The researchers used the following methodology in this study to determine carbon credits needed by a university-based flight program. First, the amount of jet fuel and amount of aviation gasoline used by the aviation program were estimated. Second, these estimates were used to estimate the amount of carbon generated by flight operations and the amount of carbon credits needed to offset. Third, the number of trees and amount of land was estimated to offset this amount of carbon. Finally, an analysis was performed on the carbon offsets and costs. 


\section{Data}

\section{Estimate Aviation Fuel Consumption}

First, the authors chose to use estimates of 10,000 gallons of Jet A and 10,000 gallons of aviation gasoline in the analysis to facilitate linear scaling of results. While the actual amounts of fuel consumed fluctuate based on the amount and characteristics of flight operations, a constant amount of 10,000 gallons of fuel was used in all years of the analysis for simplicity of method.

\section{Estimate Amount of Carbon and Carbon Credits}

Based on the literature review, the authors have chosen to use both the International Panel on Climate Change (IPCC) emissions factors and the EPA emissions factors in this step. The number of carbon credits required for each year of flight operations at 10,000 gallons of Jet A and 10,000 gallons of avgas are shown in Table 2 for IPCC emissions factors and Table 4 for EPA emissions factors. The formulas to calculate the carbon credits are shown in Table 3 for IPCC and Table 5 for EPA. In addition, simplified forms of the equations are shown using an input of gallons of fuel.

In many situations in the U.S., records of fuel purchased are in gallons. The IPCC formulas use kilograms. The conversion factors for gallons to kilograms are shown in Table 2 and in Table 4 notes. To convert gallons of avgas to pounds, a conversion factor of 6 was used (FAAFSS, 2009). To convert pounds of avgas to kilograms, a conversion factor of 0.45359 was used (EPA, 2004). To convert gallons of Jet A to pounds, a conversion factor of 6.8 was used (FAAFSS, 2009). To convert pound of avgas to kilograms, a conversion factor of 0.45359 was used (EPA, 2004). Each carbon credit represents one metric ton of $\mathrm{CO}_{2}$, therefore, the amount of carbon in kilograms was divided by 1,000 to estimate the number of carbon credits represented (Brohe, A., et al., 2009). The cost of carbon credits was obtained from Intercontinental Exchange (2012). In addition, Table 2 and Table 4 summarize the amount of fuel, amount of carbon credits or carbon in metric tons.

The number of carbon credits required to offset 10,000 gallons of aviation gasoline is 85 for IPCC (from Table 2) and 83 for EPA (from Table 4). The number of carbon credits required to offset 10,000 gallons of jet fuel is 98 (from Table 2) for IPCC and 95 for EPA (from Table 4). In Table 6, estimates for whole numbers of metric tons of $\mathrm{CO}_{2}$ are shown for 10,000 to 100,000 gallons of avgas and for Jet A. These IPCC and EPA carbon credit numbers differ from each other. IATA has also noticed that carbon estimates are not consistent among the 32 member airlines investigated (Scheider, 2012). While these IPCC and EPA carbon credit estimates for avgas are only 2 credits apart at 10,000 gallons, the difference at 100,000 gallons is 20 credits. 
Table 2

Estimated Carbon Emissions for Flight Operations Using IPCC Factors

Fuel Type Gallons of Fuel Used per Year kg of Fuel $^{\mathrm{a}} \quad$ IPCC Factor $^{\mathrm{b}}$ Total $\mathrm{CO}_{2}$ Metric Tons

\begin{tabular}{lllll}
\hline Avgas & 10,000 & 27,215 & 3.10 & 84.4 \\
Jet A & 10,000 & 30,844 & 3.15 & 97.2
\end{tabular}

Note. (Avgas) $\mathrm{kg}$ of fuel $=10,000$ gallons $* 6 \mathrm{lb} / \mathrm{gallon} * 0.45359 \mathrm{~kg} / \mathrm{lb}=27,215 \mathrm{~kg}$

(Jet A) $\mathrm{kg}$ of fuel $=10,000$ gallons $* 6.8 \mathrm{lb} / \mathrm{gallon} * .45359 \mathrm{~kg} / \mathrm{lb}=30,527 \mathrm{~kg}$

$($ Avgas $) \mathrm{CO}_{2}$ (Metric Tons $)=(27,306 \mathrm{~kg} * 3.10) / 1,000=84.4$ Metric Tons of $\mathrm{CO}_{2}$

(Jet A) $\mathrm{CO}_{2}$ (Metric Tons) $=(30,527 \mathrm{~kg} * 3.15) / 1,000=97.2$ Metric Tons of $\mathrm{CO}_{2}$

${ }^{\mathrm{a}}$ FAAFSS (2009). ${ }^{\mathrm{b}}$ Maurice, Hockstad, Höhne, Hupe, Lee, Rypdal (2006).

Table 3

Carbon Credit Worksheet Using IPCC Factors

Fuel Gallons $\quad \mathrm{lbs}_{\mathrm{gal}} \mathrm{a}^{\mathrm{a}} \quad \mathrm{kg} / \mathrm{lbs} \quad$ IPCC Factor $^{\mathrm{b}} \mathrm{kg} /$ Metric ton Carbon Credits

\begin{tabular}{|c|c|c|c|c|c|c|c|c|c|}
\hline Avgas & $*$ & 6 & $*$ & $1 / 2.2$ & * & 3.10 & I & 1,000 & $=$ \\
\hline Jet A & $*$ & 6.8 & $*$ & $1 / 2.2$ & $*$ & 3.15 & l & 1,000 & $=$ \\
\hline
\end{tabular}

Simplified Formula

Fuel

Gallons

Simplified Factor

Carbon Credits

Avgas

Jet A

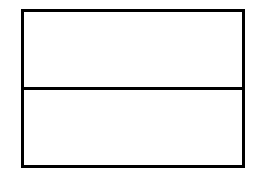

$*$

0.00845

$*$

0.00974

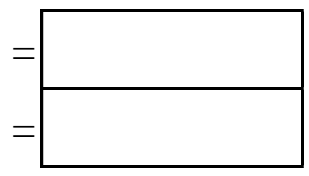

Note. ${ }^{\mathrm{a}}$ FFAFSS (2008). ${ }^{\mathrm{b}}$ Maurice et al. (2006). 
Table 4

Estimated Carbon Emissions for Flight Operations Using EPA Factors

\begin{tabular}{|c|c|c|c|}
\hline Fuel Type & Gallons of Fuel Used per Year & EPA Factor ${ }^{\mathrm{a}}$ & Total $\mathrm{CO}_{2}$ Metric Tons \\
\hline
\end{tabular}

\begin{tabular}{llll}
\hline Avgas & 10,000 & 8.31 & 83.1 \\
Jet A & 10,000 & 9.75 & 97.5
\end{tabular}

Note. (Avgas) Total $\mathrm{CO}_{2}$ (Metric Tons $)=(10,000 * 8.31) / 1,000=83.1$

(Jet Fuel) Total $\mathrm{CO}_{2}$ (Metric Tons) $=(10,000 * 9.75) / 1,000=94.8$

${ }^{\mathrm{a}} \mathrm{EPA}(2011)$.

Table 5

Carbon Credit Worksheet Using EPA Factors

$\begin{array}{llll}\text { Fuel Gallons } & \text { EPA Factor } & \text { Carbon Credits }\end{array}$

\begin{tabular}{lllllll|} 
Avgas & & $*$ & 8.31 & $/$ & 1,000 & $=$ \\
\cline { 5 - 6 } Jet A & 9.75 & $/$ & 1,000 & $=$
\end{tabular}

Formula Simplified

Fue

Gallons

Simplified Factor

Carbon Credits

Avgas

Jet A

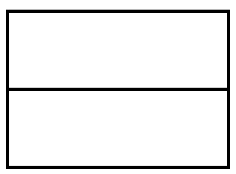

$*$

0.00831

$*$

0.00975

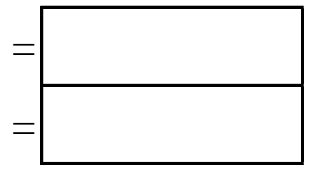

Note. ${ }^{\mathrm{a}} \mathrm{EPA}$ (2011). 
Table 6

Metric Tons of $\mathrm{CO}_{2}$ Using IPCC and EPA Factors

\begin{tabular}{lcc} 
Fuel & $\begin{array}{c}\text { Avgas } \\
\mathrm{IPCC} \mathrm{CO}_{2}\end{array}$ & $\mathrm{EPA} \mathrm{CO}_{2}$ \\
\hline 10,000 & 85 & 83 \\
20,000 & 169 & 166 \\
30,000 & 254 & 249 \\
40,000 & 338 & 332 \\
50,000 & 422 & 416 \\
100,000 & 844 & 831
\end{tabular}

$\underline{\text { Jet A }}$

\begin{tabular}{lcc} 
Fuel & $\mathrm{IPCC} \mathrm{CO}_{2}$ & $\mathrm{EPACO}_{2}$ \\
\hline 10,000 & 98 & 98 \\
20,000 & 195 & 195 \\
30,000 & 292 & 293 \\
40,000 & 389 & 390 \\
50,000 & 486 & 488 \\
100,000 & 972 & 975
\end{tabular}

Note. Numbers are rounded up to the next whole metric ton (1 metric ton is approximately 2,200lbs). Avgas and Jet A numbers in gallons.

\section{Estimate the Offsets}

The amount of carbon dioxide offsets needed is determined by the amount of carbon dioxide produced per year through the consumption of fuel. As shown in Table 6, the number of carbon credits required to offset 10,000 gallons of aviation gasoline is 85 for IPCC emissions factors and 83 for EPA emissions factors. The number of carbon credits required to offset 10,000 gallons of jet fuel is 98 for IPCC emissions factors and 95 for EPA emissions factors. In this discussion, the EPA estimates are used. To offset 83 metric tons using donations to carbonfund.org would cost $\$ 830$ at $\$ 10$ per metric ton (carbonfund.org, n.d.b). In addition, carbonfund.org offers trees for sale to offset carbon at $\$ 1$ per tree, but do not specify the number of metric tons offset by trees.

The Energy Information Administration within the U.S. Department of Energy has provided a method for estimating carbon sequestration in trees (EIA, 1998). The amount of carbon dioxide absorbed is dependent upon the type of tree, how fast it grows and the trees survival rate. Fast-growing species of hardwood trees, such as yellow poplar, red 
oak, elm and white ash offer the best combination of carbon dioxide sequestration and survival rate (EIA, 1998). Calculations for carbon sequestration are based upon 680 trees per acre, which is the ideal spacing for reforestation (SCFC, n.d.). In these calculations, based on South Carolina Forestry Commission (SCFC) information, the 6,800 trees are planted are in a 15-gallon container or balled and burlapped spaced evenly over a 10acre plot. Year 0 represents the year that the trees are planted. At planting, the SCFC estimates that only $87.3 \%$ of the original 6,800 trees planted will survive. In year 6 , the number of surviving trees will be roughly 4,346 (EIA, 1998). Therefore, if 10 acres of trees are planted, it would only take 6 years for the trees to sequester enough carbon dioxide to offset the amount produced from the combustion of 10,000 gallons of avgas, as demonstrated in Table 7. These calculations in Table 7 are dependent on the number of trees planted per acre. Other combinations of tree type, tree size at planting, and density of trees planted per acre will alter the results.

\section{Carbon Offsets and Costs}

Estimating aviation emissions offsets and costs may be done in at least two different ways. One way is to purchase certified offsets recognized by the pertinent regulatory bodies. Another way is to develop an offset program. For instance, carbonfund.org offers carbon offsets at $\$ 10$ per metric ton or trees at one dollar each for an unspecified amount of carbon (carbonfund.org, n.d.b). If a flight program chooses to develop their own offset program using newly planted trees, then for every 10,000 gallons of avgas consumed each year, 6,800 fast growing hardwood trees would need to be planted on 10 acres of land. The selection of tree type would be based on the climate and soil conditions were planted. Using the rates of carbon sequestration by the trees and the percentages of surviving trees, this research shows that at least 86 carbon credits are generated per year after year 6. No costs for land, trees, planting, or maintenance of the trees are included in this analysis; therefore, no cost per carbon credit generated is provided in the analysis. These costs for implementation and maintenance are not included due to several factors including fluctuation of costs over time and regions; regional variations in land, labor, trees, equipment and material costs; the types of trees appropriate for different regions; fertilizer and pesticide costs; regional climate differences; and other agricultural risk factors. In addition to these two ways to offset carbon, other ways to offset emissions may be forthcoming in future ETS programs. 
Table 7

$\mathrm{CO}_{2}$ Sequestration Evaluation of 6,800 Fast Growing Hardwood Trees

\begin{tabular}{lcccccc} 
Year & Survival & $\begin{array}{c}\text { Pounds of Carbon per } \\
\text { Tree per Year }\end{array}$ & $\begin{array}{c}\text { Trees } \\
\text { Planted }\end{array}$ & $\begin{array}{c}\mathrm{CO}_{2} \mathrm{lbs} \text { per } \\
\text { year }\end{array}$ & $\begin{array}{c}\mathrm{CO}_{2} \mathrm{~kg} \text { per } \\
\text { year }\end{array}$ & $\begin{array}{c}\text { Carbon Credit } \\
\text { per year }\end{array}$ \\
\hline 0 & $87.3 \%$ & 2.7 & 5,937 & 58,824 & 26,738 & 26.7 \\
1 & $79.8 \%$ & 4.0 & 5,427 & 79,660 & 36,209 & 36.2 \\
2 & $73.6 \%$ & 5.4 & 5,005 & 99,185 & 45,084 & 45.1 \\
3 & $70.6 \%$ & 6.9 & 4,801 & 121,571 & 55,259 & 55.3 \\
4 & $67.8 \%$ & 8.5 & 6,611 & 143,821 & 65,373 & 65.4 \\
5 & $65.8 \%$ & 10.1 & 4,475 & 165,853 & 75,388 & 75.4 \\
6 & $63.9 \%$ & 11.8 & 4,346 & 188,173 & 85,533 & 85.5 \\
7 & $62.1 \%$ & 13.6 & 4,229 & 210,768 & 95,804 & 95.8
\end{tabular}

Note. Information is based on 10 acres of land and initial 6,800 hardwood trees planted.

\section{Results}

An aviation program consuming 10,000 gallons of avgas per year would produce an estimated 83 metric tons of carbon dioxide using EPA emissions factors. Using offset projects from organizations such as carbonfund.org, the carbon offset would cost $\$ 10$ per metric ton or $\$ 830$. Using trees as a way to offset the carbon dioxide for 10,000 gallons of avgas per year, a flight program would need to start 6,800 fast growing hardwood trees in 15-gallon containers planted on 10 acres of land. In the regulatory carbon market, prices fluctuate over time; on the other hand, in the voluntary markets, prices depend on the project costs itself. (Brohe, et al., 2009). Currently, carbon credits from domestic reforestation projects can only be traded in the voluntary markets, due to a non-existent regulatory market in the U.S. It is essential that carbon measurements are reliable and valid so that one carbon credit is equivalent to any other around the world (Brohe, et al., 2009).

\section{Discussion and Conclusion}

In the U.S., limitations on the amount of carbon emissions are not imposed on aviation activities as of February 2013. The EU started to regulate aviation carbon emissions on January 1, 2012 for flights originating or landing at an EU airport, even those flights that extend beyond EU borders. ICAO is studying the EU's carbon trading scheme and investigating alternative methods to limit aviation carbon on a global basis. Therefore, the EU delayed implementation of the EU ETS on flights to or from the EU on non-EU airlines. The authors believe that it is only a matter of time before aviation activities in the U.S. and North America are affected by carbon regulation. This article presented carbon offsets that may be purchased from organizations or carbon offsets that may be produced using reforestation projects. Whether these types of offsets may be used to 
offset aviation activities in the U.S. is a question for the regulatory agencies. Offsetting the carbon footprint of aviation may be done through certified projects, and may or may not produce tradable or offsetting carbon credits.

\section{Future Research}

Offsetting carbon emissions is only one way to reduce the carbon footprint of aviation activities. Other ways to reduce the carbon footprint include improvements to fuels, aircraft and procedures that reduce fuel consumption. Future research will explore specific forestation and herbaceous plants as carbon sequestration methods, and specific fuel reduction methods for university-related aviation activities. In addition, future research will explore the total carbon footprint of university aviation activities to include impacts from fuel and other items such as lubricants, paper, electricity usage, and movement of students to and from the campus. 


\section{References}

Air Transport Action Group. (2011). Beginner's guide to aviation biofuels. Retrieved from http://www.atag.org/our-publications/latest.html

British Airways. (2012). One Destination Carbon Fund. Retrieved from http://www.onedestination.co.uk/environment/climate-change/one-destinationcarbon-fund/

Brohe, A., Eyre, N., \& Howarth, N. (2009). Carbon Markets an International Business Guide. London, UK: Earthscan.

Buyck, C. (2011). More Than 20 Countries to Declare Joint Opposition to EU ETS. Retrieved from http://atwonline.com/international-aviation-regulation/news/more20-countries-declare-joint-opposition-eu-ets-1003

CalAir Aviation, LLC. (n.d.). About CalAir, Carbon Free Flight School. Retrieved from http://www.calaironline.com/about.html

Carbonfund.org. (n.d.a). Our mission: Towards a ZeroCarbon world. Retrieved from http://carbonfund.org/about

Carbonfund.org. (n.d.b). Reduce your individual carbon footprint, use our calculators. Retrieved from_http://carbonfund.org/individuals

Carbon Neutral Plane. (2012). Carbon Neutral Plane program. Retrieved from http://www.carbonneutralplane.com/program.html

Collinson, P. (2012, October 13). Money: Hang up on this sickening scam. The Guardian. Retrieved from http://www.lexisnexis.com/lnacui2api/auth/checkbrowser.do?rand=0.56849920589 $27117 \&$ cookieState $=0 \&$ ipcounter $=1 \& b h c p=1$

Delta Airlines. (2012). Improving the Environment. Retrieved from http://www.delta.com/about_delta/global_good/environment/

Energy Information Administration (EIA). (1998). Method for calculating carbon sequestration by trees in urban and suburban setting. Retrieved from ftp://ftp.eia.doe.gov/pub/oiaf/1605/cdrom/pdf/sequester.pdf

Environmental Protection Agency. (2011). Emission Factors for Greenhouse Gas Inventories. Retrieved from http://www.epa.gov/climateleadership/documents/emission-factors.pdf

Environmental Protection Agency. (2010.). Pollutants in the Ambient Air. Retrieved from http://www.epa.gov/eogapti1/course422/ap2.html 
Environmental Protection Agency. (2012). Green House Gas Emissions. Retrieved from http://www.epa.gov/climatechange/ghgemissions/gases.html

European Commission. (2012a). Climate Action: Transport Aviation Reducing Emissions from the Aviation Sector. Retrieved from http://ec.europa.eu/clima/policies/transport/aviation/index_en.htm

European Commission. (2012b). Climate Action: Emission Trading System Emission Trading System (EU ETS). Retrieved from http://ec.europa.eu/clima/policies/ets/index_en.htm

European Environment Agency. (2012). Carbon dioxide. Retrieved from http://www.eea.europa.eu/maps/ozone/resources/glossary/carbon-dioxide

Federal Aviation Administration. (2005). Aviation and emissions a primer. Washington DC: Author.

Federal Aviation Administration. (2012). United States Aviation Greenhouse Gas Emissions Reduction Plan, Submitted to the International Civil Aviation Organization, June 2012. Retrieved from http://www.faa.gov/about/office_org/headquarters_offices/apl/environ_policy_guid ance/policy/media/Aviation_Greenhouse_Gas_Emissions_Reduction_Plan.pdf

Federal Aviation Administration Flight Standards Service (FAAFSS). (2009). Pilot's Handbook of Aeronautical Knowledge. Oklahoma City, OK: United States Department of Transportation, Federal Aviation Administration Airman Testing Standards Branch.

International Air Transport Association. (n.d.). Industry carbon offset program. Retrieved from http://www.iata.org/whatwedo/environment/Documents/carbon-offsetsep2010.pdf

International Civil Aviation Organization. (2010). Industry Carbon Offset Program. Retrieved from http://www.iata.org/whatwedo/environment/Documents/carbonoffset-sep2010.pdf

International Civil Aviation Organization. (2011). Guidance Material for the Development of States' Action Plans Towards the Achievement of ICAO's Global Climate Change Goals. Retrieved from http://www.icao.int/environmentalprotection/Documents/GuidanceMaterial_DevelopmentActionPlans.pdf

International Civil Aviation Organization. (2012a). Carbon Emissions Calculator. Retrieved from http://www.icao.int/environmentalprotection/CarbonOffset/Pages/default.aspx 
International Civil Aviation Organization. (2012b). Carbon Emissions Calculator Version 5, June 2012. Retrieved from http://www.icao.int/environmentalprotection/CarbonOffset/Documents/Methodology\%20ICAO\%20Carbon\%20Calcu lator_v5-2012.Revised.pdf

Intercontinental Exchange. (2012). Emissions. Retrieved from https://www.theice.com/productguide/ProductGroupHierarchy.shtml?groupDetail= \&group.groupId=19

International Panel on Climate Change. (2006). IPCC Guidelines for National Greenhouse Gas Inventories Volume 2 Energy. Retrieved from http://www.ipccnggip.iges.or.jp/public/2006gl/vol2.html

ISO (2006a) Standard 14064-2:2006: Greenhouse gases -- Part 2: Specification with guidance at the project level for quantification, monitoring, and reporting of greenhouse gas emission reductions or removal enhancements.

ISO (2006b) Standard 14064-3:2006: Greenhouse gases -- Part 3: Specification with guidance for the validation and verification of greenhouse gas assertion.

Johnson, M. E. \& Gonzalez, A. (in press). Effects of a carbon emissions trading system on aviation financial decisions. Journal of Aviation Technology and Engineering.

Kelly, L. (2011). CalAir Creates Carbon-Neutral Flight Training in LA Area. Carbonfund.org. Retrieved from http://carbonfund.org/blog/item/3812-cal-aircreates-carbonneutral-flight-training-la-south-bay

Moores, V. (2012). ICAO Sees EU ETS as Regional Issue. Air Transport World. Retrieved from http://atwonline.com/international-aviation-regulation/news/icaosees-ets-regional-issue-1001

Nature Conservancy. (2012). Carbon Calculator. Retrieved from http://www.nature.org/greenliving/carboncalculator/index.htm

Russell, J. (2012, June 6). Carbon credit fraud soaring, warns FSA. The Daily Telegraph. Retrieved from http://www.lexisnexis.com/lnacui2api/results/docview/docview.do?docLinkInd=tru e\&risb=21_T15856827096\&format=GNBFI\&sort=BOOLEAN\&startDocNo=26\&r esultsUrlKey=29_T15856830903\&cisb=22_T15856830902\&treeMax =true \&treeWi $\mathrm{dth}=0 \& \mathrm{csi}=8109 \& \mathrm{docNo}=43$

Schneider, M. (2012). Voluntary airline carbon offset programs. Retrieved from http://www.uncsd2012.org/content/documents/743presentationschneider.pdf

South Carolina Forestry Commission (SCFC). (n.d.). Seedling spacing trees per acre. Retrieved from http://www.state.sc.us/forest/nurspa.htm 
Struck, D. (2010, April 20). Buying carbon offsets may ease eco-guilt but not global warming. The Christian Science Monitor. Retrieved from http://www.csmonitor.com/Environment/2010/0420/Buying-carbon-offsets-mayease-eco-guilt-but-not-global-warming

United Airlines, 2012. United's carbon offset program. Retrieved from http://CO2offsets.sustainabletravelinternational.org/ua/offsets/

United Nations Framework Convention on Climate Change. (2012). Background on the UNFCCC: The international response to climate change. Retrieved from http://unfccc.int/essential_background/items/6031.php

United Nations Framework Convention on Climate Change. (2012a). Kyoto Protocol. Retrieved from http://unfccc.int/kyoto_protocol/items/2830.php

United Nations Framework Convention on Climate Change. (2012b). The Mechanisms under the Kyoto Protocol: Emissions Trading, the Clean Development Mechanism and Joint Implementation. Retrieved from http://unfccc.int/kyoto_protocol/mechanisms/items/1673.php

United Nations Framework Convention on Climate Change. (2006). Kyoto Protocol Status of Ratification. Retrieved from http://unfccc.int/files/essential_background/kyoto_protocol/status_of_ratification/ap plication/pdf/kpstats.pdf 


\title{
Bioavailable Lead in Topsoil Collected from General Aviation Airports
}

\author{
Jerry H. Kavouras, Randal J. DeMik, and Allison C. Hopkins \\ Lewis University
}

\begin{abstract}
Representatives of the aviation community are interested in determining the environmental effects of leaded fuel emissions from general aviation flight operations. Soil is an environmental sink for lead to accumulate over time. This study measured bioavailable lead concentrations in topsoil at three general aviation airports and at one site with no general aviation operations in order to determine if general aviation aircraft operations are contributing to the contamination of airport topsoil at levels that require remediation by law. Bioavailable refers to substances that organisms can absorb, because they have access to them. Topsoil was collected from refueling areas, run-up areas, and approach corridor/departure end runways. The samples were dried and the fine fractions were separated. The fine fractions were suspended in nitric acid to extract the lead for laboratory analysis. A univariate ANOVA was computed comparing the quantity of soluble lead in the topsoil from three general aviation airports (further classified as high, moderate, and low volume of flight operations) and at one site with no general aviation operations (arboretum). A significant main effect for the high volume airport was found $(F[2,24]=10.966, p<.05)$, in which the lead in topsoil samples from high volume airports were lower than the samples from the other airports, but similar to the arboretum. Another analysis was calculated comparing quantity of soluble lead in topsoil at sites within airports (refueling areas, run-up areas, and approach corridor/departure end runways). No significant main effect was found among the sites $(F[4,24]=1.065, p>$ $.05)$. However, an interaction was observed when comparisons were made between the airport sites $(n=3)$ and locations sampled at the sites $(n=3)$ that was significant $(F[4$, $24]=2.902, p<.05)$. Tukey's HSD was used to determine the nature of the differences. The analysis revealed that concentrations of lead in soil samples collected from the high volume airport refueling area, run-up area, and approach corridor/departure end runway were significantly lower than the moderate volume airport run-up area lead concentrations. The results at the three airports investigated support the conclusions that the risk of ingesting lead from surface soils is low and bioavailable lead in the soil sampled from general aviation airports is not accumulating in quantities that require remediation according to Environmental Protection Agency requirements.
\end{abstract}

\section{Introduction}

Representatives of the aviation community are interested in determining the environmental effects of leaded fuel emissions from general aviation flight operations because lead is a neurotoxin and there are potential consequences to public health. The Institute of Medicine (1998) defined public health as, "what we as a society do collectively to assure conditions in which people can be healthy" (p. 19). The majority of general aviation piston-engine powered aircraft use aviation gasoline (Avgas) that is designated as 100 Low Lead (100LL). According to Schaufele (2008), more than 
200,000 general aviation aircraft burn approximately 190 million gallons of 100LL annually. This exhaust makes up $45 \%$ of the total lead emissions in the air over the United States.

Early automotive engineers discovered that gasoline has a tendency to "knock" that is, explode rapidly instead of burning smoothly inside engine cylinders. According to Midgley (1937), knocking was eliminated when the chemical compound tetra-ethyl lead (TEL) was added to gasoline because it reduces temperature and pressure build up within cylinders. Lead additives in gasoline prevent detonation, which causes a high-pressure spike in the combustion chamber (Cline, 2000) and eventually engine damage (Harvey, 2006). The discovery of leaded fuel allowed for the development of powerful high compression engines. As leaded fuel was found to be very effective in high compression engines, its use spread from the automotive to the aviation industry.

When TEL was first added to fuel, there was no information about the negative health consequences of lead exposure. Recognition of TEL as a toxic substance has guided the phase-out of leaded gasoline in automobiles that began in 1970 in the United States (Matsui, 2007). According to the Agency for Toxic Substances \& Disease Registry (2007), lead can affect every organ in the human body and exposure to high levels of lead can damage the brain, kidneys, and nervous system. A 2001 report by the Environmental Protection Agency (EPA) defined a soil lead hazard as "bare soil that contains $400 \mathrm{ppm}$ of lead in a play area or $1200 \mathrm{ppm}$ in other parts of a yard" (p. 21). Less than $400 \mathrm{ppm}$ is considered urban background and does not require remediation (EPA, 2001). Young people are more susceptible to lead poisoning, and even small amounts of lead ingestion can impair their mental and physical growth (U.S. Department of Health and Human Services, 2007).

Lead is not only harmful to humans, but wildlife as well. Predators accumulate higher pollutant concentrations than their contaminated prey because of bio-magnification. As a result, the EPA (2011) determined that "people and other animals at the top of the food chain who eat contaminated fish or meat are exposed to concentrations that are much higher than the concentrations in the water, air, or soil" (p. 13).

Soil is an environmental sink for lead to accumulate over time. Anthropogenic sources of lead deposited in soil typically remain at high levels because they do not biodegrade or decay, and plants do not absorb them quickly (EPA, 2001). According to Howden, Schneider, and Grosser (1996), lead paints used on deteriorating exterior surfaces for homes built before 1980 can highly contaminate soils. Lead concentrations in soils near roadways exposed to leaded gasoline over time can be 30 to 2000 times greater than natural levels, particularly older roadways within large cities (Howden et al., 1996).

Piston-engine-equipped general aviation aircraft still use leaded fuel. The EPA estimates that between 1970 and 2007, the combustion of avgas in general aviation has released 34,000 tons of lead into the atmosphere and affects three million children who attend school near aviation facilities (EPA, 2010). The EPA has issued an advance notice of proposed rulemaking (ANPR) addressing engine emission standards for piston aircraft 
(EPA, 2010). Awareness of the negative health and environmental consequences of leaded fuel and the recent ANPR are prompting research towards developing an unleaded alternative to avgas.

\section{Statement of the Problem}

Aviation gasoline or avgas achieves higher octane ratings by the addition of tetra-ethyl lead (TEL), a toxic substance that was phased out for automobile use in the United States. Few studies have provided empirical evidence of lead contamination in soil from general aviation operations that continue to use avgas containing TEL. This study will measure soluble (bioavailable) lead concentrations in topsoil at three general aviation airports and at one non-airport site located several miles from any general aviation operations in order to determine if general aviation aircraft operations are contaminating the airport topsoil at levels that require remediation by law. Use of the term "bioavailable" in this study refers to substances that organisms can absorb, because they have access to them. The methods in this study allowed the investigators to measure lead that is soluble using nitric acid extraction (Howden et al., 1996). Soluble lead is potentially available to soil organisms for ingestion or uptake. This study tested the following research hypotheses:

1. Airports with higher volumes of general aviation operations would have greater quantities of soluble lead in the topsoil compared to airports with lower volumes of general aviation operations.

2. Sites (refueling area, run-up area, and runway approach corridor/departure end) within each general aviation airport differ in the quantity of soluble lead in the topsoil.

3. The quantities of soluble lead in the topsoil of general aviation airports are greater than or equal to levels that require remediation as established by the EPA.

\section{Methodology}

\section{Sites}

The sampling sites are three general aviation airports in northeastern Illinois that are distinguished based on numbers of annual departures and arrivals. The Airport Inventory Report (Illinois Department of Transportation, 2012) listed annual operations for Airport 1 as 104,000, Airport 2 as 50,000, and Airport 3 as 25,000. The Airport Inventory Report refers to operations as the number of take-offs and landings at an airport. The majority of operations at the selected airports were piston engine aircraft. The researchers classified the airports as high (Airport 1), moderate (Airport 2), and low (Airport 3) volume based on the data. Soil samples were collected near the highest use approach corridor/departure end runway, run-up areas, and refueling areas (see Figures 1-3). The approach corridor is the same as the take-off point, where emissions from aircraft exhaust are the greatest discharge due to high power settings at beginning of take-off roll. At airports with multiple runways, the run-up area and approach corridor/departure end were sampled at the runway of primary use. The nearest topsoil to paved areas was collected in this study. Samples were also collected from forested areas within the Morton Arboretum as a 
control since there is no direct contact with airplanes. The sites within the arboretum were Location $1\left(41^{\circ} 49^{\circ} 07^{\circ} \mathrm{N}, 88^{\circ} 05^{\circ} 02 \mathrm{~W}\right)$, Location $2\left(41^{\circ} 48^{\circ} 52^{\circ} \mathrm{N}, 88^{\circ} 02^{\circ} 34^{\circ} \mathrm{W}\right)$, and Location $3\left(41^{\circ} 49^{\circ} 09^{\circ} \mathrm{N}, 88^{\circ} 03^{\circ} 21^{\circ} \mathrm{W}\right)$.

\section{Procedures}

Each site was visited during a normal operational day (meaning no special events, air shows, or fly-ins, which would have a direct effect of the number of planes). A coring sampler (LaMotte Company) was bored into the ground at a depth of 1.5 to 2 inches. The top $1 / 2$ inch of soil was placed into a sterile Whirlpak bag (Howden et al., 1996). Each sample consisted of three samplings within a one-foot diameter of the initial sampling that were placed into the same Whirlpak bag (Fig. 4). To reduce contamination, excess soil was wiped from the sampling tube between sampling using a gloved finger and then the tube was washed with distilled water and wiped with clean paper towels. Three samples were collected from each location (Fig. 4). The samples were transported to the Biology Department at Lewis University and stored at room temperature. According to Materials Analytical Services Inc. (n.d.), no refrigeration or preservation was required.

\section{Measures}

Soil samples were dried using a conventional microwave. Dried soil samples were separated into fine and coarse fractions using two sieves - a $4.75 \mathrm{~mm}$ (No. 4) sieve to remove large debris, e.g. rocks and sticks, and a $250 \mu \mathrm{m}$ (No. 60) sieve to separate coarse and fine fractions of soil. The fractions were weighed, placed into sterile Whirlpak bags, and stored at room temperature until ready for use.

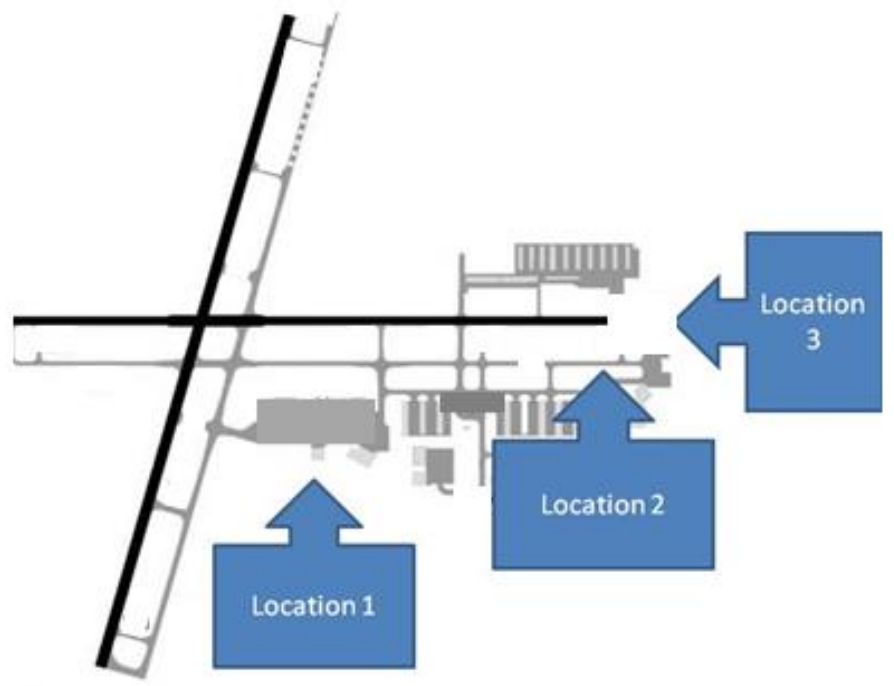

Figure 1. Map of high volume airport sample site locations. Soil samples were collected from the refueling area (Location 1), the run-up area (Location 2), and the approach corridor/departure end runway (Location 3). 


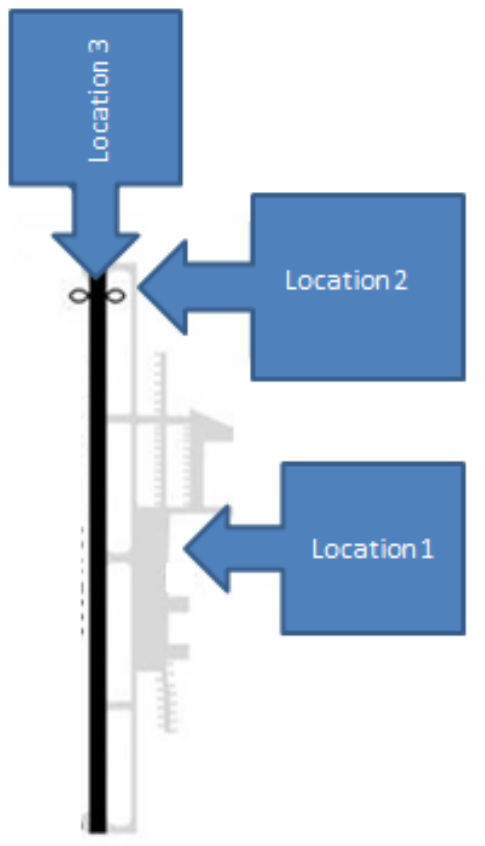

Figure 2. Map of moderate volume airport sample site locations. Soil samples were collected from the refueling area (Location 1), the run-up area (Location 2), and the approach corridor/departure end runway (Location 3).

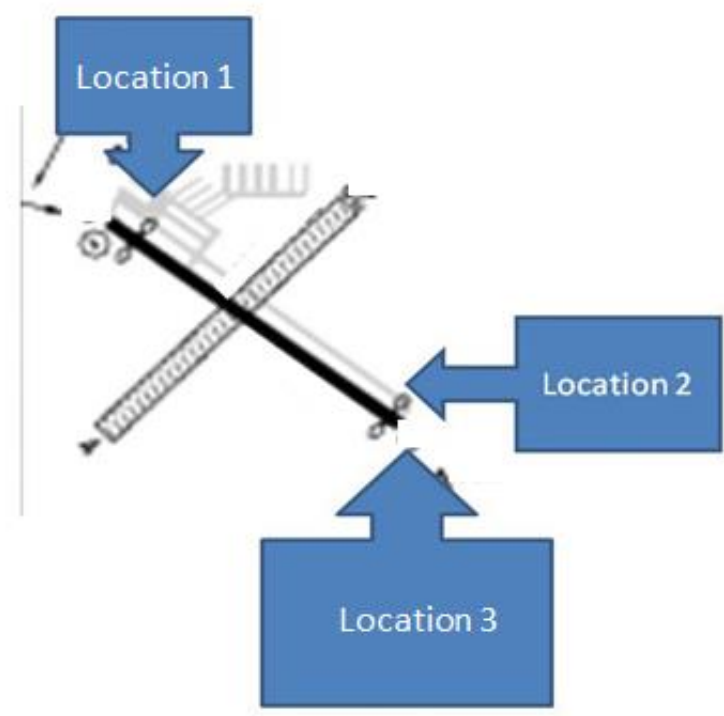

Figure 3. Map of low volume airport sample site locations. Soil samples were collected from the refueling area (Location 1), the run-up area (Location 2), and the approach corridor/departure end runway (Location 3). 


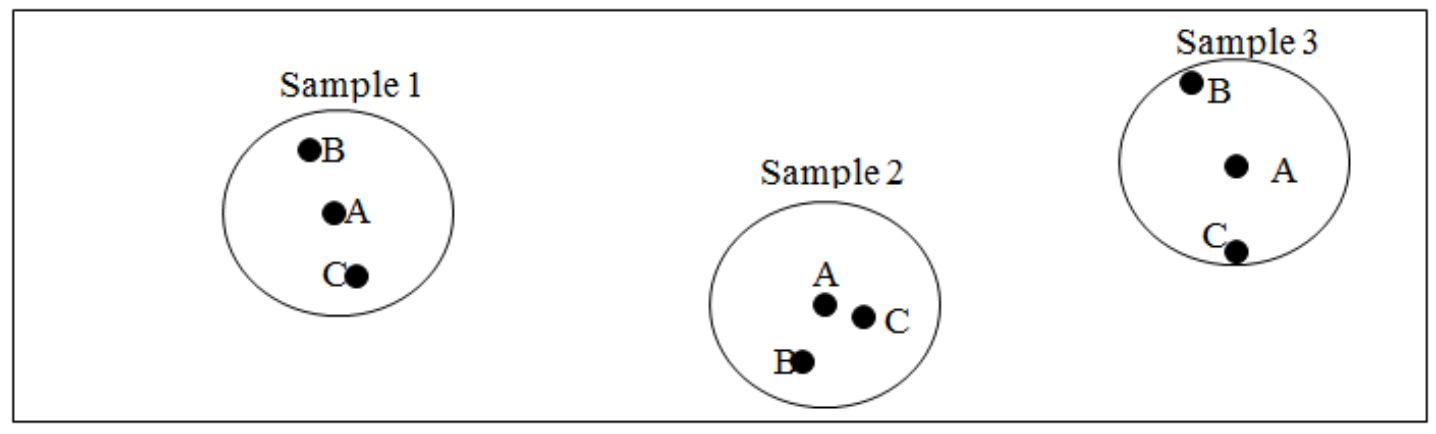

Figure 4. An example of three samples taken from one location within a site. The large circle is one foot in diameter from the initial sampling (A), whereas the other samples (B, C) are taken within the circle. The large circle represents one sample.

The investigators were able to measure the lead concentration in fine fractions using nitric acid extraction (Howden et al., 1996). Generally, fine fractions are the source of ingested lead because particles of this size sticks to hands and objects, such as clothing, which transfer lead to the mouth (EPA, 2000). Three grams of the fine fraction were added to $30 \mathrm{~mL}$ of $1 \mathrm{M}$ nitric acid. The mixture was shaken for one hour on an orbital shaker to extract the lead from the soil. Then the mixture was centrifuged $(1000 \mathrm{x} \mathrm{g}, 10$ minutes) and the aqueous supernatant was removed for analysis. The lead concentration was determined for each fine fraction using the Pocket Colorimeter II Test Kit (Hach Company) according to the manufacturer's instructions. Lead nitrate was used as a positive control and to calibrate the colorimeter.

\section{Statistical Analysis}

The data were analyzed using a multi-factorial analysis of variance. The independent variables were the sites (High, Moderate, and Low Volume Airports, and Morton Arboretum) and the locations within the sites (refueling area, run-up area, and approach corridor/departure end). The dependent variable was the bioavailable lead concentration in the soil measured in parts per million (ppm). IBM SPSS Statistic 19 software analyzed the data. A $p$ value $<0.05$ was chosen to determine significance.

\section{Results}

The first hypothesis sought to determine if the volume of arrivals and departures at a general aviation airport relate to the quantity of soluble lead in the topsoil. A univariate ANOVA was computed comparing the quantity of soluble lead in the topsoil from three general aviation airports (further classified as high, moderate, and low volume of flight operations) and at one site with no general aviation operations (arboretum). A significant main effect for the high volume airport was found $(F(2,24)=10.966, p<$ $.05)$, in which the lead in topsoil samples from high volume airports were lower than the samples from the other airports, but similar to the arboretum (refer to Table 1 and Figure $5)$. The concentrations of lead in samples collected from the high volume airport $(m=$ $0.286, s d=0.147)$ were lower than the samples from the low $(m=0.677, s d=0.264)$ and 
moderate $(m=0.763, s d=0.39)$ volume airports but similar to concentrations from the arboretum $(m=0.498, s d=0.147)$.

The second hypothesis sought to determine if sites within each general aviation airport vary in the quantity of soluble lead in topsoil. Another analysis was calculated comparing quantity of soluble lead in topsoil at sites within airports (refueling areas, run-up areas, and approach corridor/departure end runways). No significant main effect was found among the sites $(F(4,24)=1.065, p>.05$, refer to Table 1$)$. However, an interaction was observed when comparisons were made between the airport sites $(n=3)$ and locations sampled at the sites $(n=3)$ that was significant $(F(4,24)=2.902, p<.05$, refer to Table 1 and Figure 6). Tukey's HSD was used to determine the nature of the differences. This analysis revealed that concentrations of lead in soil samples collected from the high volume airport refueling area $(m=0.2577, s d=0.23897)$, run-up area $(m=0.25, s d=$ $0.14)$, and approach corridor/departure end runway $(m=0.35, s d=0.025)$ were significantly lower than the moderate volume airport run-up area $(m=1.07, s d=0.506)$ lead concentrations.

The third hypothesis sought to determine if the quantity of soluble lead in the topsoil of general aviation airports meet levels that require remediation. The levels of lead in this study were considerably lower than the levels established by federal agencies (refer to Figures 5 \& 6).

Table 1

Two-factor analysis of variance of lead levels in soil samples.

\begin{tabular}{l|cccccc}
$\begin{array}{l}\text { Source } \\
\text { Variation }\end{array}$ & of & df & SS & MS & F & $\boldsymbol{P}$ \\
\hline Intercept & 1 & 106687.289 & 106687.289 & 200.159 & $<0.001$ \\
Site & 2 & 11690.081 & 5845.040 & 10.966 & $<0.001$ \\
Location & 4 & 2270.783 & 567.696 & 1.065 & 0.395 \\
Site x Location & 4 & 6186.213 & 1546.553 & 2.902 & 0.043 \\
\cline { 3 - 6 }
\end{tabular}




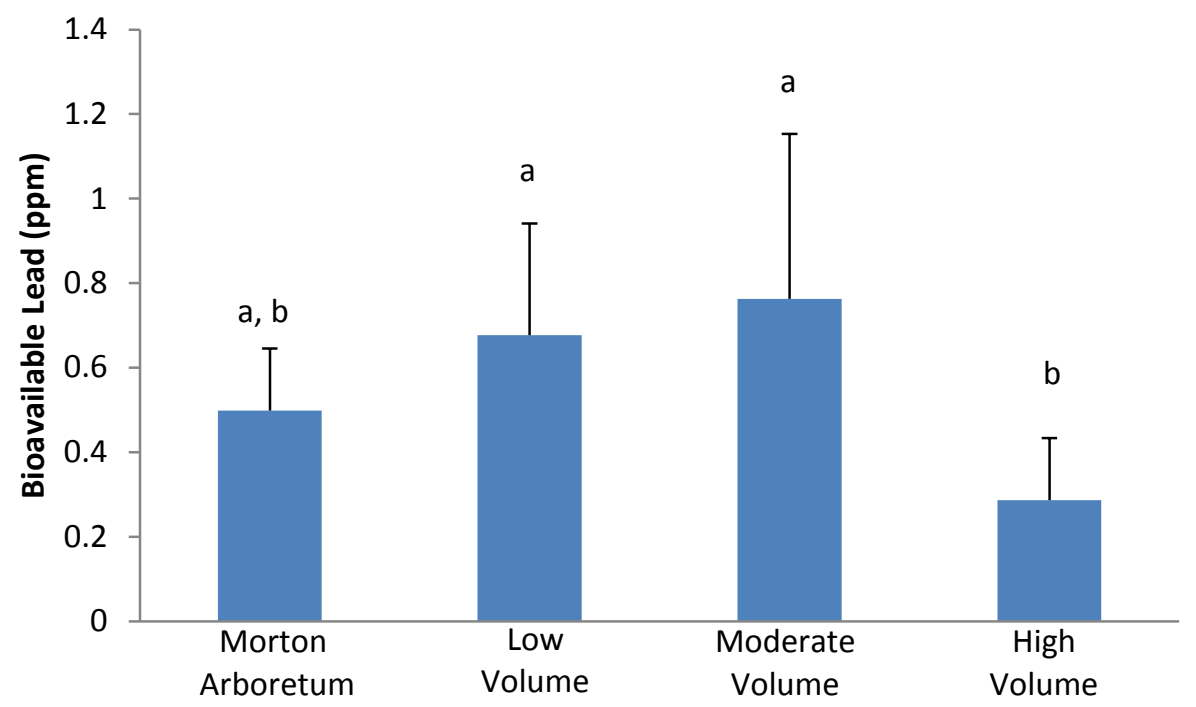

Figure 5. Lead concentrations in soil samples collected from Morton Arboretum and general aviation airports. Each bar represents the mean of all samples collected from the site. Error bars are standard deviations. The letters above the bars denote similarities among the sites in regards to lead concentrations $(p>0.05)$.

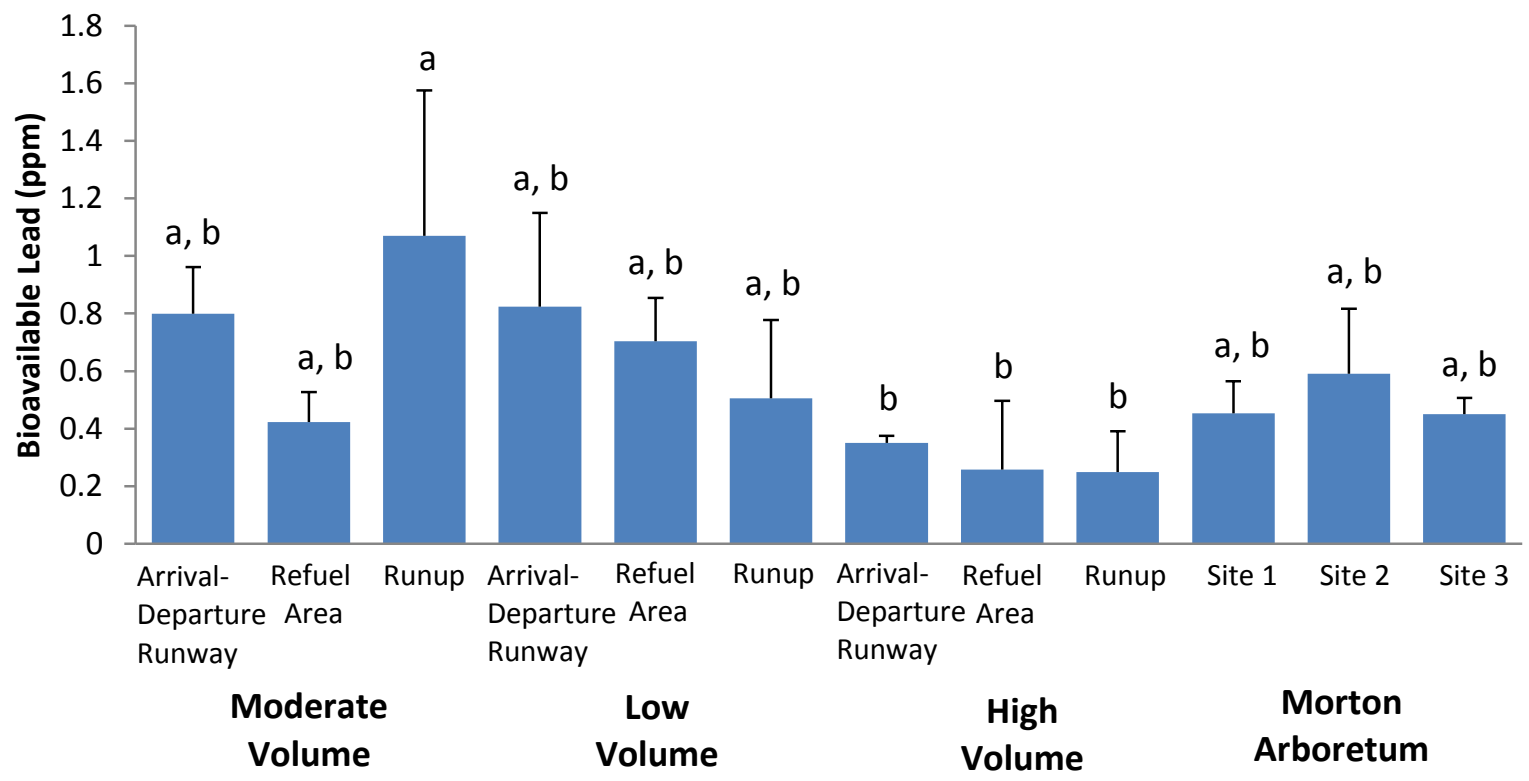

Figure 6. Lead concentrations in soil samples sorted by site and location. Each bar represents the mean of all samples collected from the location within the site. Error bars are standard deviations. The letters above the bars denote similarities among the sites in regards to lead concentrations $(p>0.05)$. 


\section{Discussion of the Results}

The overall purpose of this soil lead study was to determine if general aviation operations increase the quantity of lead in airport soils. The study examined three airports based on traffic volume and Morton Arboretum, which is not exposed directly to general aviation. The soil lead concentrations at the airports should increase with traffic volume if there was a positive correlation between general aviation operations and lead in the soil. The trend appears to be present, steadily increasing from Morton Arboretum to the moderate volume airport, until one examines the high volume airport, which is the lowest of the four sites (refer to Figure 5). Why would this trend disappear when reaching the high volume airport? First, it was discovered that the sites within the high volume airport were reconstructed recently and the topsoil was replaced. This may explain the discrepancy, because the topsoil would not have been exposed to general aviation operations using leaded fuels for an extended period. The trend suggests that traffic volume at general aviation airports increases soil lead levels, but not significantly (refer to Figure 5). Secondly, the high volume airport had multiple runways (refer to Figure 1) leading to emissions not concentrated in one area by spreading operations for engine run-up, arrivals, and departures as compared to the one runway configuration at the moderate and low volume airports where operation areas were concentrated (refer to Figures 2 \& 3). Interpretation of the data strongly suggests that both factors, reconstruction and runway configurations, are important in soil lead accumulation.

The concentrations of lead in soils were also lower than the levels defined as a soil lead hazard by the EPA (refer to Figures $5 \& 6$ ). As stated in the introduction, a soil lead hazard is bare soil that contains $400 \mathrm{ppm}$ of lead in a play area or $1200 \mathrm{ppm}$ in other parts of a yard, and remediation is not required for levels below $400 \mathrm{ppm}$. The run-up at the low volume airport had the highest soil lead concentration in this study at approximately $1.1 \mathrm{ppm}$ (refer to Figure 6). The topsoil at these sites was not bare, so the chance of ingestion was low. Some of the areas within the airports had greater levels of soil lead than other areas within the site, but they were not significantly different (refer to Figure $6)$.

The findings are consistent with those of Taylor, Park, Murphy, and Mortvedt (2010), which reported concentrations of soil lead at the perimeter of an airport in quantities well below $400 \mathrm{ppm}$. The concentrations of lead reported by Taylor et al. (2010) were greater than reported in this study; however, both were less than urban background, which supports the view that soil lead at general aviation airports does not exceed levels that require remediation. Therefore, people are not at risk of exposure to high levels of lead through ingestion of fine soil particles that could be dislodged from surfaces during routine maintenance operations.

\section{Recommendations for Future Research}

Soluble lead concentrations in fine fractions of topsoil collected from general aviation airports were below the level required for remediation by the EPA. Future work could include the coarse fractions of topsoil collected from these sites in order to create a complete soil profile. The literature recommends the fine fraction for lead analysis 
because it provides an accurate assessment of the risk from incidental ingestion; however, it does state that some soils do have higher concentrations in coarse fractions.

The three airports in northeastern Illinois that varied in traffic volume were a good start. A more complex study could be performed to confirm that traffic volume and soil lead levels are correlated, and to determine if other factors, such as length of time exposed to general aviation, runway configurations, and reconstruction are significant.

\section{Acknowledgements}

Special thanks to Tyler Dean for his assistance during sample collection and lead analysis, and Dr. Salim Diab for his technical expertise. This research was sponsored, in part, by a grant from The Colonel Stephen S. And Lyla Doherty Center for Aviation and Health Research. 


\section{References}

Agency for Toxic and Substances Disease Registry. (2007). ToxFAQs for lead (CAS \# 7439921). Retrieved from http://www.atsdr.cdc.gov/tfacts13.pdf

Cline, A. (2000). Engine Basics: Detonation and Pre-Ignition. Contact Magazine, 54 Retrieved from http://www.contactmagazine.com/Issue54/EngineBasics.html

Environmental Protection Agency. (2000). Short sheet: TRW Recommendations for sampling and analysis of soil at lead (Pb) sites. (EPA/540-F-00-010). Retrieved from http://epa.gov/superfund/lead/products/sssiev.pdf

Environmental Protection Agency. (2001). Lead-safe yards: Developing and implementing a monitoring, assessment, and outreach program for your community. (EPA/625/R-00/012). Retrieved from http://www.epa.gov/region1/leadsafe/pdf/chapter3.pdf

Environmental Protection Agency. (2010). Advance notice of proposed rulemaking on lead emissions from piston-engine aircraft using leaded aviation gasoline: Regulatory announcement (EPA420-F-10-013). Retrieved from http://www.epa.gov/nonroad/aviation/420f10013.htm

Environmental Protection Agency. (2011) Lead in air. Retrieved from http://epa.gov/airquality/lead/health.html

Harvey, A.D. (2006). Air records and war flying. Air Power History 53(3), 35-39.

Howden, S., Schneider, C., \& Grosser, Z. (1996). The analysis of soil, paint, and house dust for lead contamination. Atomic Spectroscopy 17(4), 171-175.

Illinois Department of Transportation. (2012). Airport inventory report. Retrieved from http://www.dot.state.il.us/aero/2012inventory.pdf

Institute of Medicine. (1998). The future of the public's health in the $21^{\text {st }}$ century. Washington, D.C.: National Academies Press.

Materials Analytical Services, Inc. (n.d.). Environmental lead sampling procedures. Retrieved from http://www.mastest.com/pdf/LeadSamplingMethod.pdf

Matsui, A. (2007). Case study: Switch to unleaded gas. PBS Newshour. Retrieved from http://www.pbs.org/newshour/indepth_coverage/science/alt_fuels/unleaded.html

Midgely, T. (1937). From the periodic table to production. Industrial and Engineering Chemistry 29(2), 41-44. 
Schaufelle, R. D. (2008). FAA aerospace forecast. Washington, DC. Retrieved from http://www.faa.gov/data_research/aviation/aerospace_forecasts/2009 $-2025 /$ media/2009\%20Forecast\%20Doc.pdf

Taylor, C., Park, K., Murphy, K., \& Mortvedt, T. (2010) Lead and halogen contamination from aviation fuel additives at Brackett Airfield. Retrieved from http://ea.pomona.edu/1151-2/student-research-funded-by-the-mellon-foundation/ 


\title{
Snap-Courses: An Instructional Design Strategy for Aviation Mobile Learning
}

\author{
Suzanne K. Kearns \\ The University of Western Ontario
}

\begin{abstract}
The aviation industry is rapidly adopting mobile technology through the use of electronic flight bags (EFBs) in cockpits. In addition to EFB charts and manuals, mobile devices can deliver instructional content to facilitate mobile learning (m-learning). However, mlearning is still in its infancy, and little work has been done to explore how people learn through this technology. This article explores how the features of mobile devices may facilitate new aviation instructional approaches, as well as a blended learning instructional design model that incorporates snap-courses. Snap-courses are short, 5minute segments of training that are designed to be distributed over several weeks or months. Snap-courses may be well suited to a mobile learning context and facilitate long-term retention.
\end{abstract}

\section{Introduction}

The aviation industry has been an early adopter of mobile technology through the use of tablet computers as electronic flight bags (EFBs; Federal Aviation Administration, 2007). The current usage of mobile technology within aviation can be classified as justin-time training or performance support. This means that information such as a textbook, chart, or checklist is stored on the mobile device and available when the operator hits a stumbling block and needs additional information.

However, the opportunities for mobile learning (m-learning) within aviation are farreaching. As these devices are increasingly used, both professionally and personally, an educational opportunity has emerged that was not previously possible. The opportunity lies in the continual access to individuals throughout their day-to-day lives. When mobile users are seeking a few minutes of entertainment, while waiting in line or sitting in a coffee shop, it is common for them to pull out their device. This continual access to learners makes it possible to take advantage of these small windows of opportunity to provide aviation training courses of a very short duration. This style of instruction may be used to enhance pilot safety skills, reinforce technical knowledge of air law, weather, and general airmanship, or to distribute information on company-specific standard operating procedures.

Within the current discussion, the term snap-course is introduced to describe a short unit of training that is about 5 minutes in length. The goal of snap-courses, taken just once or twice a week throughout the year, is to promote high levels of retention compared to levels achieved in a once-a-year visit to a classroom (Cepeda, Pashler, Vul, Wixted, \& Rohrer, 2006). The following discussion will explore the current definition of $\mathrm{m}$ learning, as well as the features of the technology, and the instructional design considerations that highlight the potential benefits of snap-courses. 


\section{What Is M-Learning?}

Generally, most people associate m-learning with the newest forms of technology, such as smartphones or tablet computers. M-learning is also commonly regarded as having evolved from personal computer-based electronic learning (e-learning). However, m-learning can exist even without such technology. For example, a person travelling with a book is participating in mobile learning (Low \& O'Connell, 2006). Ultimately, the mobile element of learning is based upon the mobility of the individual rather than the technology (Sharples, Taylor, \& Vavoula, 2005).

M-learning has been defined as "any educational provision where the sole or dominant technologies are handheld or palmtop devices" (Traxler, 2005, p. 262). However, there is some ambiguity within this definition, as one may ask if training on ultra-light laptop computers would be categorized as m-learning. The term tethered is often used to distinguish between personal computers (PCs) and mobile devices, with laptops and PCs considered to be tethered. The terms lightweight, personal, informal, spontaneous, portable, situated, and context-aware have been used to describe m-learning, whereas the terms media-rich, connected, multimedia, institutional, structured, massive, and interactive have been used to describe e-learning (Traxler, 2005).

Some of the emerging characteristics of mobile learning include personalized instruction that is spontaneous, portable, and situated. Mobile learning has also been characterized as a personal learning environment, meaning that training is learner-centric, unlike most classroom environments, which are instructor-centric (Ally, 2009).

\section{M-Learning Features}

Although m-learning is not dependent upon technology, the features of modern mobile devices allow instructors to revolutionize teaching practices. At present, these features include push notifications, location-specific applications through global positioning systems (GPS), massive storage at a low weight, and video and still camera functions.

Push notifications allow for information to be immediately sent to mobile devices, which trigger an audio alert to the user upon arrival. Aviation training applications using push notifications could include a company sending safety- or time-critical information to employees. Push notifications can be enhanced with interactivity, such as a short quiz. Companies can track which employees have looked at and responded to the push

notification, thereby eliminating the need to gather employees in a classroom to deliver short training courses.

Most modern mobile devices include GPS functionality. This allows for the development of applications that sense the location of the user and transmit critical information that is specific to that environment. Within aviation, this functionality could allow for a pilot to access weather information or navigational charts that are relevant to the pilot's current location. 
The large storage capacity and low weight of mobile devices facilitates just-in-time learning, by allowing professionals to easily carry a massive amount of information that can be used to support their performance on the job. For example, if an aviation mechanic encountered a flaw that he or she had not seen before, a mobile device that contained electronic versions of manuals would allow the mechanic to search out the information needed without leaving the aircraft. This immediate application of new knowledge facilitates high-level learning (Ally, 2009).

Finally, the video and still camera functions within mobile devices can also be used to enhance learning and performance. These devices allow users to establish a more humanistic face-to-face connection with another person, perhaps a mentor who is located in a separate geographic area. These functions also facilitate easy sharing of visual information, such as an image of a mechanical component or weather system. This can allow individuals who are deployed on-the-line to access expertise and resources at a home base.

All of these features have significant potential to transform aviation training. However, it is crucial to remember that in order for m-learning to be effective, it needs to be based on instructional design theories.

\section{M-Learning Instructional Design}

It has long been known that technology has the potential to be a powerful educational tool (Kay \& Goldberg, 1977). As we enter the era of m-learning, it is beneficial to consider the challenges faced in the early days of e-learning. Initially, many companies were eager to reap the financial benefits of e-learning, such as reducing a pilot's time offthe-line and maintaining a fully staffed training center. This eagerness resulted in a large number of e-learning courses being developed very quickly, without due consideration given to how people learn electronically.

Research into the effectiveness of e-learning found that some courses significantly outperform classroom instruction, while others do not (Bernard et al., 2004; Cavanaugh, 2001). It is assumed that e-learning courses that underperform classroom instruction were developed rapidly, without being properly tested, as this type of training became popular before anyone truly understood how to use it (Zemsky \& Massy, 2004). In addition, as a result of exposure to poorly designed e-learning, many aviation professionals developed a negative opinion of e-learning as a whole (Kearns, 2010). To avoid repeating the same mistakes made with the rapid adoption of e-learning, it is crucial that aviation training professionals carefully consider how people will learn through mobile devices, which represent an entirely new medium.

Ultimately, the effectiveness of the training is more important than the nature of the technology. Unfortunately, instructional design theories for mobile platforms are immature compared to e-learning or classroom-based training (Gedik, HanciKarademirci, Kursun, \& Cagiltay, 2012). Some theories developed for e-learning can be adapted and applied to m-learning, yet there are many more questions than answers about how people learn through mobile devices. 
For example, a significant body of research has explored how learning is impacted by the environment within which instruction is delivered. Contextual learning theory suggests that the more realistic the instructional environment, the more likely it is that learners will be able to apply new knowledge in the real world (Jonassen, 1993). Contextual learning theory is the foundation of problem-based learning (PBL), and is the reason why many instructors present real-world examples so that learners can relate new knowledge to their own experiences (Hull, 1993). Another interesting example of context impacting learning is that seating comfort impacts one's performance and ability to pay attention (Gay, 1986; Tessmer \& Harris, 1992). Yet, with mobile learning, such a consideration is inherently unpredictable. Learners may complete m-learning while walking, sitting in a coffee shop, or travelling on a bus or aircraft. It is important to anticipate that a mobile context will create a new relationship with training, compared to traditional e-learning or classroom instruction.

Within the instructional design process, careful consideration must be given to exploring the characteristics of learners. With m-learning, acceptance of technology is likely to vary between generations. Prensky (2001) originated the terms digital immigrants and digital natives. The concept is that those who did not have access to digital technology in their youth must take on the challenge of learning to use digital technology in their adulthood; thus they are digital immigrants. By comparison, younger generations are digital natives, as digital technology has always been a part of their lives. Similarly, it can be expected that there will be a divide between mobile immigrants and mobile natives (Low \& O'Connell, 2006). This generation-gap theory is supported by the prevalence of mobile technology among teenagers (Gedik et al., 2012).

However, there will always be a segment of the population who do not own, or cannot afford to maintain access to, mobile technology. In addition, there is a lack of compatibility between types of mobile devices (currently the main three being Apple, Blackberry, and Android). This makes m-learning design difficult, increases development costs, and makes it challenging to reach all mobile users.

Yet, m-learning may have a large impact on developing nations. In many countries with limited access to PCs, the number of mobile phones is relatively high. In fact, it has been suggested that it would be a serious disservice to teachers and learners in Asian and African countries if these countries were to move toward e-learning instead of m-learning (Motlik, 2008). It is logical for these nations to move directly to mobile learning, based on the ease of use, prevalence of mobile technology, and students' and instructors' familiarity with the technology.

\section{Blended Learning Approach}

Blended learning is a term used to describe a program that incorporates two or more types of instruction. Pilot training is a natural example of blended learning, as it combines elements of classroom instruction with training in an aircraft or flight simulator. For job-relevant knowledge and skills, blended learning that includes both elearning and classroom instruction has been found to be more effective than either 
approach alone (Sitzmann, Kraiger, Stewart, \& Wisher, 2006; Zhao, Lei, Yan, Lai, \& Tan, 2005).

To determine which delivery methods to choose within a blended learning approach, a four-part process is recommended (Kearns, 2010):

1. Consider the cognitive, psychomotor, and affective training objectives.

2. For each of the objectives, consider the following:

a. What is the best teaching activity to accomplish this objective?

b. Is human interaction required?

c. How could this instruction be delivered?

3. Then, list which activities should be accomplished before classroom training, which activities require human interaction or specialized equipment (like a flight simulator), and which activities can be delivered on-the-line once learners have returned to their job. These three components make up the aviation blended learning model:

a. Pre-learning (e-learning, m-learning)

b. Training center (classroom and/or simulator)

c. On-the-line (e-learning, m-learning) (pp. 111-113).

Organizational factors, such as a company's training budget or a culture of being early adopters of technology, often impact instructional delivery decisions. However, it is crucial to remember that the ultimate goal of training is not to implement a new technology, but to accomplish training objectives. Training should be designed to maximize learning with the minimum cost.

Horton (2006) suggested a "sandwich" strategy for blended learning, placing classroom instruction after and before e-learning or m-learning elements. This strategy has been adapted for aviation companies to create the pre-learning, training center, onthe-line blended learning model shown in Figure 1 (Kearns, 2010). Pre-learning is accomplished through e-learning or m-learning. Pre-learning is meant to deliver the foundational knowledge and skills that learners require before classroom and simulator instruction. Training center learning is classroom and simulator-based instruction, specifically for topics that require human interaction, aircraft, or specialized equipment (such as flight simulators). On-the-line training extends training beyond the classroom to the workplace, and is accomplished through e-learning or m-learning. 


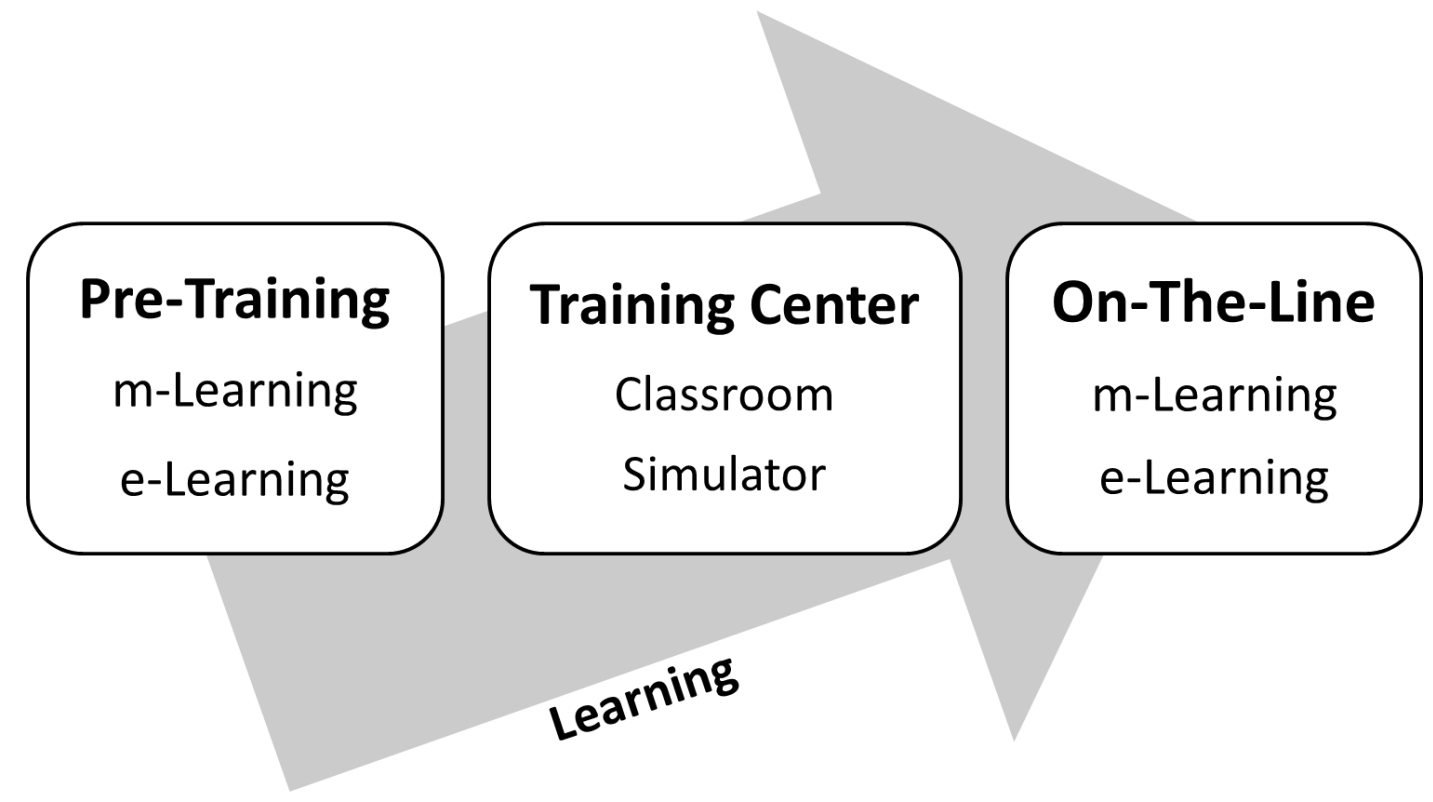

Figure 1. Kearns's (2010) aviation blended learning model.

An advantage of on-the-line training is that distributed practice has been shown to reduce the forgetting that occurs naturally after classroom instruction (Ebbinghaus, 1964). Distributed practice refers to a series of short courses spread out over time, compared to massed practice, which refers to a longer single session of training. When comparing the effectiveness of massed to distributed practice, researchers equate the duration of a single session of massed training to the cumulative duration of a series of short distributed practice sessions (Cepeda et al., 2006). For example, one hour of massed practice within a classroom could be compared against a series of twelve 5minute distributed practice courses spread out over several weeks. Several major quantitative and qualitative reviews have determined that distributed practice results in increased retention over massed practice (Cepeda et al., 2006; Donovan \& Radosevich, 1999; Greene, 1992; Janiszewski, Noel, \& Sawyer, 2003; Lee \& Genovese, 1988).

Of course, a major challenge in designing on-the-line distributed practice within aviation is that it is expensive and logistically challenging to bring professionals back to a classroom on a continual basis. However, m-learning technology facilitates this type of distributed practice.

\section{Snap-Courses}

A snap-course is only about 5 minutes long and is an increment of a larger m-learning module. Snap-courses are meant to facilitate distributed practice, and therefore are designed to be completed over a longer period of time rather than in a single session. Snap-courses represent an instructional design strategy that is unique to m-learning. It is expected that the short duration will suit mobile contexts in which it may be unrealistic for a learner to remain focused for a continued amount of time within a variable environment filled with distractions. 
The recommended characteristics of snap-courses include the following:

- Approximately 5 minutes in duration

- Include interactivity

- Design for personalization, rewards, and choice to facilitate intrinsic motivation (Cordova \& Lepper, 1996; Dickinson, 1995)

- Facilitate discussions among learners

- Incorporate repetition to promote retention

- Integrate quizzes that facilitate retrieval practice (Roediger \& Butler, 2011)

- Allow learners to choose a convenient time to complete training

- Encourage learners to complete training over a longer period of time.

M-learning allows for the aviation industry to create a continual training cycle at a reasonable cost, delivering snap-courses throughout the year to facilitate high levels of retention. This continual access to learners is something that was not possible before the proliferation of mobile devices.

The aviation blended learning model, while incorporating snap-courses, recognizes that not all training is feasible through technology. Classroom instruction can be valuable when it is used effectively to build upon existing knowledge. It is possible to enhance student learning through a training design that incorporates classroom instruction and technology-based learning. This model pieces apart the aspects of training that do not require human interaction and therefore can, and should, be delivered through technology to maximize efficiency while minimizing costs (Kearns, 2010).

\section{Conclusion}

The aviation industry is rapidly adopting mobile technology and EFBs. However, it is important for the industry to exercise caution and to remember that it is the learning that matters, rather than the technology. In order to avoid the rapid but poor-quality development that occurred with early e-learning, aviation training professionals need to recognize that sound instructional design is more important than the technology being used. E-learning instructional design principles can be adapted for mobile platforms; however, m-learning is still in its infancy. Systematic investigation is required to determine the characteristics of m-learning that maximize training effectiveness and to measure the impact of snap-courses on retention. In addition, continual research must be conducted not only to assess how people learn through mobile technology and how snapcourses affect retention, but also to identify variations between e-learning and m-learning practices. However, if introduced thoughtfully, it is possible that mobile technology may extend instructional capability beyond what was possible in a classroom and revolutionize an individual's relationship with training. 


\section{References}

Ally, M. (2009). Mobile learning: Transforming the delivery of education and training. Edmonton, AB: AU Press.

Bernard, R. M., Abrami, P. C., Lou, Y., Borokhovski, E., Wade, A., Wozney, L., . . Huang, B. (2004). How does distance education compare with classroom instruction? A meta-analysis of the empirical literature. Review of Educational Research, 74, 379-439.

Cavanaugh, C. S. (2001). The effectiveness of interactive distance education technologies in K-12 learning: A meta-analysis. International Journal of Educational Telecommunications, 7, 73-88.

Cepeda, N. J., Pashler, H., Vul, E., Wixted, J. T., \& Rohrer, D. (2006). Distributed practice in verbal recall tasks: A review and quantitative synthesis. Psychological Bulletin, 132, 354-380.

Cordova, D. I., \& Lepper, M. R. (1996). Intrinsic motivation and the process of learning: Beneficial effects of contextualization, personalization, and choice. Journal of Educational Psychology, 88, 715-730.

Dickinson, L. (1995). Autonomy and motivation a literature review. System, 23, 165-174.

Donovan, J. J., \& Radosevich, D. J. (1999). A meta-analytic review of the distribution of practice effect. Journal of Applied Psychology, 84, 795-805.

Ebbinghaus, H. (1964). Memory: A contribution to experimental psychology (H. A. Ruger, C. E. Bussenius, \& E. R. Hilgard, Trans.). New York, NY: Dover.

Federal Aviation Administration. (2007). Use of Class 1 or Class 2 Electronic Flight Bag (EFB). Retrieved from http://rgl.faa.gov/Regulatory_and_Guidance_Library /rgAdvisoryCircular.nsf/list/AC\%2091-78/\$FILE/AC\%2091_78.pdf

Gay, K. (1986). Ergonomics. Hillsdale, NJ: Enslow.

Gedik, N., Hanci-Karademirci, A., Kursun, E., \& Cagiltay, K. (2012). Key instructional design issues in a cellular phone-based mobile learning project. Computers \& Education, 1149-1159.

Greene, R. L. (1992). Human memory: Paradigms and paradoxes. Hillsdale, NJ: Erlbaum.

Horton, W. (2006). E-learning by design. San Francisco, CA: Pfeiffer.

Hull, D. (1993). Opening minds, opening doors: The rebirth of American education. Waco, TX: Centre for Occupational Research and Development. 
Janiszewski, C., Noel, H., \& Sawyer, A. G. (2003). A meta-analysis of the spacing effect in verbal learning: Implications for research on advertising repetition and consumer memory. Journal of Consumer Research, 30, 138-149.

Jonassen, D. (1993). The trouble with learning environments. Educational Technology, 33(1), 35-37.

Kay, A., \& Goldberg, A. (1977). Personal dynamic media. IEEE Computer, 10(3), 31-41.

Kearns, S. K. (2010). E-learning in aviation. Burlington, VT: Ashgate.

Lee, T. D., \& Genovese, E. D. (1988). Distribution of practice in motor skill acquisition: Learning and performance effects reconsidered. Research Quarterly for Exercise and Sport, 59, 277-287.

Low, L., \& O’Connell, M. (2006). Learner-centric design of digital mobile learning. Retrieved from http://citeseerx.ist.psu.edu/viewdoc/download?doi=10.1.1.123.48\&rep=rep1\&typ $\mathrm{e}=\mathrm{pdf}$

Motlik, S. (2008). Mobile learning in developing nations. International Review of Research in Open and Distance Learning, 9(2). Retrieved from http://www.irrodl.org/index.php/irrodl/article/viewArticle/564/1039

Prensky, M. (2001). Digital natives, digital immigrants. On the Horizon, 9(5), 1-6.

Reigeluth, C. M. (1999). Instructional design theories and models: A new paradigm of instructional theory (Vol. II). Mahwah, NJ: Erlbaum.

Roediger, H. L., III, \& Butler, A. C. (2011). The critical role of retrieval practice in longterm retention. Trends in Cognitive Sciences, 15(9), 20-27.

Sharples, M., Taylor, J., \& Vavoula, G. (2005). Towards a theory of mobile learning. Retrieved from http://www.mlearn.org.za/CD/papers/Sharples\%20Theory\%20of\%20Mobile.pdf

Sitzmann, T., Kraiger, K., Stewart, D., \& Wisher, R. (2006). The comparative effectiveness of web-based and classroom instruction: A meta-analysis. Personnel Psychology, 59, 623-664.

Tessmer, M., \& Harris, D. (1992). Analysing the instructional setting: Environmental analysis. London, England: Kogan Page.

Traxler, J. (2005). Defining mobile learning. In Proceedings of the IADIS International Conference: Mobile Learning 2005 (pp. 261-266). Qawra, Malta: IADIS. 
Zemsky, R., \& Massy, W. F. (2004). Thwarted innovation: What happened to e-learning and why. Retrieved from http://www.cedmaeurope.org/newsletter\%20articles/misc/ThwartedInnovation\%20(Jun\%2004).pdf

Zhao, Y., Lei, J., Yan, B., Lai, C., \& Tan, H. S. (2005). What makes the difference? A practical analysis of research on the effectiveness of distance education. Teachers College Record, 107, 1836-1884. 


\title{
Automatic Dependent Surveillance-Broadcast Training: Does it exist in Collegiate Aviation?
}

\author{
Andrew Leonard \\ South Dakota State University
}

\begin{abstract}
One of the key elements to NextGen is the transition from the current ground- based radar monitoring system to a satellite-based system using the Automatic Dependent Surveillance-Broadcast System (ADS-B). The FAA has set a mandate which requires all aircraft to be ADS-B equipped by the year 2020 in order to continue operating in the National Airspace System. However, the FAA has not set forth any training requirements for aviation instructors or designated examiners. This study looked at how ADS-B is currently being taught among aviation educators across the United States and how important this training is to current aviation curriculum. With the information collected, it was determined that only a minimal amount of ADS-B training is currently taking place across the country, and the training that is taking place is non-standardized and limited due to the perception that ADS-B is only to be used as a traffic advisory tool. There was significant difference in the perceived importance of ADS-B, $t(73)=-2.79, p<.01$ between the flight instructor group and the group containing mostly professors and administrators. Also, a significant difference was found in the comparison of perceived importance and institution, $t(73)=-3.11, p<.01$. There was no significance found when comparing the perceived importance of ADS-B training to the number of years a respondent had worked as an aviation educator, $F(1,73)=.44, p=.508$ or the number of hours a respondent had received ADS-B training, $F(1,60)=.15, p=.699$. There was also no significant difference in the perceived importance of ADS-B training dependent upon if participants operated in a geographic location that had ADS-B coverage, $t(73)=-1.88$, $p=.063$. Several factors were discovered as to why there seems to be no current urgency among aviation educators to train their students in this new technology. In addition, recommended steps the FAA could take in order to help aviation educators with the ADS-B training process were suggested.
\end{abstract}

\section{Introduction}

As the number of flights across the U.S. grows, the current system is causing traffic delays in order to maintain high levels of safety. The Federal Aviation Administration (FAA) estimates that by 2025, the U.S. will average over 128,000 flights per day (FAA, 2010). If a fundamental change to our current system does not occur, the U.S. could see large-scale gridlock in the sky that could cost the U.S. economy $\$ 22$ billion annually (FAA, 2010).

The current solution is the FAA's Next Generation Air Transportation System (NextGen). NextGen represents a large-scale redesign of the National Airspace System (NAS), including upgrades in safety, environmental performance, and airport infrastructure (FAA, 2012). The most critical aspect of the NextGen plan is transitioning our air traffic control ground-based radar system to a satellite-based system that will 
allow pilots and controllers to have access to and share all available information. With this transition from the current ground-based radar system to the satellite-based system, pilots will need to train in new technology such as ADS-B. Currently, however, there are no stated training requirements or proposed training lists for instructors or FAA examiners to determine if a student has adequate ADS-B knowledge.

\section{Background Information and Review of Literature}

Over the last few decades, computer technology advancement has led to sophisticated flight deck technology (Young \& Fanjoy, 2003). Global Positioning Systems (GPS), Glass Cockpits, Flight Automation, and now ADS-B are giving pilots more information and tools to use than ever before. However, as Technically Advanced Aircraft (TAA) have been integrated into the general aviation population, one of the key issues is informing pilots how to take advantage of the increased safety opportunities that are available (Dornan, Beckman, Gossett, \& Craig, 2005). Part of this inquiry into training was caused by an observed increase in fatal accidents in TAA at a time when it was expected that new technology should be causing a decrease in fatal accidents (Fiduccia et al., 2003).

A study of four-year collegiate aviation programs suggested that elements of glass cockpit technology, in some cases, received little or no consideration within the institutions' flight-training curriculums (Young \& Fanjoy, 2002). The study also found that, due to the cost of acquiring appropriate instructional materials, a number of college aviation departments had decided that the responsibility for this advanced training more appropriately belonged with the employing airlines (Young \& Fanjoy, 2002).

Several government institutions and universities agreed to investigate how flight training needed to adapt for TAA. One of these teams, the General Aviation Joint Steering Committee (GAJSC), suggested that the current training format in the general aviation industry was insufficient to exploit the additional safety features of TAA's, and that there was a need to develop a specific TAA training program (Fiduccia et al., 2003).

The purpose of this study was to see what level of ADS-B training was currently taking place in collegiate aviation institutions, and whether the perceived value of ADS-B training was significantly different between aviation educators who provided ADS-B training and those educators who did not provide ADS-B training. It also looked at the types of media and methods some institutions were currently using to teach ADS-B information, and whether more specific training requirements from the FAA would help to increase the efficiency of ADS-B training.

\section{Methodology}

\section{Participants}

The sample for this study consisted of aviation educators working in four-year colleges and universities who were members of the University Aviation Association. In order to keep the sample size at a reasonable number, only those members listed in the 
University Aviation Association's Collegiate Aviation Guide (2008) who offered flight/pilot programs were considered. Following these criteria, the sample for the study was 85 educators from various aviation institutions around the country.

\section{Materials}

The survey tool and methodology was adapted with permission from the study completed by Young and Fanjoy (2002). Their study examined how glass cockpit training was being addressed in collegiate flight programs and contained numerous similarities to this study. In 2002, glass cockpit aircraft were considered a new technology, and many aviation educators were in the beginning stages of trying to implement these systems into their training. Today, glass cockpits are more common in aviation training while ADS-B is considered new technology.

\section{Procedures}

To collect data for this study, emails with a link to an electronic survey were sent to individuals listed as the point of contact in the University Aviation Association's Collegiate Aviation Guide (2008). These individuals were asked to forward the survey link on to any educators working directly with students in their pilot training programs. Due to the recent addition of ADS-B, it might have been ineffective to try to target only one particular person within each institution, so opening the survey to all educators within the institutions allowed for the largest amount of useable data. This group was called the "General Sample."

A separate email was also sent directly to Chief Flight Instructors at two aviation institutions that have ADS-B coverage and the majority of their aircraft equipped with ADS-B. The Chief Instructors were asked to send the email and survey directly to their flight instructors. The survey they received was identical to the survey sent out to other points of contact; however, the data was tabulated separately. This response group was referred to as the "Flight Instructor Sample."

Based on previous research, it was expected that because of their size, there would be a higher response rate from these two particular institutions than other institutions surveyed (FAA, 2010). There was a fear that the data could become skewed, showing that a significant amount of aviation educators currently had and were using ADS-B, when research suggested otherwise. By separating the data of these two institutions, the study gained a more accurate picture of current ADS-B use while having the ability to make comparisons between the two groups.

\section{Results}

Fifty-six (65.8\%) of the participants were line flight instructors, 17 (20\%) were chief flight instructors or managers, $6(7 \%)$ were department chairs or directors, and $6(7 \%)$ were professors. The mean number of years the participants had worked as aviation educators was 5.11 with the maximum number of years being 35 and the minimum number of years being less than 1 . 
When asked about the current state of ADS-B coverage in the participants' geographic areas, $61(71.8 \%)$ stated they had ADS-B coverage while $14(16.5 \%)$ stated they did not have coverage; 10 of the participants did not answer the question. When broken down further, $13.3 \%$ from the general survey stated that they had ADS-B coverage in their regions while $66.6 \%$ stated they did not have coverage; $20 \%$ chose not to respond. The total sample reported that $78.49 \%$ of the aircraft used for training at the participants' institutions were equipped with ADS-B hardware, but the general survey reported only $6.25 \%$ of the aircraft were equipped with ADS-B hardware.

Subjects were asked how many hours of ADS-B training their students received. The mean was 19.63 hours with the maximum being 200 and the minimum being .5. Three outliers of 30, 190, and 200 existed, but with the outliers removed from the data, the mean dropped to 3.06 hours. Subjects were also asked to report how many hours of training they themselves had received. The mean for this question was 35.88 hours with the maximum being 1400 and the minimum being 0. Again, with this analysis we saw outliers of $1400,450,270$, and 100 . With the outliers removed, the mean dropped to 1.8 hours.

Educators were asked if the institutions they worked for were currently teaching anything about ADS-B. $50(58.82 \%)$ responded that ADS-B was being taught while 25 $(29.41 \%)$ reported that ADS-B was not being taught at all; $10(11.76 \%)$ did not respond. When looking at the general survey responses, $5(33.33 \%)$ responded that there was some sort of ADS-B training taking place while $7(46.66 \%)$ reported that no training was taking place. In this group, $3(20 \%)$ chose not to respond. Of the educators who said training was currently taking place in their institutions, 11 (22\%) said the training was happening in flight, $8(16 \%)$ said it was taking place in ground school, and $22(44 \%)$ said the training was taking place in both ground school and in the flight training; $9(18 \%)$ did not answer.

The educators who stated their institutions did not currently teach ADS-B to their students were asked if they planned to teach it in the near future. Qualitatively, two themes emerged from this question: (a) respondents felt that there were no current formal plans to start teaching ADS-B in the future and (b) respondents did not know if their institution had plans to start teaching this technology in the near future.

Subjects were asked to rate how effective different media and methods were in trying to educate students about ADS-B. The subjects had the option to rate five different training methods on a five-point scale, with 1 representing "Very Effective" and 5 representing "Not Effective." Subjects also had the option to choose "Not Applicable." The greatest response for effective training material was in "Training Aircraft" with 35, followed by "Lecture" with 31, "Internet" with 28, "Flight Simulator" with 19, and "Video" with 18. The highest percentage of effectiveness was seen in "Training Aircraft," which had a mean score of 1.57. The lowest percentage of effectiveness was seen in "Lecture," which had a mean score of 3.00. 
Table 1

Effectiveness of Training

\begin{tabular}{llllll}
\hline $\begin{array}{l}\text { Training } \\
\text { Option }\end{array}$ & Lecture & Video & Internet & Simulator & Aircraft \\
\hline Very Effective & $2(6.45 \%)$ & $2(11.11 \%)$ & $3(10.72 \%)$ & $5(26.32 \%)$ & $22(62.86 \%)$ \\
Between & $2(6.45 \%)$ & $9(50 \%)$ & $7(25 \%)$ & $7(36.84 \%)$ & $8(22.86 \%)$ \\
Effective & $23(74.2 \%)$ & $6(33.33 \%)$ & $16(57.14 \%)$ & $4(21.05 \%)$ & $4(11.43 \%)$ \\
Between & $2(6.45 \%)$ & $1(5.56 \%)$ & $2(7.14 \%)$ & $0(0 \%)$ & $0(0 \%)$ \\
Not Effective & $2(6.45 \%)$ & $0(0 \%)$ & $0(0 \%)$ & $3(15.79 \%)$ & $1(2.85 \%)$ \\
Not Applicable & $0(0 \%)$ & $0(0 \%)$ & $0(0 \%)$ & $0(0 \%)$ & $0(0 \%)$ \\
\hline
\end{tabular}

Table 2

Effectiveness of Methods and Media

\begin{tabular}{llllll}
\hline Effectiveness & $\mathrm{N}$ & Minimum & Maximum & Mean & \\
\hline & Statistic & Statistic & Statistic & Statistic & Std. Error \\
\hline Lecture & 31 & 1 & 5 & 3.00 & .147 \\
Video & 18 & 1 & 4 & 2.33 & .181 \\
Internet & 28 & 1 & 4 & 2.61 & .149 \\
Simulator & 19 & 1 & 5 & 2.42 & .309 \\
Aircraft & 35 & 1 & 5 & 1.57 & .155 \\
\hline
\end{tabular}

Educators were asked to respond to how the FAA's input or lack of input was affecting their ADS-B training. Themes that were discovered from educators' responses were that the FAA's lack of input had a significant effect on them not being able to train students and that more guidance from the FAA would help with their abilities to effectively teach about this new technology.

Respondents were also asked to select types of things the FAA could provide to support ADS-B training. They could select "PTS Standards," "access to training material," and "access to ADS-B equipment." Respondents also had the option to write in responses. Responses included the following: $35.3 \%(n=30)$ stated that training material provided by the FAA would help to support their ADS-B training, 27\% $(n=23)$ said access to ADS-B equipment would help, while $18.9 \%(n=16)$ said PTS Standards would be helpful. Other write-in comments suggested the FAA could provide online training materials, ADS-B simulators, and broadcast ADS-B nationwide.

Respondents were asked how important ADS-B training was to meeting the goals of their curriculums. The variables evaluated were: institutions that currently taught ADS-B versus those that did not, years worked as an aviation educator, hours of ADS-B training received, ADS-B coverage, and a comparison of the general population versus the flight instructor population. $t$-Tests were utilized for comparisons with two means, while OneWay ANOVA was used for groups with more than two means.

There was significant effect found for the perceived importance of ADS-B training between samples, $t(73)=-2.79, p<.01$ with the flight instructor group perceiving ADS- 
B training to be more important than the general sample consisting of mostly professors and administrators.

Significance was also found between perceived importance and whether educators worked in institutions that were currently teaching ADS-B, $t(73)=-3.11, p<.01$ with educators working in institutions that teach ADS-B finding the training more important. There was no significance found when comparing the perceived importance of ADS-B training to the number of years a respondent had worked as an aviation educator, $F(1,73)$ $=.44, p=.508$ or the number of hours a respondent had received ADS-B training, $F(1,60)=.15, p=.699$. There was also no significance found when comparing the perceived importance of ADS-B training to whether an educator's geographic location had ADS-B coverage, $t(73)=-1.88, p=.063$.

\section{Discussion and Conclusion}

The results of this study indicate that currently there is a minimal amount of ADS-B training taking place across the country. Some of the training that is happening appears un-standardized, sporadic, and untested. From the total sample, it was reported that the average number of hours that students were receiving ADS-B training was 19.629 hours. Earlier, it was mentioned that with three outliers removed, the average dropped dramatically to 3.06 hours of training. It is believed that the mean with the outliers removed produces a more accurate reading of the current state of ADS-B training. It is extremely unlikely that any student would receive 30, 190, or 200 hours of ADS-B instruction during their flight training. It is more likely that the respondents interpreted the question as asking how many hours their students train in an aircraft with ADS-B technology.

The same response occurred with the number of hours of ADS-B training the aviation educators stated they had received. The mean for this question was 35.88 hours with multiple outliers. With the outliers removed, the average dropped significantly to 1.8 hours. As discussed before, this would seem to be a more appropriate mean to the question. The means for these questions were reached by using the numbers from the total sample. This indicates, even with the responses from two institutions that are known to have ADS-B coverage and have roughly $92 \%$ of their aircraft equipped with ADS-B technology, that still only a small amount of time is spent educating students about this technology. When looking at the responses from the general sample, the mean drops to 0.46 hours of training. Again, due to the small size of the general sample, this number may fluctuate with future studies; it is an indication, however, that very little time is currently spent on ADS-B training.

The conclusion that only minimal training is currently taking place is also seen in the percentage of institutions that are currently teaching ADS-B technology. It was reported that of the total sample, 58.82\% were teaching ADS-B in some form. This seems to suggest that over half of all institutions are training on this new technology. However, once again, the total sample of this study includes numerous survey responses from two institutions, which are known to have ADS-B coverage and have ADS-B equipped aircraft. These institutions were also sent the survey directly instead of through the UAA 
representative. Because of this, we must look at the responses from the general sample; this group indicated that only $33.33 \%$ of the institutions are teaching ADS-B technology to its students.

This is a more accurate representation of the majority of aviation educators across the country. However, only having 15 responses in the general sample, it is likely that the percentage of institutions currently teaching ADS-B is even lower than what this study reports. Further study needs to be done in order to confirm this hypothesis, but the results of this study combined with previous research suggest this.

The educators who stated their institutions are not currently teaching ADS-B were asked if they felt their institutions were planning on teaching ADS-B in the future, and further, to explain their answers. The majority of the qualitative responses indicated that there are currently no formal plans to teach ADS-B in the future, with one of the largest reasons being a lack of equipment and coverage. Data from this study indicates that currently only $13.3 \%$ of the respondents from the general sample have ADS-B coverage in their geographic areas, with $66.7 \%$ reporting that they do not have coverage. Again, due to the small number of responses from the general survey, it is difficult to say for certain that this is an exact representation of the country, but the responses in the general survey do cover five of the nine FAA regions.

When looking at the training that is currently taking place, this study shows that the information being presented by educators was being collected from several different sources. The majority of the respondents indicated they collect material through the use of the internet or they create their own material, with only one educator indicating they use the FAA website.

Results from this study also support past research, with educators reporting that using training aircraft is the most effective way to train students on ADS-B technology. Previous research shows that, with the implementation of GPS, educators feel that handson training with the equipment is the best way for students to learn about the technology, and because of the cost of the GPS units, many educators are unable to train their students (Norton, 1997). While responses do indicate that lecture, video, internet, and FTD are also effective, training aircraft is seen as the most effective.

One of the most common trends seen in the current training responses is that the majority of the educators currently teaching ADS-B consider it to be nothing more than a traffic advisory service. They state that since there are no standards or guidelines for training, they educate their students to use ADS-B as a traffic advisory service. Only a couple of responses seem to have an understanding of what the FAA hopes the future of ADS-B will entail. Many compare ADS-B to TCAS and feel as though their students can simply learn how to use the technology through trial and error.

In this study, we compared how educators viewed the importance of ADS-B training to how many hours of ADS-B training they had received; there was no significance. The same was true when importance was compared to the number of years worked as an aviation educator. Based on past research, it was thought that those educators with more 
ADS-B training and those educators with more years working as an educator would find ADS-B training to be more important. However, with the average number of hours of ADS-B training received by the respondents being only 1.8 , it seems that more training will need to take place in order to determine if ADS-B will follow the trend of past technology such as GPS.

While there was no significance found between importance and hours of training received by educators, or importance and years worked as an educator, there was significance found between the two different sample groups. It was discovered that the flight instructor group indicated ADS-B training to be significantly more important to their curriculums than the general group sample. Because this relationship cannot be tied to more training or more time spent as a flight instructor, it is assumed that the relationship is due to more time using the ADS-B technology.

The flight instructor group consists of educators who work at institutions with ADS-B coverage and with $92 \%$ of their aircraft equipped with ADS-B technology. Because of these numbers and several qualitative responses, the study can assume that the majority of their flight time is spent in aircraft with ADS-B technology. Therefore, it is concluded that the more time someone spends using ADS-B, the more important they believe it is. These results are consistent with past studies involving technology such as GPS (Norton, 1997).

In order to further the idea that the importance of ADS-B training is increased by the amount of time an individual spends using the technology, the study compared if those educators who work in areas with ADS-B coverage feel ADS-B training is more important than those educators who work in areas that do not have coverage. This comparison was made because it seems likely that those educators training students in areas that have ADS-B coverage are more likely to be using the technology. The results of this comparison were not found to be significant; however, it is believed that a trend does occur that supports this theory, and if further research is done involving a larger number of participants, a significant result may occur.

A significant finding also occurred when the study compared educators who are currently working in institutions that teach ADS-B to educators who work in institutions that do not currently teach the new system. Results show that educators working in institutions that currently teach ADS-B believe the training is significantly more important than those who are working in institutions where no training is taking place. These results add support to the earlier findings that educators who spend more time working with ADS-B view the training in a more positive light.

ADS-B implementation seems to be following a path that was seen with earlier technologies such as GPS. According to Norton (1997), similar issues, such as the cost of GPS equipment and lack of training standards, caused the delay in the implementation of GPS. While future studies will have to be completed in order to determine how much ADS-B training is appropriate to establish proficiency, only a minimal amount of ADS-B specific training is currently taking place across the country. This study shows that the reason for this is due to a lack of ADS-B coverage, high cost of ADS-B equipment, lack 
of material, and no definable training standards or goals. Also, the training that is taking place is defining ADS-B as a traffic advisory service and allowing students to learn by trial and error.

The concern with this trend is that air traffic is projected to triple over the next several decades. NextGen is the FAA's solution to handling this traffic increase while trying to maintain the current level of aviation safety. Because of this, ADS-B implementation seems to have less flexibility then GPS, and therefore, should be approached in a more aggressive fashion.

Educators reported that traditional training methods such as lecture, videos, and Internet are effective, but it is the hands-on experience in flight simulators and training aircraft that provides the most effective training environment. Past research dealing with technically advanced aircraft supports these findings when implemented with scenario based training (Ayers, 2006). Respondents also stated that more training materials and training guidelines would allow for a more efficient approach to training students.

ADS-B is currently in the very early stages of the implementation process. A significant amount of information was gathered about current training methods and about what could be done to help improve those methods. However, as ADS-B coverage continues to increase across the country, there are many different areas that will need to be studied.

Currently, there are no training standards in place for ADS-B. In order for the FAA to implement NextGen and to reach its ultimate goal of free flight, future studies will need to be done to create effective training methods and standards. In this study, it is seen that training aircraft are rated to be the most effective training tool for ADS-B. However, it is also discussed that lack of other training options, such as simulators or classroom material, could be one of the reasons for this finding. Future research should be done to determine if an increase in training options, such as classroom material and simulators, would affect these findings.

Another area for future study is how to improve the perceived importance of ADS-B training. Currently, ADS-B is looked at as a luxury, and no real urgency exists among aviation educators. In order for ADS-B to develop in a timely manner, educators need to understand the importance that training plays in the implementation process. While this study suggests that increased exposure to the technology causes educators to view ADSB training as more important, studies should be done to determine other possible avenues to improve aviation educators' understandings of the importance of ADS-B training.

NextGen and ADS-B are the future of our air transportation system. As their implementation process continues and ADS-B coverage expands, continued studies will be necessary to insure that pilots are properly prepared for the Next Generation Air Transportation System. 


\section{References}

ADS-B Technologies, L.L.C. (2010). What is ADS-B. Retrieved from http://www.ads-b.com/home.htm

Aerospace. (2010). GPS timeline. Retrieved from http://www.aero.org/education/primers/gps/gpstimeline.html

Carney, T. Q., \& Fanjoy, R. O. (2006). Best evidence for the FAA Industry Training Standards (FITS) program for pilot training in technically advanced aircraft. Collegiate Aviation Review, 24(1), 58-66.

Casner, S. M. (2003). Learning about cockpit automation from piston trainer to modern jet transport. In Proceedings of the $12^{\text {th }}$ International Symposium on Aviation Psychology. Dayton, OH: ISAP.

Civil Aviation Safety Authority. (2006). ADS-B workbook (1 ${ }^{\text {st }}$ ed.). Canberra City, Australia: Air Services of Australia.

Craig, P. A., Bertrand, J. E., Dornan, W., Gossett, S., \& Thorsby, K. K. (2007). Scenario-based private/instrument syllabus versus traditional maneuver-based syllabi: A preliminary descriptive analysis. Collegiate Aviation Review, 23(1), $17-$ 23.

Dornan, W. A., Beckman, W., Gossett, S., \& Craig, P. A. (2007). A FITS scenariobased training program enhances GPS pilot proficiency in the general aviation pilot. Collegiate Aviation Review, 25(1), 19-27.

Federal Aviation Administration. (2010a). Automatic Dependent Surveillance Broadcast System. Retrieved from http://www.faa.gov/air_traffic/technology/ads$\mathrm{b} /$

Federal Aviation Administration. (2010b). The next generation air transportation system. Retrieved from http://www.faa.gov/about/initiatives/nextgen/defined/

Federal Aviation Administration. (2012). Next generation implementation plan. Retrieved from http://www.faa.gov/nextgen/slides/?slide=10

Fero, D. (2000). The impact of human factors on airborne separation assurance systems (ASAS). In Proceedings of the $3^{\text {rd }}$ USA/Europe Air Traffic Management $R \& D$ Seminar. Napoli: ATIO.

Fiduccia, P. (2003). General aviation technology advanced aircraft FAA-industry safety study, Final Report. Retrieved from http://www.faa.gov/training_testing/training/fits/research/media/TAA\%20Final\% 20Report.pdf 
Hilburn, B. G., Bakker, M. W. P., Pekela, W. D., \& Parasuraman, R. (1997). The effect of free flight on air traffic controller mental workload, monitoring and system performance. In Proceedings of the 10th International CEAS Conference on Free Flight (pp. 14-1/14-12). Amsterdam: CEAS.

ITT Corporation. (2010). NextGen and ADS-B: How it works and why we need it. Retrieved from http://www.itt.com/ADSB/nextgen.html

Martin, L. Using ADS-B at UND to conduct advanced navigation research in helicopter training program [Power Point slides]. Retrieved from http://www.google.com/search?sourceid=navclient\&ie=UTF8\&rlz=1T4SUNA_e nUS269US331\&q=ADS-B+UND+Martin

Mozdzanowska, A. L., Weibel, E. L., Lester, E., Hamnsman, J. R., Weigel, A., \& Marais, K. (2007). Dynamics of Air Transportation System transition and implications for ADS-B equipage. In Proceedings of the 7th AIAA Aviation Technology, Integration and Operations Conference. Belfast, Northern Ireland: ATIO.

Norton, D. (1997). A lawyer-flight instructors prognostications on the implementation of free flight: How will the large-scale of GPS into the general aviation cockpits affect the liabilities that face pilots and the flight instructors who train them? Journal of Air Law Commerce, 62.

Universal Aviation Association. (2008). Collegiate aviation guide. Auburn, AL: Author.

Williams, K., Yost, A., Holland, J., \& Tyler, R. (2002, December) Assessment of advanced cockpit displays for general aviation aircraft - The capstone program. Springfield, VA: National Technical Information Service.

Young, P., \& Fanjoy, R. (2002). Glass cockpit technology training: How is it addressed in collegiate flight programs. Collegiate Aviation Review, 20(1), 85-94.

Young, P., \& Fanjoy, R. (2003). Advanced collegiate flight automation training: What is needed and at what cost. International Journal of Applied Aviation Studies, 3(2), 215-225. 


\title{
Promotion and Tenure Perceptions of University Aviation Association (UAA) Collegiate Aviation Administrators and Faculty: Administration Perceptions versus Faculty Perceptions
}

\author{
Samuel R. Pavel and Bryan T. Harrison \\ Southern Illinois University Carbondale
}

Authors' Note:

Samuel R. Pavel, Department of Aviation Management and Flight, Southern Illinois University Carbondale; Bryan T. Harrison, Department of Aviation Management and Flight, Southern Illinois University Carbondale. Correspondence pertaining to this article may be addressed to Dr. Samuel Pavel, Department of Aviation Management and Flight MC 6623, Southern Illinois University Carbondale, Carbondale, IL 62901; phone: 618.453.7269 email: spavel@ aviation.siu.edu.

\begin{abstract}
This study compared the perceptions of faculty members and administrators of the value placed on the pillars of tenure, the value of various aviation publications, sole versus multi-authorship, and the geographic venue for presenting scholarly research. The study used a database created from a survey administered by Dr. Ruiz of Southern Illinois University (see Pavel, Legier, and Ruiz, 2012). The database contains responses to 20 multiple-choice questions (with additional comments) of 19 department chairs, 10 full professors, 29 associate professors, and 24 assistant professors from four-year collegiate UAA member institutions. The respondents responses were divided by employment classification and institution type (research versus non-research). The results indicated that there was generally little difference between administration and faculty perceptions to the survey questions at similar institution types. Survey responses differed more when comparing research to non-research institutions, specifically responses on the value of scholarship in the promotion and tenure process. Teaching and service perceptions were generally similar for all groups of respondents.
\end{abstract}

\section{Introduction}

The promotion and tenure process can be a challenging endeavor for new faculty members. The specific policies and procedures vary among institutions. Finding the right balance of the three pillars is imperative to receiving promotion and tenure.

The previous study by Pavel, Legier, and Ruiz (2012) indicated that "perceptions of faculty workload items used to determine fitness for promotion and tenure are not uniform throughout collegiate aviation" (p. 49). The survey they administered indicated that scholarship, teaching, and research were all important to some level but the survey responses differed based on the size of institution. In addition to the survey results their study recommended further study, "comparing the perceptions of administrators versus faculty on the topic of promotion and tenure" (p. 50). Faculty members needing to navigate their individual institutions procedures for promotion and tenure they may receive conflicting advice from department chairs and other faculty members. 
This study compares the perceptions of faculty members and administrators by reviewing the same database created by the Pavel et al. (2012) study. A comparison of faculty and administration responses of the value placed on the pillars of tenure, the value of various aviation publications, sole versus multi-authorship, and the geographic venue for presenting scholarly research was conducted. For the purposes of this study department chairs are considered to be university administrators since they have more supervisory duties and may have a smaller teaching load than regular faculty.

\section{Literature Review}

In Pavel et al. (2012), the literature review focused on the roots of the promotion and tenure and identified some perceptions of the workload components in the process. In this study, the literature review further explored the development and weight of the workload components, a brief examination of promotion and tenure in three unrelated academic disciplines (counselor educators, information systems, and business), and finally a look at lessons learned from an administration/faculty study from the Recreation and Leisure Studies discipline.

\section{Workload Components in Promotion and Tenure: Comparison Across Disciplines}

A study performed in 2006 by Davis, Levitt, McGlothlin, and Hill evaluated the perceived expectations relating to the promotion and tenure process in the discipline of counselor educators. More specifically, this study was to determine the practices that contribute to decisions in the promotion and tenure process. Seventy-four counseling and related educational programs were assessed in this study. The results from this study indicated that a relatively equal amount of emphasis was placed on scholarship, teaching, and service.

Although the primary purpose of this study was to explore the views of the promotion and tenure process, the secondary purpose was to understand respondent's perceptions on the definition of scholarship according to Boyer's (1990) model. Following the methodology of Emmert and Rollman (1997) in defining workload assignments for an academic year, the authors reported that the results of percent faculty time assigned to scholarship, teaching, and service were relatively (statistically) insignificant for this discipline.

Results from this study recognized that the mean analysis for teaching, scholarship, and service were $M=2.08, M=2.33$, and $M=2.38$, respectively, with a mean faculty teaching assignment load of 4.04 courses per academic year. Further, the respondents were asked to indicate their percentage of time as related to teaching, scholarship, and service. The results indicated that assistant professors spend more time in teaching, than in service or scholarship activities. The authors also identified in this study, that there is a perceived increase in service activities as a faculty member moves from assistant to associate professor. With this identified, the authors urge caution for new faculty members in that service as identified by assignment workload had the least impact on promotion and tenure to the associate professor level. The final survey questions of this 
study asked respondents to indicate their support for Boyer's (1990) model. Respondents to this study strongly endorsed Boyer's model integration to this discipline with a mean score of $M=3.64$ out of 4.0 on a Lickert-type scale.

Dennis, Valacich, Fuller, and Schneider (2006) additionally evaluated the standards for promotion and tenure in the discipline of Information Systems (IS). The authors presented the following question in their study. "...... what constitutes appropriate research standards for tenure and promotion in the IS profession?" (p. 2). With the overall purpose of this study to provide a set of benchmarks that can be used for establishing standards in the promotion and tenure decision making process, the authors further based this study on defining "elite journals" for publication in the IS discipline, stating that journal publications are a principal consideration in the promotion and tenure process.

The authors state that teaching and service often have clear standards established by local institutions, but in the judging of research performance, the quality and quantity of publications is a difficult task. To define an elite level of journals, the authors followed the approach prepared by Trieschmann, Dennis, Northcraft, and Niemi (2000) in which journals were perceived as being "good quality" or "beyond reproach." This methodology led to the development of a listing of two IS journals and 18 additional cross-disciplinary business journals. This analysis provides a recommendation of journals for the IS discipline and increased quality of publications.

An additional underlying purpose identified in this study was to educate and encourage faculty members making promotion and tenure decisions of the need to understand the levels of publication and the need for individuals to increase the number of publications in elite journals. Further the authors called on colleagues writing external letters to use the recommendations of this study and the journals identified in evaluating research performance during the promotion and tenure process. The bottom-line argument in this study was that the promotion and tenure decision making process in the IS discipline requires re-evaluation. As the authors argued, teaching and service are more clearly defined measures in the process. What is not presently clear in the promotion and tenure merits in the IS discipline, is a measure or "benchmark" of what a quality or "elite" publication is. Therefore, this study tried to provide a more defined understanding as to which journals, quality research can be published. With only two discipline-specific journals available for publication to this discipline at the time of this study (Information Systems Research and MIS Quarterly), the authors efforts to show that cross-discipline quality publishing requires re-examination by those that are making promotion and tenure decisions in the IS profession.

A two-year longitudinal study performed by Lein and Merz (1978) from 1977 through 1978 evaluated faculty evaluations concerning required activities for promotion and tenure. This study found that in institutions that achieve accreditation through the Association to Advance Collegiate Schools of Business (AACSB) - accredited schools weighted teaching at $39 \%$, research at $40 \%$, and service at $21 \%$. Accordingly, nonaccredited AACSB schools weighted teaching at 56\%, research at $19 \%$, and service at $25 \%$. As reported in the study, though service is traditionally one of the three components relating to decisions in promotion and tenure, non-accredited AACSB schools identified 
service as a higher importance than research. For AACSB accredited schools, teaching and research were statistically measured at the same level or weight, but the authors argue there is still an inconsistency, dependent on this study (accreditation vs. nonaccreditation), as to the focus of the type of institution in their decisions during the promotion and tenure decision making process.

Saunders, Luchs, and Smith (2006) investigated the perceived importance of service in promotion and tenure decisions. The authors argue that even at the time of this inquiry, why is the definition of service so vague? Of the three major merits in the promotion and tenure process, service is one of the three. The authors distributed a survey $(N=1,335)$ consisting of two series of statements relating to the perceived importance of service in the promotion and tenure process and how important should service be. The questions were also divided into sub-questions relating to two responses, 1) promotion and 2) tenure. The survey questions were rated on a 5-point type Lickert scale from 1-not important to 5-very important. The mid-scale of 3 related to a response of moderately important. Subjects for this survey were drawn from nation-wide faculty who were listed in the Hasselback directory. Additionally, the authors requested demographic information pertaining to the size of the institution from which respondents were submitting the survey. They found that $39 \%$ of all respondents worked in an institution in the "small school" category (less than or equal to 5,000 FTE), 30\% of the respondents were associated with the "medium" category (5,001 to 10,000 FTE), and $31 \%$ of the respondents responded from the "large" category (more than 10,001 FTE).

Results $(n=147)$ from the survey identified that for the decision to promote faculty to the position of associate professor, the $M=2.44$ or "slightly" to "moderately important." Additionally, the results found that the decision to grant tenure also had a $M=2.44$. The authors believed that the agreement in mean scores between these two questions is based on the fact that many institutions combine promotion and tenure in same decision making process. Further, results for decision to promote to full professor yielded a $M=2.92$, again, rated at the "moderately important" level.

Based on further comparison of the size of the institutions and survey results, the authors state that the overall results indicated that the performance of service is not consistent among institutions for promotion and tenure decisions. The results of the survey identified "service" as only "slightly important" to "moderately important" in decisions to achieve the level of associate professor, with a slightly higher result of "moderately important" for achieving the level of full professor. The authors furthermore stated that small and medium size institutions place a higher emphasis on service, than larger schools. Also, institutions without $\mathrm{PhD}$ programs value service more than those institutions with $\mathrm{PhD}$ programs.

Administration Versus Faculty Perceptions: Lessons Learned From the Recreation and Leisure Studies Discipline

In a special report on Faculty Promotion and Tenure: Eight Ways to Improve the Tenure Review Process at Your Institution, Cipriano and Riccardi (2009) reported the performance of two national studies on recreation department chairs and full-time faculty 
members in the recreation and leisure studies discipline. The purpose of these studies was to have the respondent's rank the most important factors leading to the awarding of promotion, tenure, and reappointment. In both the 2004 and 2006 studies, both chairs and faculty listed as the top three factors in considering promotion and tenure as: a) teaching, b) research, and c) publications.

The first of the studies (2004) consisted of 17 factors to be considered by department chairs and directors during the promotion and tenure selection process. Along with factors relating to scholarship, teaching, and service, other factors (not all inclusive) in the survey identified areas such as: a) student advisement, b) time spent on campus, c) consultation, d) use of technology, and e) supervision of independent studies. The authors found from the rankings, that $50 \%$ of the chairs in this study listed teaching (99\%), publications $(86 \%)$, and research $(85 \%)$ as the top three ranked major factors in personnel decisions when considering faculty for promotion and tenure. What was further noted by the authors in this study was that none of the other 14 factors were ranked at a greater than 50\% agreement by the responding chairs. In their 2006 study, the results found that five factors were listed as major factors by more than $50 \%$ of the respondents. This included: a) teaching $(95 \%)$, b) publications $(81 \%)$, c) research $(79 \%)$, d) service to the department (55\%), and e) grants submitted (50\%).

Further, the 2006 study included faculty members and the number of survey factors included increased from 17 to 21. The purpose of adding more factors was based on identifying faculty's perceptions in achieving tenure, promotion, and/or reappointment. Results from the faculty responses showed that they identified eight major factors to be considered for tenure. These included: a) teaching (95\%), b) research $(73 \%)$, c) publications $(68 \%), \mathrm{d})$ interaction with students $(61 \%)$, e) evidence of student learning $(59 \%), \mathrm{f})$ service to the department $(55 \%), \mathrm{g})$ interpersonal attributes/collegiality (54\%), and h) grants submitted (52\%).

Cipriano and Riccardi conclude "....it is clear that faculty perceive that there is more for them to do than their department chairs" (p. 10) based on the comparison of chair and faculty perceptions in the decision process of tenure and promotion. Further, the authors raised the question, what are the implications for the potential disconnect between chair decisions and those perceived by faculty in achieving tenure and promotion?

\section{Summary Thoughts}

Evident from the studies and literature provided above, there is still an inconsistency amongst discipline-specific, departments/units, institutions, and further, academe on what are the requirements for achieving promotion and tenure. A sample to the open-ended responses to questions on the relationship between attitudes toward promotion and tenure presented by Diamantes's (2004) research through a survey to the members of the National Council of Professors of Educational Administration (NCPEA) and Association/Advancement of Educational Research (AARE) should awaken those in the promotion and tenure (decision-making) process: 
- Promotion and tenure are supposed to be based on a combination of teaching, research, and service, but in fact they appear to be based solely (or at least primarily) on research that has little relation to reality.

- Definitions exist, but the P\&T committee's presentations obfuscate the definitions. For example, one tenured faculty member said to group of non-tenured teachers that, "This is a club and acceptance to it is getting more difficult.

- The tenure and promotion process should not be a mystery. As we work with folks who are on tenure track, we should offer support and guidance and give them on-going feedback as to whether or not they are making appropriate progress (Diamantes, 2004, pp. 6 - 7).

\section{Method}

This study used the same database developed from a survey developed by Dr. Ruiz of Southern Illinois University Carbondale. For a complete description of the survey and supporting materials see Pavel et al. (2012). The data did not allow for reporting responses of administration and faculty by institution size because of the limited number of responses from persons identified as administration. However, slightly more than half of the administrator responses came from institutions classified as Research Universities. Slightly over 58\% of the responses from faculty were from institutions classified as Research Universities. Therefore the data was categorized as either Administration or Faculty and when appropriate subcategorized as "research" or "non-research." Means, frequencies, and standard deviations were calculated and used to analyze information in the database.

\section{Results}

\section{Three Pillars of Tenure}

Each participant in the survey was asked to rank their perception of the standard three "pillars" of promotion and tenure (scholarship, teaching, and service) on the following scale: Not Important $=1$; Minimally Important $=2$; Somewhat Important $=3$; Important $=$ 4 ; Very Important $=5$. The results are presented in Table 1 . The smallest number of survey respondents were Full Professors, of which only three were from non-research institutions. Therefore Full Professors results were not differentiated between research and non-research. Interestingly, all three Full Professors from non-research institutions ranked scholarship and teaching as Very Important (5) for tenure and/or promotion.

In the aggregate, faculty and administration rated service as the least important of the three pillars. However, when broken down into the subcategory of research and nonresearch institutions a different result appears. Each group in the non-research subcategory ranked service above scholarship. Whereas, all groups in the research subcategory and the full professor group ranked scholarship as the most important pillar. All groups in the non-research subcategory ranked teaching as the most important pillar. 
Specific questions about each pillar were asked to get more detail about the perception of each pillar. The results are presented in the next three sections.

Scholarship. A majority (61\%) of all survey respondents "Strongly Agree" or "Agree" when asked if scholarship is a critical gauge in determining an individual's fitness for promotion and/or tenure. However, the proportion of those who "Strongly Agree" or "Agree" falls when the survey respondents are separated into research and non-research subgroups. For the non-research subgroup the proportion that "Strongly Agree" or "Agree" falls to $38 \%$ (Table 2).

Scholarly activity venues. Survey respondents were asked to rank venues of scholarly activity on the same five-number scale used above: Not Important $=1$; Minimally Important $=2$; Somewhat Important $=3$; Important $=4$; Very Important $=5$. The results are presented in Table 3.

The highest rated scholarly venue by both administration and faculty was publishing a peer-reviewed journal article. The faculty ranked receiving an external grant and publishing a book as comparable with the peer-reviewed journal article. The only other venue the faculty ranked above "Important" was publishing a chapter in a book. Administration survey respondents agreed with the faculty that publishing a book was comparable to a peer-reviewed journal article, but did not rank receiving an external grant or publishing a chapter in a book above "Important." The lowest ranked venues by both faculty and administration were any non-peer-reviewed venue.

Table 1

Perceived Importance of the Three Standard Pillars of Promotion and Tenure

\begin{tabular}{lccc}
\hline & Scholarship & Teaching & Service \\
\cline { 2 - 4 } Employment and Institution Classification & $M(S D)$ & $M(S D)$ & $M(S D)$ \\
\hline Administration - research & $4.80(0.63)$ & $3.70(1.55)$ & $2.80(1.33)$ \\
Administration - non-research & $2.75(1.58)$ & $4.63(0.70)$ & $3.25(0.83)$ \\
All Administration & $3.89(1.53)$ & $4.11(1.37)$ & $3.00(1.19)$ \\
Full Professor & $4.80(0.63)$ & $4.60(0.97)$ & $3.70(1.16)$ \\
Associate Professor - research & $4.75(0.72)$ & $4.05(0.89)$ & $3.05(1.10)$ \\
Associate Professor - non-research & $4.00(1.00)$ & $4.78(0.44)$ & $4.11(1.05)$ \\
Assistant Professor - research & $4.27(1.27)$ & $3.73(1.49)$ & $3.09(1.14)$ \\
Assistant Professor - non-research & $3.38(0.96)$ & $4.69(0.85)$ & $3.77(1.09)$ \\
All Faculty & $4.31(1.01)$ & $4.29(1.04)$ & $3.43(1.12)$ \\
\hline
\end{tabular}


Table 2

Scholarship is a critical gauge in determining an individual's fitness for promotion and/or tenure

\begin{tabular}{|c|c|c|c|c|c|}
\hline Employment Classification & $\begin{array}{c}\text { Strongly } \\
\text { Agree }\end{array}$ & Agree & Disagree & $\begin{array}{l}\text { Strongly } \\
\text { Disagree }\end{array}$ & Neither \\
\hline Administration - research & 5 & 3 & 2 & 0 & 0 \\
\hline Administration - non-research & 0 & 5 & 2 & 1 & 1 \\
\hline Faculty - research & 11 & 22 & 5 & 2 & 3 \\
\hline Faculty - non-research & 3 & 4 & 7 & 4 & 7 \\
\hline
\end{tabular}

Aviation publications. Survey respondents were asked to rank specific aviation publications on the five-number scale: Not Important $=1$; Minimally Important $=2$; Somewhat Important $=3$; Important $=4$; Very Important $=5$. The results are presented in Table 4. There was very little difference between the responses of faculty at all ranks from research and non-research institutions. Therefore the faculty scores are aggregated. The administration responses were different based on if the administrator was from a research or non-research institution.

Table 3

Perceived Value of Scholarly Activity Venue

\begin{tabular}{llc}
\hline \multicolumn{1}{c}{ Publishing Venues } & Administration & Faculty \\
& \multicolumn{2}{c}{$M(S D)$} \\
\hline Peer-Reviewed Journal Article & $4.61(0.85)$ & $4.66(0.68)$ \\
Externally Funded Grant & $3.76(1.48)$ & $4.62(0.62)$ \\
Publishing a Book & $4.56(1.15)$ & $4.60(0.63)$ \\
Publishing a Chapter in a Book & $3.89(1.13)$ & $4.04(0.82)$ \\
Peer-Reviewed Abstract, Conference & $3.44(1.15)$ & $3.71(0.93)$ \\
$\quad$ & & \\
$\quad$ Proceedings, etc. & $3.18(1.24)$ & $3.68(0.84)$ \\
Conference/ Professional Presentation & $2.82(1.19)$ & $3.50(0.91)$ \\
Internally Funded Grant & $3.50(1.25)$ & $3.49(0.80)$ \\
Member of Peer-Reviewed Journal Panel & $2.67(0.97)$ & $2.76(0.95)$ \\
Consultantship & $2.61(1.24)$ & $2.74(0.92)$ \\
Research Posters & $2.61(1.33)$ & $2.68(1.10)$ \\
Aviation Trade Magazine Article & $2.59(1.18)$ & $2.67(0.93)$ \\
Book Review & $2.44(0.78)$ & $2.60(0.87)$ \\
Non Peer-Reviewed Abstract, & & \\
$\quad$ Conference Proceedings, etc. & $2.44(0.86)$ & $2.49(0.87)$ \\
Non Peer-Reviewed Journal Article & & \\
\hline
\end{tabular}


Administration from non-research institutions were fairly consistent ranking all publication venues as "Somewhat Important" and "Minimally Important." There also was a wide variation in their rankings of the publications with no standard deviation below 1.00. There is agreement between the faculty and the administration from research institutions. They all rated six publications above "Important," and also agreed that publishing in an aviation trade magazine or publishing in a non-peer-reviewed journal was "Minimally Important."

When asked about the value of single-author verses multi-authored publications the administrator tended to see more value in single-author publications. Faculty were split between a single-author publication being more valuable and single-author and multiauthor publication being of equal value (Table 5).

However, being lead author in a multi-publication was deemed more valuable by every group except faculty at non-research institutions, which were split between equal and more valuable (Table 6).

When asked if authors were asked to report the percentage of individual effort/contributions in a multi-author publication, most replied "No" (Table 7).

Table 4

Perceived Value of Aviation Publication

\begin{tabular}{lccc}
\hline & \multicolumn{2}{c}{ Employment Classification } \\
\cline { 2 - 3 } & \multicolumn{2}{c}{ Administration } & \\
\cline { 2 - 3 } \multicolumn{1}{c}{ Publication Name } & Research & Non-research & Faculty \\
& $M(S D)$ & $M(S D)$ & $M(S D)$ \\
\hline Collegiate Aviation Review & $4.50(0.81)$ & $3.44(1.26)$ & $4.46(0.70)$ \\
International Journal of Applied Aviation Studies & $4.30(0.90)$ & $3.44(1.77)$ & $4.42(0.77)$ \\
Journal of Air Transportation & $4.50(0.81)$ & $3.56(1.71)$ & $4.40(0.70)$ \\
Journal of Aviation/ Aerospace Education and & $4.70(0.64)$ & $3.44(1.77)$ & $4.39(0.76)$ \\
$\quad$ & & & \\
$\quad$ Research & $4.70(.064)$ & $3.44(1.77)$ & $4.39(0.76)$ \\
Journal of Aviation Management and Education & $4.50(0.67)$ & $3.56(1.71)$ & $4.17(0.86)$ \\
International Journal of Professional Aviation & & & \\
$\quad$ Training and Testing Research & & $3.85(1.18)$ \\
The International Journal of Safety Across High- & $3.90(1.22)$ & $3.44(1.77)$ & 3.85 \\
$\quad$ Consequence Industries & & & \\
Academic and Business Research Institution & $3.67(1.41)$ & $2.89(1.37)$ & $3.44(1.08)$ \\
American Technical Education Association & $3.22(1.40)$ & $2.89(1.37)$ & $3.44(1.11)$ \\
Aviation Trade Magazine Article & $2.56(1.26)$ & $2.89(1.29)$ & $2.88(1.15)$ \\
Non Peer-Reviewed Journal Publications & $2.20(0.98)$ & $2.56(1.07)$ & $2.48(0.99)$ \\
\hline
\end{tabular}




\section{Table 5}

Do you consider a single-author publication more valuable than a multi-author publication in achieving promotion and/or tenure?

\begin{tabular}{lcccc}
\hline & Yes & No & $\begin{array}{c}\text { Single and Multiple } \\
\text { Author Equal }\end{array}$ & Don't know \\
\hline Employment Classification & 7 & 1 & 2 & 0 \\
Administration - research & 5 & 1 & 2 & 1 \\
Faculty - research & 21 & 2 & 15 & 0 \\
Faculty - non-research & 10 & 3 & 17 & 0 \\
\hline
\end{tabular}

\section{Table 6}

Do you believe that being identified as the first author in a multi-author publication is more valuable than other authorships in achieving promotion and/or tenure?

\begin{tabular}{lcccc}
\hline Employment Classification & Yes & No & $\begin{array}{c}\text { All Authorships } \\
\text { Possess Equal Value }\end{array}$ & Don't know \\
\hline Administration - research & 8 & 1 & 1 & 0 \\
Administration - non-research & 3 & 3 & 2 & 1 \\
Faculty - research & 32 & 2 & 4 & 0 \\
Faculty - non-research & 10 & 5 & 12 & 3 \\
\hline
\end{tabular}

Table 7

Are authors in multi-author publication required to report percentages of individual effort/contribution made in the development of the publication during the promotion and/or tenure process?

\begin{tabular}{lccc}
\hline Employment Classification & Yes & No & Don't know \\
\hline Administration - research & 3 & 6 & 1 \\
Administration - non-research & 0 & 8 & 1 \\
Faculty - research & 11 & 22 & 5 \\
Faculty - non-research & 3 & 18 & 9 \\
\hline
\end{tabular}

The last area surveyed in the area of scholarship was the perceived value of scholarly activity in various geographical venues (Table 8). Again the faculty from research and non-research institutions were similar and thus aggregated. The administration from research and non-research were again dissimilar in every geographical venue except Local. However, the variation in the responses in once again large.

Teaching. Almost all survey respondents consider teaching to be a critical gauge in determining an individual's fitness for promotion and/or tenure. Over $87 \%$ of the survey respondents from both research and non-research institutions either "Strongly Agree" or "Agree" when asked about the importance or teaching (Table 9). 
Table 8

Perceived value of scholarship activity in geographical venues toward successfully achieving promotion and/or tenure.

\begin{tabular}{cccccc}
\hline $\begin{array}{c}\text { Employment } \\
\text { Classification }\end{array}$ & $\begin{array}{c}\text { International } \\
M(S D)\end{array}$ & $\begin{array}{c}\text { Local } \\
M(S D)\end{array}$ & $\begin{array}{c}\text { National } \\
M(S D)\end{array}$ & $\begin{array}{c}\text { Regional } \\
M(S D)\end{array}$ & $\begin{array}{c}\text { State } \\
M(S D)\end{array}$ \\
\hline Administration & & & & & \\
$\quad$ research & $4.80(0.60)$ & $3.20(1.40)$ & $4.50(0.81)$ & $4.20(0.75)$ & $3.90(0.83)$ \\
$\quad$ non-research & $3.67(1.70)$ & $3.22(1.13)$ & $3.89(1.45)$ & $3.78(1.31)$ & $3.67(1.33)$ \\
Faculty & $4.32(1.07)$ & $3.03(1.04)$ & $4.46(0.76)$ & $3.76(0.85)$ & $3.44(0.92)$ \\
\hline
\end{tabular}

Table 9

Teaching performance is a critical gauge in determining an individual's fitness for promotion and/or tenure.

\begin{tabular}{lccccc}
\hline Employment Classification & $\begin{array}{c}\text { Strongly } \\
\text { Agree }\end{array}$ & Agree & Disagree & $\begin{array}{c}\text { Strongly } \\
\text { Disagree }\end{array}$ & Neither \\
\hline Administration - research & 4 & 3 & 1 & 2 & 0 \\
Administration - non-research & 4 & 3 & 0 & 2 & 0 \\
Faculty - research & 19 & 11 & 0 & 0 & 1 \\
Faculty - non-research & 15 & 16 & 1 & 2 & 2 \\
\hline
\end{tabular}

However, when asked if the evaluation of teaching was fair and accurate only one administrator and faculty (both from a research institution) "Strongly Agree." Almost $59 \%$ of the survey respondents responded with something other than "Strongly Agree" or "Agree." Almost 13\% "Strongly Disagree" that teaching evaluation is fair and accurate (Table 10).

Table 10

The methods used for evaluating classroom instruction at my institution are fair and accurate.

\begin{tabular}{lccccc}
\hline Employment Classification & $\begin{array}{c}\text { Strongly } \\
\text { Agree }\end{array}$ & Agree & Disagree & $\begin{array}{c}\text { Strongly } \\
\text { Disagree }\end{array}$ & Neither \\
\hline Administration - research & 1 & 3 & 3 & 2 & 1 \\
Administration - non-research & 0 & 6 & 0 & 1 & 2 \\
Faculty - research & 1 & 15 & 12 & 4 & 6 \\
Faculty - non-research & 0 & 10 & 10 & 4 & 6 \\
\hline
\end{tabular}

Almost all survey participants responded that students evaluate classroom instruction. Administration responded that peers/faculty evaluate classroom performance more than $67 \%$ of the time. While faculty responded that peers/faculty only evaluate classroom instruction at non-research institutions $57 \%$ of the time and only $37 \%$ at research institutions. The chairperson most likely did not evaluate classroom instruction at research institutions (Table 11). 
Service. Although the service pillar of tenure was rated the lowest of the three pillars of tenure by administration and faculty, most still agree the pillar is critical in determining an individual's fitness for promotion and/or tenure. Service was divided into three categories: professional, university/institutional, and community. The responses are presented in Tables 12, 13, and 14.

Table 11

How classroom instruction is evaluated?

\begin{tabular}{lcccccc}
\hline \multirow{2}{*}{ Employment Classification } & \multicolumn{2}{c}{ Students } & \multicolumn{2}{c}{ Peers/Faculty } & \multicolumn{2}{c}{ Chairperson } \\
& Yes & No & Yes & No & Yes & No \\
\hline Administration - research & 10 & 0 & 7 & 3 & 2 & 8 \\
Administration - non-research & 6 & 3 & 6 & 3 & 5 & 4 \\
Faculty - research & 36 & 2 & 14 & 24 & 8 & 30 \\
Faculty - non-research & 26 & 4 & 17 & 13 & 13 & 17 \\
\hline
\end{tabular}

Table 12

Professional service is a critical gauge in determining an individual's fitness for promotion and/or tenure.

\begin{tabular}{lccccc}
\hline Employment Classification & $\begin{array}{c}\text { Strongly } \\
\text { Agree }\end{array}$ & Agree & Disagree & $\begin{array}{c}\text { Strongly } \\
\text { Disagree }\end{array}$ & Neither \\
\hline Administration - research & 1 & 7 & 1 & 1 & 0 \\
Administration - non-research & 1 & 5 & 0 & 1 & 2 \\
Faculty - research & 5 & 21 & 3 & 0 & 9 \\
Faculty - non-research & 1 & 18 & 3 & 1 & 7 \\
\hline
\end{tabular}

Professional service was ranked as most important of the three categories of service. Approximately 69\% of the survey respondents either "Strongly Agree" or "Agree" that professional service is a critical factor to gauging and individual's fitness for promotion and/or tenure. However, less than 10\% "Strongly Agree," while over 10\% either "Disagree" or "Strongly Disagree."

Table 13

University/institutional service is a critical gauge in determining an individual's fitness for promotion and/or tenure.

\begin{tabular}{lcccccc}
\hline Employment Classification & $\begin{array}{c}\text { Strongly } \\
\text { Agree }\end{array}$ & Agree & Disagree & $\begin{array}{c}\text { Strongly } \\
\text { Disagree }\end{array}$ & Neither \\
\hline Administration - research & 0 & 6 & 1 & 2 & 1 \\
Administration - non-research & 1 & 5 & 0 & 1 & 2 \\
Faculty - research & 1 & 21 & 8 & 0 & 8 \\
Faculty - non-research & 5 & 17 & 2 & 1 & 5 \\
\hline
\end{tabular}

There was less support for university/institutional service than professional service. Only 64\% of survey responses were either "Strongly Agree" or "Agree." 
Table 14

Community service is a critical gauge in determining an individual's fitness for promotion and/or tenure.

\begin{tabular}{lccccc}
\hline Employment Classification & $\begin{array}{c}\text { Strongly } \\
\text { Agree }\end{array}$ & Agree & Disagree & $\begin{array}{c}\text { Strongly } \\
\text { Disagree }\end{array}$ & Neither \\
\hline Administration - research & 1 & 2 & 1 & 1 & 5 \\
Administration - non-research & 0 & 5 & 0 & 1 & 3 \\
Faculty - research & 3 & 15 & 13 & 1 & 6 \\
Faculty - non-research & 0 & 11 & 7 & 3 & 9 \\
\hline
\end{tabular}

Community service was the least valued of the types of service. Less than $44 \%$ of the responses were either "Strongly Agree" or "Agree" that community service is a critical factor for gauging an individual's fitness for promotion and/or tenure. Almost one third of the survey respondents answered "Disagree" or "Strongly Disagree."

Progress and/or reviews. The final question in the survey asked if probationary faculty members received annual promotion and tenure progress reports and/or reviews. The responses are presented in Table 15.

Table 15

Probationary (tenure track) faculty members at my institution receive annual promotion and tenure progress and/or reviews.

\begin{tabular}{cccc}
\hline Employment Classification & Yes & No & Don't know \\
\hline Administration - research & 8 & 0 & 2 \\
Administration - non-research & 5 & 4 & 0 \\
Faculty - research & 28 & 7 & 3 \\
Faculty - non-research & 16 & 11 & 3 \\
\hline
\end{tabular}

Over $70 \%$ of the administration and faculty at research institutions responded that probationary faculty are given some sort of annual promotion and tenure review and/or report. In non-research institutions the reported number falls to below $55 \%$.

\section{Discussion}

In the previous paper reporting the perceptions of promotion and/or tenure of the aggregated administration and faculty of UAA institutions (Pavel, Legier, \& Ruiz, 2012) the data indicated that the size of the institutions was an important factor in determining the importance level of the so-called three pillars of tenure and promotion - scholarship, teaching, and service. In this paper we find administration status, faculty rank, and the research classification of the institution also matter. 
In the aggregate administration rated teaching $(M=4.11)$ higher than scholarship (M = 3.89). However administration from research institutions rated scholarship by far the highest $(M=4.80)$, as well did full professors from both research and non-research institutions $(M=4.80)$. Service was rated lowest by all categories, except administration from non-research institutions $(M=3.25)$ and assistant professors from non-research institutions $(M=3.43)$.

The overall trend shows that scholarship and teaching are the important pillars for promotion and/or tenure with service being viewed as somewhat important. Each pillar will now be discussed separately.

Scholarship. Whether or not scholarship was viewed as a critical factor in determining an individual's fitness for promotion and/or tenure appears to depend on the research classification of the institution. Administration and faculty from research institutions tended to view scholarship as critical to the determination. Administration and faculty from non-research institutions viewed scholarship as less critical to the determination, although three of the faculty members strongly agreed scholarship was critical.

When asked about publication venues for scholarship there is considerable agreement between administration and faculty from both research and non-research institutions. The most important publication venue for both administration and faculty was the peerreviewed journal article $(M=4.61$ and $M=4.66$ respectively). Faculty also rated externally funded grant, publishing a book, and publishing a chapter in a book as important $(M>4.00)$. Administration agree that publishing a book was important, but rated externally funded grant and publishing a chapter in a book as somewhat important (3.00<M<4.00). The least important venue for all was non peer-reviewed publications that were ranked minimally important $(2.00<M<3.00)$.

There were differences between administration and faculty when asked about the importance of specific aviation publications. Administration from research institutions and faculty agree that six publications were important for promotion and/or tenure Collegiate Aviation Review, Journal of Air Transportation, International Journal of Applied Aviation Studies, Journal of Aviation/Aerospace Education and Research, Journal of Aviation Management Education, and International Journal of Professional Aviation Training and Testing Research. Administration from non-research institutions did not rank any specific aviation publication as important. Which is consistent with their overall view of scholarship in the tenure and promotion process. The one area of agreement however, was every group agreed that an aviation trade magazine article and non-peer-reviewed journal publication were minimally important.

When asked if a single author publication is more valuable than a multi-author publication, administration from both research and non-research institutions said yes (70\% and 56\% respectively). The faculty yes response was considerably less (56\% and $33 \%$ respectively). Forty-six percent of the faculty tended to view single and multiple authored publications as equal. 
Being identified as lead author in a multi-author publication is viewed as more valuable by all groups, except faculty from non-research institutions. Seventy five percent of all administration and faculty from research institutions stated that being lead author is more important. Only $33 \%$ of faculty from non-research institutions felt that being lead author was more important, with $40 \%$ of the group stating that all authorships possess equal value. Even though being identified as lead author is viewed favorably, only $20 \%$ of all respondents stated that the percentage of individual effort/contribution to the multi-authored publication was required by their institution.

The last question about scholarship in the survey was the importance of the geographic venue of publication. Administration from non-research institutions did not rank any geography venue as important. Their highest ranking was the national venue $(M$ = 3.89). Faculty ranked national and international publication venues as important $(\mathrm{M}=$ 4.46 and 4.32 respectively). Administration from research institutions also ranked international and nation publication venues as important $(M=4.80$ and 4.50 respectively), and also included regional publication venues as important $(M=4.20)$. All groups rated local publication venues the lowest as somewhat important.

Teaching. Teaching was the pillar that largest majority of all groups considered critical to gauging an individual's fitness from promotion and/or tenure. Over $87 \%$ of all survey respondents answered "Strongly Agree" or "Agree" when asked if teaching was critical to the process. Even as important as teaching is, fair and accurate evaluation of teaching appears to be lacking. Only two of all the survey respondents answered "Strongly Agree" when asked if teaching evaluation was fair and accurate. Over $41 \%$ either "Disagreed" or "Strongly Disagree" that teaching evaluation was fair and accurate, which identifies an interesting contradiction. How can teaching be so important to the promotion and tenure process, but teaching evaluation not be fair and accurate?

Perhaps the view that teaching is not as fair and accurate as it could be is because of who is doing the teaching evaluation. The far majority of survey respondents reported that students evaluate classroom instruction. However, slightly over half of the respondents reported that a peer or faculty member evaluated classroom instruction, and less than one-third of the classroom evaluation is done by the chairperson. It appears that classroom evaluation is primarily in the hands of students, who are probably least equipped to evaluate classroom instruction.

Service. Even though service is rated the lowest of the three pillars of promotion and/or tenure, service is still considered critical to determining the fitness of an individual for promotion and/or tenure. The importance of service to the promotion and/or tenure process was separated into three areas - professional service, university/institutional service, and community service. A generic category of service was not included in the survey.

Of the three areas of service, professional and university/institutional service were viewed as the most critical. Sixty-nine percent of the survey respondents either "Strongly Agree" or "Agree" that professional service was critical for promotion and/or tenure. The 
number for university/institutional service was $64 \%$. Community service was viewed by the least number as critical, with only 44\% "Strongly Agree" or "Agree".

Tenure Progress and/or Reviews. The last question on the survey asked if probationary faculty received annual progress and/or reviews. There were a surprising number of survey responses indicating that no such review was given at their institution. Over $18 \%$ of the faculty at research institutions stated that no annual progress and/or review were made. However, all of the administration from research institutions reported that annual progress and/or reviews were made at their institutions. This discrepancy could be explained because not all UAA research institutions are represented in the responses. Over one-third of the administration and faculty at non-research institutions reported that no annual progress and/or review was given to probationary faculty. For probationary faculty member at one of the institutions that do not provide annual reviews, this would seem to be an obstacle to a probationary faculty's progress to promotion and/or tenure. How can progress be made in a deficient area if there is no regular evaluation of faculty performance?

\section{Summary and Conclusion}

This study indicates that there are some perceptual differences between faculty and administrators, but the responses were more aligned by type of institution (research versus non-research) than by employment classification. For example, scholarship was indicated as more critical for promotion and tenure determinations by research institutions than non-research institutions. All groups indicated that teaching was critical to tenure and/or promotion. One concern raised by this survey is that $41 \%$ of respondents indicated that fair and accurate evaluation of teaching was an issue. Student evaluation is the most frequent method of classroom evaluation. Chairperson evaluation is the least frequent method of classroom evaluation. Fewer respondents considered service as critical a pillar as scholarship and teaching. Professional service was the most valued while community service was valued least.

What is clear about the promotion and tenure process in collegiate aviation is there is nothing clear about the promotion and tenure process across all of collegiate aviation. This, and the previous study, do highlight some interesting trends. Larger research institutions will tend to value scholarship over teaching and service. However, all three

are critical to achieve promotion and/or tenure. Smaller non-research institutions tend to value service and teaching and are less likely to have annual progress and/or reviews. The best advice the authors can give when it comes to promotion and/or tenure is, find out which pillars are most important to your institution and excel in all three. 


\section{References}

Boyer, E. (1990). Scholarship reconsidered: Priorities of the professoriate. Princeton, NJ: Carnegie Foundation for the Advancement of Teaching

Cipriano, B., \& Riccardi, R. (2009). Faculty expectations regarding personnel decisions. Special report: Faculty promotion and tenure: Eight ways to improve the tenure review process at your institution. Retrieved from http://www.facultyfocus.com/free-reports/faculty-promotion-and-tenure/

Davis, T. E., Levitt, D. H., McGlothlin, J. M., Hill, N. R. (2006). Perceived expectations related to promotion and tenure: A national survey of CACREP program liaisons. Counselor Education \& Supervision, 46, 146 - 156.

Dennis, A. R., Valacich, J.S., Fuller, M. A., \& Schneider, C. (2006). Research standards for promotion and tenure in information systems. MIS Quarterly, 30(1), 1 - 34.

Diamantes, T. (2004). Online survey research of faculty attitudes toward promotion and tenure. Retrieved from http://www.usca.edu/essays/vol122004/diamantes.pdf

Emmert, P., \& Rollman, S. A. (1997). A national survey of tenure and promotion standards in communication departments. Journal of the Association for Communication Administration, 1, 10-23.

Lein, C. D., \& Merz, C. M. (1978, Winter). Faculty evaluation in schools of business: The impact of AACSB accreditation on promotion and tenure decisions. Collegiate News and Views, 21(24).

Pavel, S. R., Legier, J. T., \& Ruiz, J. R. (2012). Promotion and tenure perceptions of University Aviation Association (UAA) collegiate aviation administrators and faculty. Collegiate Aviation Review, 30(1), 32-61.

Saunders, G., Luchs, C., \& Smith, W. (2006, April). The role of service in P\&T decisions. Journal of College Teaching \& Learning, 3(4), 51-58.

Trieschmann, J. S., Dennis, A. R., Northcraft, G. B., \& Nemi, A. W. (2000). Serving multiple constituencies in the business school: MBA program versus research performance. Academy of Management Journal, 43(6), 1130-1141. 


\title{
Leadership Effectiveness of Collegiate Aviation Program Leaders: A Four-frame Analysis
}

\author{
Ryan S. Phillips \\ Lewis University \\ Mark A. Baron \\ The University of South Dakota
}

\begin{abstract}
The purpose of this study was to examine the perceived leadership effectiveness of aviation program leaders at higher education institutions utilizing the four leadership frames of Drs. Lee Bolman and Terrence Deal. A frame is a tactic which allows an individual to gain a perspective on a given situation. The four frames of Bolman and Deal are the structural, human resources, political, and symbolic frames. An anonymous online survey, developed using the Leadership Orientation Instrument of Bolman and Deal, was sent electronically to aviation faculty and staff followers at University Aviation Association higher education institutions. Five-point Likert scales were used by aviation faculty and staff to assess the perceived leadership effectiveness of aviation program leaders. A one-way ANOVA was conducted comparing the perceived leadership effectiveness scores based on the four leadership frames. No significant difference was found in perceived leadership effectiveness based on the primary leadership frame, $F(3,90)=1.08, p>.05$. An additional one-way ANOVA was run comparing the perceived leadership effectiveness scores of the four frame groups (no frames, single frame, paired frames, and multiple frames). A significant difference was found in perceived leadership effectiveness based on the number of frames utilized, $F(3,222)=$ 101.93, $p<.05$. Post-hoc tests revealed that aviation program leaders scored higher in perceived leadership effectiveness if they subscribed to the paired frames or multiple frames approaches.
\end{abstract}

\section{Introduction}

Aviation is inherently a high-stakes environment, and if an organization is to be effective it must work as a team and be led by a strong leader. These leader/team interactions must be cohesive for an organization to safely achieve its objectives (Senko, 2010). Additionally, Kutz (1998) stressed the importance of aviation leaders to have a vision that consists of the inputs from followers across the entire organization. In addition to a leader being effective in an organization, the Federal Aviation Administration (FAA) further stresses the importance of leadership in aviation not only in the United States but past our borders on a global scale (FAA, 2009).

The academic environment is also challenging and ever-changing as well. Leaders in this field must be able to balance budgets, meet the demands of superordinates (presidents, provosts, deans, and governing boards), and effectively empower their employees to achieve college and department goals (Napier, 1996; Wolverton \& Ackerman, 2006). Aviation academic leaders face the aforementioned challenges 
imposed by both the aviation industry and academic arenas. These individuals must successfully find ways to prepare graduates for the challenging industry while negotiating with the rigors of academia at the same time (Phillips, Ruiz, \& Mehta, 2006). In order to meet these challenges an effective leadership strategy must be put in place (Phillips, 2012).

One such leadership strategy was proposed by Drs. Lee Bolman and Terrence Deal (2008). Their strategy incorporates the use of four different leadership frames to effectively lead in a complex environment. A frame is a tactic which allows a leader to view an issue from a particular perspective. The first frame is the structural which deals with the physical makeup of an organization and how it is organized to accomplish a task. The second frame is human resources which focuses on how leaders interact with their people and provides them with what they need (resources, encouragement, etc.) (Bolman $\&$ Deal, 2010). The next frame is the political frame which focuses on the competition over scarce resources both inside and outside of the organization. The final frame is the symbolic frame which attaches an organization's culture to symbols of meaning for the leaders and their followers (Bolman \& Deal, 2006). McDonald's restaurant has the golden arches and Southwest Airlines has the heart symbol. These symbols embody what it means to be a part of an organization and its culture. For the purposes of this study, the primary leadership frame is the frame a leader utilizes the most. In a 2012 study by Phillips, data analysis revealed that aviation program leaders utilize the human resources frame the most, followed by the structural, political, and symbolic frames, respectively.

Using Bolman and Deal's (2003) framework, this study specifically addresses the following questions:

1. How effective are aviation program leaders perceived to be by faculty and staff?

2. What differences in perceived leadership effectiveness exist based on the primary leadership frame used?

3. What differences in perceived leadership effectiveness exist based on the number of leadership frames used (no frames, single frame, paired frames, and multiple frames)?

\section{Review of Literature}

Leadership is one of the most studied and documented subjects (Manning \& Curtis, 2011). Carlyle (1840) was one of the first to look for common traits among successful leaders. He hoped to identify a common thread or trait which could be used to unlock the secrets of great leadership. Over time, many additional leadership theories have abounded which include trait, behavioral, contingency, situational, path goal, power and influence, transactional and transformational, and cultural leadership theories (Bass, 1985; Bensimon, Neumann, \& Birnbaum, 1989; Downton, 1973; Fiedler, 1964; Hemphill, 1950; Hershey, Blanchard, \& Johnson, 2007; House, 1977; Lewin \& Lippit, 1938; Lick, 2002; Stogdill, 1948, Vroom \& Yetton, 1973). This study utilized the four 
frames theory of Bolman and Deal (2003). This leadership theory was selected because it synthesizes many of the organizational leadership theories previously mentioned, and it is highly adaptable to differing leadership environments (Bolman \& Deal, 1990; Little, 2010). Each theory seeks to determine what makes leaders effective in navigating the challenges they face within their fields. Both the aviation industry and higher education offer unique challenges to leaders, and an aviation program leader must successfully handle challenges from both groups.

Regarding the aviation industry, many challenges have surfaced to complicate aviation industry operations. In his 2009 address, Giovanni Bisignani, former Director General and Chief Executive Officer of the International Air Transport Association, highlighted just some of the challenges facing the global aviation industry. Oil prices escalated to a peak of $\$ 144$ per barrel, an increase in labor productivity occurred, noise and carbon emission standards were tightened, and all of these changes occurred rapidly due to these global events and the leadership of industry professionals (Bisignani, 2009). All of these changes adversely affected the aviation industry and have added unique challenges to industry organizations to be effective. According to the Federal Aviation Administration Economic Impact Report of 2011, aviation serves as the conduit to further business and commerce on a global scale. These large-scale operations have provided many opportunities to the country and world. With these opportunities, however, come many challenges that need to be addressed by leaders in the industry and field.

Leaders in a higher education setting must also deal with multitudes of challenges. A study conducted by Wolverton, Gmelch, Wolverton, and Sarros (1999) discovered that some of the challenges facing higher education leaders include assigning faculty workloads (teaching, research, etc.), managing and distributing the department's budget, carrying forward the vision of the dean and higher administrators, setting goals and objectives to achieve the aforementioned vision, etc. These leaders also serve as mentors for faculty and must successfully handle concerns, difficulties, and conflicts that arise among their followers as well. In addition to these daily challenges, leaders also must deal with budgetary shortfalls in higher education which place additional strain on the shoulders of academic leaders (Graham, Heiman, \& Williams, 2004). To further complicate matters, a study by Gmelch (2000) discovered that only 3\% of 2,000 surveyed had any leadership training before stepping into leadership roles similar to those in aviation higher education.

The aviation program leader must handle both sets of the aforementioned challenges. Many challenges faced in academia are financial, and it is up to the leaders to address these challenges using their leadership skills (Middlehurst, 2010). Many of the challenges facing the aviation industry are also the result of economic factors and safety objectives put in place by the FAA (2009). It is up to aviation program leaders to address these challenges and effectively prepare students for their careers (UAA, 2012). Additionally, aviation program leaders must effectively lead the faculty and staff members of their organizations to obtain the objectives set in place.

One way to evaluate leadership effectiveness and deal with the demands of an everchanging workforce is to utilize Bolman and Deal's (2008) four frame model (McArdle, 
2008; Parry \& Horton, 1998). A strong knowledge of the four frames is essential in handling the multitudes of differing tasks and situations that arise in an industry or academic setting.

Before describing each of the four frames, it is essential to further define the terms "frames" and "aviation program leader". "Frames are both windows on the world and lenses that bring the world into focus. Frames filter out some things while allowing others to pass through easily. Frames help us order experience and decide what to do" (Bolman $\&$ Deal, 1997, p. 12). Each frame allows a leader to gain a different perspective on a given situation. For the purposes of this study an "aviation program leader" is the individual who shoulders the main responsibilities for an aviation program (budget, curriculum, vision, mission, etc.). Since institutions are organized differently, this individual could be a dean, department chair, program coordinator, program leader, etc. (Phillips, 2012).

The first frame is structural, and it focuses on how leaders arrange and setup their organizations to accomplish its tasks. This frame is also concerned with the procedures and protocols that leaders and followers must utilize to successfully meet their objectives (Bolman \& Deal, 2003). Bolman and Deal also stress the importance of using more than one single frame to evaluate leadership effectiveness. "In a world of increasing ambiguity and complexity, the ability to use more than one frame should increase an individual's ability to make clear judgments and to act effectively" (Bolman \& Deal, 1991, p.519).

The second frame is the human resources frame. "The human resource frame highlights the relationship between people and organizations. Organizations need people (for their energy, effort, and talent), and people need organizations (for the many intrinsic and extrinsic rewards they offer), but their needs are not always well aligned. When the fit between people and organizations is poor, one or both suffers: individuals may feel neglected or oppressed, and organizations sputter" (Bolman \& Deal, 1997, p. 119). This frame is focused on leaders providing the required support to followers so they may have adequate resources to succeed in the organization.

The political frame is concerned with the use and distribution of power. Leaders must compete for scarce resources that exist in the organization's environment. Some of these resources include time, money, supplies, equipment, facilities, etc. This frame is important because leaders must form coalitions and avoid pitfalls while building a base of power to best serve their followers (Bolman \& Deal, 2003).

The final frame is the symbolic frame. This frame is utilized to promote a culture in an organization. One way to do this is through the use of symbols. A symbol is something that everyone in an organization can readily identify with and take pride in. Although a symbol is important, leaders of organizations must be the one to attach meaning to the symbol. Herb Kelleher, former CEO of Southwest Airlines, would show his employees what it meant to be a Southwest employee through his example (Freiberg \& Freiberg, 1996). The leader in the symbolic frame "...believes that the most important 
part of a leader's job is inspiration---giving people something they can believe in" (Bolman \& Deal, 2003, p. 329).

Many additional studies have utilized Bolman and Deal's theory in academia, but after extensive literature review, none have looked at aviation higher education specifically (Beck-Frazier, 2005; Burks, 1992; Cantu, 1997; Chang, 2004; DeFrank-Cole, 2003; Englert, 2008; Goldsmith, 2005; Griffin, 2005; Guidry, 2007; Little, 2010; Maitra, 2007; McArdle, 2008; Sypawka, 2008; Tedesco, 2004; Tingey, 1997). This gap in research served as the catalyst for this study.

Limitations and Delimitations of the Study. This study was limited by the number of responses from contacted respondents and by the demographics associated with the population (gender, faculty status, etc.). The results of this study are therefore confined to those responding and do not describe the entire population. The first delimitation of this study was that it only consisted of faculty and staff from aviation higher education institutions that are members of the University Aviation Association to ensure data manageability. The second delimitation was that only the Leadership Orientation Instrument (LOI) Other version was administered to respondents. Doing so prevented the possible loss of paired sample data as is later explained.

\section{Methodology}

\section{Purpose}

The purpose of this study was to examine leadership effectiveness in aviation higher education utilizing the leadership theory of Bolman and Deal (2008). The study focused on the perceived leadership effectiveness derived from faculty and staff evaluations, and answered the following specific research questions:

1. How effective are aviation program leaders perceived to be by faculty and staff?

2. What differences in perceived leadership effectiveness exist based on the primary leadership frame used?

3. What differences in perceived leadership effectiveness exist based on the number of leadership frames used (no frames, single frame, paired frames, and multiple frames)?

\section{Population}

The population for this study consisted of 878 aviation faculty and staff members from approximately 100 University Aviation Association (UAA) member institutions. The UAA is an organization that fosters excellence in collegiate aviation and works to constantly improve the quality of aviation programs (UAA, 2012). Due to these high standards, faculty and staff from member institutions of this organization were selected as the population for this study. It is important to note all subjects were not necessarily 
members of the UAA, but they belonged to member institutions. The UAA website provided the basic program and web addresses required to begin further researching faculty and staff contacts. Once the program websites were obtained, searches of the employee directories ensued to develop an email list of faculty and staff members for participation in the survey. A database of faculty member emails was compiled in January of 2012, and it was placed into SurveyMonkey®, an online-based survey administration tool. Furthermore, aviation program leaders were excluded from this study as is later explained, and the population consisted solely of respondent followers.

\section{Instrument}

The instrument used to collect these data was the Leadership Orientation Instrument which was developed by Bolman and Deal (1990). Written permission to utilize the instrument was obtained from Dr. Bolman. The survey was developed to identify the frame(s) in use by leaders in various organizations. There are two primary versions of the survey. One is the LOI-Self which is answered by the leader of the organization (aviation program leader) to determine the leadership frames as the individual perceives them. The second section is the LOI-Other and is answered by followers to measure their perceptions of the leadership frame(s) in use by their leader. Both sections seek to measure the frame use of the leader. This study utilized the Other portion of the survey only. Using solely the Other part of the instrument was elected to prevent the sample size from being limited. If the Self and Other portions of the instrument were both utilized at an institution, the result would be a paired sample. If aviation program leaders failed to respond to the Self portion of the instrument, the data collected from the Other portion of the instrument at the same institution would no longer be paired. This would have resulted in losing data from multiple followers who completed the Other portion.

The LOI-Other consists of four sections (Bolman \& Deal, 1990). This study used sections I, III, and IV. Section II seeks to further identify leadership sub classifications such as analytic, supportive, powerful, inspirational, organized, participative, adroit, and charismatic. To solely focus on the primary leadership frames and limit the length of the survey, section II was eliminated. Section I consists of eight Likert questions per frame, totaling 32 total questions. Respondents rated the frequency of their leader's structural frame use on a Likert scale where $1=$ Never, $2=$ Occasionally, $3=$ Sometimes, $4=$ Often, and $5=$ Always.

Section III focuses on the perceived effectiveness of the leader (Bolman \& Deal, 1990). Subjects again rated their leader on a Likert scale of 1 to 5, where 1 is a leader whose effectiveness is ranked in the bottom $20 \%$ of all leaders the subject has known $(0-$ $20 \%), 2$ is in the next $20 \%$ bracket $(21-40 \%), 3$ is a leader in the middle $20 \%$ bracket (41$60 \%), 4$ is in the next higher bracket (61-80\%), and a 5 is a leader whose effectiveness is in the top $20 \%$ of all leaders the subject has known (81-100\%).

Lastly, Section IV focuses on basic demographic questions with regard to gender and type of position held by the respondent. 


\section{Data Collection and Analysis}

Once the population was identified, the email addresses of these individuals were entered into SurveyMonkey® and persons were automatically invited to participate in the study online through an email invitation. This email addressed their individual rights as human subjects in this study and provided a link to the survey. Contacting respondents in this manner ensured confidentiality of the participants and also reduced the possibility of errors occurring in data collection. A reminder email was sent every five days encouraging individuals to take part in the survey. Three total reminders were issued, and the total window for participation was open for 21 days.

Once data collection was complete, statistical analysis was accomplished using the Statistical Package for the Social Sciences (SPSS) software version 19.0. First an analysis was run using the composite mean from Section I of the LOI. The frame with the highest composite mean identified the leadership frame being utilized the most. Second, the number of leadership frames used by a leader was determined by identifying the number of frames having composite means of leaders 4.0 and above. If a subject scored below a 4.0 for a frame, the subject was counted as not using that frame. Therefore, an individual who had no composite mean score greater than 4.0 was classified as no frames (used zero of the four frames). An individual who had one composite mean equal to or greater than 4.0 was classified as single frame (used one of the four frames). An individual who had two composite means equal to or greater than 4.0 was classified as paired frames (used two of the four frames). Lastly, an individual who had three or four composite mean scores equal to or greater than 4.0 was classified as multiple frames (used three or four of the frames).

Research question one focused on identifying how effective aviation program leaders are perceived to be by aviation faculty and staff. These data originated from Section III of the LOI and are descriptive in nature. Means and standard deviations were calculated based on the same five-point Likert scale.

The second research question focused on identifying the differences of perceived leadership effectiveness based on the primary frame used by the leader. Subjects were grouped by primary frame utilizing the same method explained in the previous paragraph. Individuals with a 4.0 or higher composite score were considered to subscribe to a frame. Leaders who did not score above a 4.0 composite mean were not used in answering this question. Individuals that had equal composite mean for two or more frames were also not counted. For example, an individual who scored a 4.1 for both the structural and human resources frames would not be considered to utilize one primary frame over the others. This individual would therefore not be counted. After subjects were grouped a Levene test of homogeneity was conducted. Next, a one-way analysis of variance (ANOVA) was performed to determine differences in perceived leadership effectiveness based on each frame orientation. The independent variable was the primary leadership frame, and the dependent variable was the mean of the perceived leadership effectiveness. The ANOVA was run at the .05 level of significance. 
Research question three focused on identifying the difference in perceived leadership effectiveness based on the number of leadership frames used (no frames, single frame, paired frames, and multiple frames). Levene and ANOVA tests were once again performed. The independent variable was the number of frames used, and the dependent variable was the mean of the perceived leadership effectiveness. Again, these tests were run at the .05 level of significance.

\section{Findings}

\section{Response Rate}

Of the 878 surveys sent out, 231 were returned. Of this group five were not completely filled in due to technical problems and were discarded from the study. The remaining usable surveys yielded a response rate of $25.7 \%$ (226/878), and this generated a confidence interval of 5.62. The Instructional Assessment Resources webpage at the University of Texas (2013) states that the average response rate for an online survey is $30 \%$. Thus this study yielded a slightly reduced response rate.

\section{Demographic Data}

Of the 226 returned surveys, 54 of the respondents were women (23.9\%) and 172 were men $(76.1 \%)$. Of the respondents, $142(62.8 \%)$ were classified as faculty members who serve in a full-time capacity, $13(5.8 \%)$ were adjunct faculty, 62 (27.4\%) were staff, and $9(4.0 \%)$ were other.

Aviation program leader effectiveness. Section III of the LOI-Other consisted of one question where respondents ranked their leaders on their overall leadership effectiveness (research question 1). The same 1 to 5 Likert scale was used. A selection of 1 is a leader whose effectiveness is ranked in the bottom $20 \%$ of all leaders the subject has known (0-20\%), 2 is in the next $20 \%$ bracket $(21-40 \%), 3$ is a leader in the middle bracket (41-60\%), 4 is in the next higher bracket (61-80\%), and a 5 is a leader whose effectiveness is in the top $20 \%$ of all leaders the subject has known (81-100\%).

A frequency response was computed for perceived leadership effectiveness. Respondents reported that $21(9.3 \%)$ were in the lowest bracket, $19(8.4 \%)$ were in the $21-40 \%$ bracket, $43(19.0 \%)$ were in the $41-60 \%$ bracket, $82(36.3 \%)$ were in the $61-80 \%$ bracket, and $61(27.0 \%)$ were in the top bracket (see Table 1).

Differences in perceived leadership effectiveness based on primary leadership frame. A Levene's test for equality of variances was conducted and the data were determined to be homogenous, $F(3,90)=.90, p>.05$. A one-way ANOVA was then conducted to determine the differences in perceived leadership effectiveness based on the primary leadership frame utilized (research question 2). The dependent variable was perceived leadership effectiveness and the independent variable was the primary leadership frame. In order to properly run the ANOVA, data from each respondent were analyzed. For a primary leadership frame to be identified, only individuals who had a 
Table 1

Perceived Leadership Effectiveness Rating

\begin{tabular}{lcc}
\hline Perceived Leadership & Frequency & Valid Percent \\
\hline Lowectiveness & 21 & 9.3 \\
Next 21-40\% & 19 & 8.4 \\
Middle 41-60\% & 43 & 19.0 \\
Higher 61-80\% & 82 & 36.3 \\
Top 81-100\% & 61 & 27.0 \\
Total & 226 & 100.0 \\
\hline
\end{tabular}

Note: $n=226$

Table 2

Responses by Primary Leadership Frame

\begin{tabular}{lcccc}
$\begin{array}{l}\text { Frames } \\
\text { Utilized }\end{array}$ & Frequency & Valid Percent & $\begin{array}{c}\text { Effectiveness } \\
\text { Mean }\end{array}$ & SD \\
\hline Human & 44 & 46.8 & 4.36 & 0.57 \\
Resource & 31 & 33.0 & 4.19 & 0.75 \\
Structural & 10 & 10.6 & 4.50 & 0.53 \\
Political & 9 & 9.6 & 4.56 & 0.73 \\
Symbolic & 94 & 100 & 4.34 & 0.65 \\
Total & & &
\end{tabular}

Note: $n=94$

composite mean score in a frame of 4.0 and higher were counted as using that particular frame. Following this process, of the total survey respondents $(n=226), 133$ had mean scores of 4.0 and higher in a frame. Of these 133 leaders, 39 had frames that had the exact mean score as another frame. These individuals with "tied" scores were removed from the sample. This left 94 total leaders in the pool. Of this group, $31(33.0 \%)$ were structural, $44(46.8 \%)$ were human resource, 10 (10.6\%) were political, and $9(9.6 \%)$ were symbolic (see Table 2). Human resource leaders had a perceived leadership effectiveness mean score of $4.36(S D=0.57)$. Structural leaders had a perceived leadership effectiveness mean score of $4.19(S D=0.75)$. Political leaders had a perceived leadership effectiveness mean score of $4.50(S D=0.53)$. Symbolic leaders had a perceived leadership effectiveness mean score of $4.56(S D=0.73)$ (see Table 2). Once groupings were complete the one-way ANOVA was conducted comparing the perceived leadership effectiveness scores based on the four leadership frames (structural, human resource, political, and symbolic). No significant difference was found in perceived leadership effectiveness based on the primary leadership frame, $F(3,90)=1.08, p>.05$ (see Table 3). 
Table 3

Differences in Perceived Leadership Effectiveness Based on Primary Leadership Frame

\begin{tabular}{lccccc}
\hline & $\begin{array}{c}\text { Sum of } \\
\text { Squares }\end{array}$ & df & $\begin{array}{c}\text { Mean } \\
\text { Square }\end{array}$ & $F$ & $p$ \\
\hline Between Groups & 1.36 & 3 & 0.46 & 1.08 & .360 \\
Within Groups & 37.74 & 90 & 0.42 & & \\
Total & 39.11 & 93 & & & \\
\hline
\end{tabular}

Note: $n=94$

Differences in perceived leadership effectiveness based on number of leadership frames utilized. For research question three, a Levene's test for equality of variances was conducted and was found to be violated for the present data analysis, $F(3,222)=$ 29.01, $p<.05$. Data were further analyzed using Q-Q plots (see Figures 1-4) and were determined to be normally distributed. A one-way ANOVA was then conducted to determine the differences in perceived leadership effectiveness based on the number of leadership frames used. The dependent variable was perceived leadership effectiveness and the independent variable was the number of leadership frames used. Once again, a 4.0 and higher mean score was used to identify which frames were being utilized. In order to group individuals into the frame categories (no frames, single frame, paired frames, and multiple frames) the same procedure was followed as in research question two. A frequency of response was performed for the 226 leaders, and respondents reported that $92(40.7 \%)$ of leaders used no frames, $33(14.6 \%)$ used single frame, 24 $(10.6 \%)$ used paired frames, and 77 (34.1\%) used multiple frames (see Table 4).

Leaders who used no frames had a perceived leadership effectiveness mean score of 2.55, $(S D=1.07)$ (see Table 5). Single frame leaders had a perceived leadership effectiveness mean score of 3.79, $(S D=0.55)$. Paired frame leaders had a perceived leadership effectiveness mean score of $4.42,(S D=0.65)$, and multiple frame leaders had a perceived leadership effectiveness mean score of 4.61, $(S D=0.49)$.

Once the groupings were complete, the one-way ANOVA was run comparing the perceived leadership effectiveness scores of the four frame groups (no frames, single frame, paired frames, and multiple frames). A significant difference was found in perceived leadership effectiveness based on the number of frames utilized, $F(3,222)=$ 101.93, $p<.05$ (see Table 6). Tukey's Honestly Significant Difference (HSD) Test was used to determine the nature of the differences between the number of leadership frame groups (see Tables 5 and 7). Leaders who utilized a single frame $(M=3.79,95 \% \mathrm{CI}$ $[3.59,3.98])$ had a significantly higher perceived leadership effectiveness score than leaders who used no frames $(M=2.55,95 \%$ CI $[2.33,2.78]), p<.05$. Leaders who utilized paired frames $(M=4.42,95 \%$ CI [4.14, 4.69]) had a significantly higher perceived leadership effectiveness score than leaders who used a single frame or no frames approach, $p<.05$. Leaders who utilized multiple frames $(M=4.61,95 \%$ CI [4.50, 4.72]) had a significantly higher perceived leadership effectiveness score than leaders who used a single frame or no frames approach, $p<.05$. There was no significant difference between leaders who use multiple frames and paired frames, $p>.05$. Leaders 
who utilize paired and multiple frames had a significantly higher perceived leadership effectiveness score than individuals who used no frames or a single frame, and leaders who used a single frame had a significantly higher perceived leadership effectiveness score than leaders who utilized no frames.

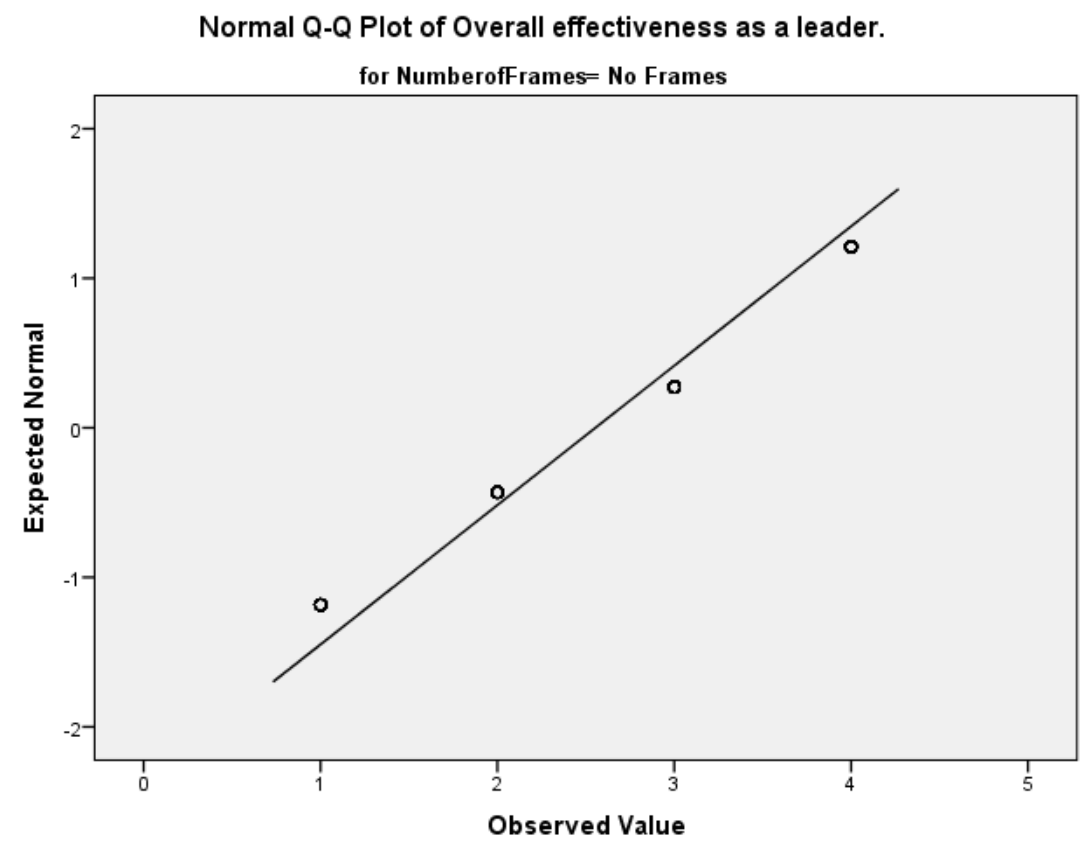

Figure 1. QQ plot for overall effectiveness as a leader - no frames.

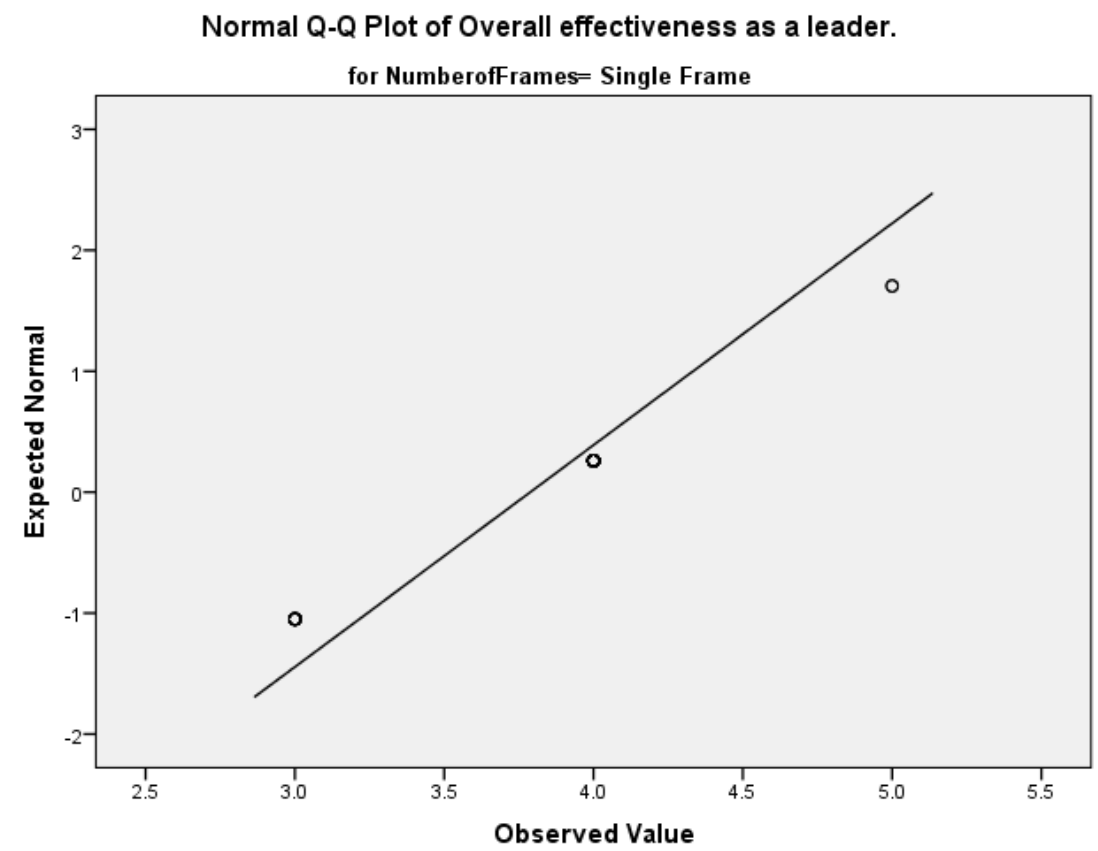

Figure 2. QQ plot for overall effectiveness as a leader - Single frame. 
Normal Q-Q Plot of Overall effectiveness as a leader.

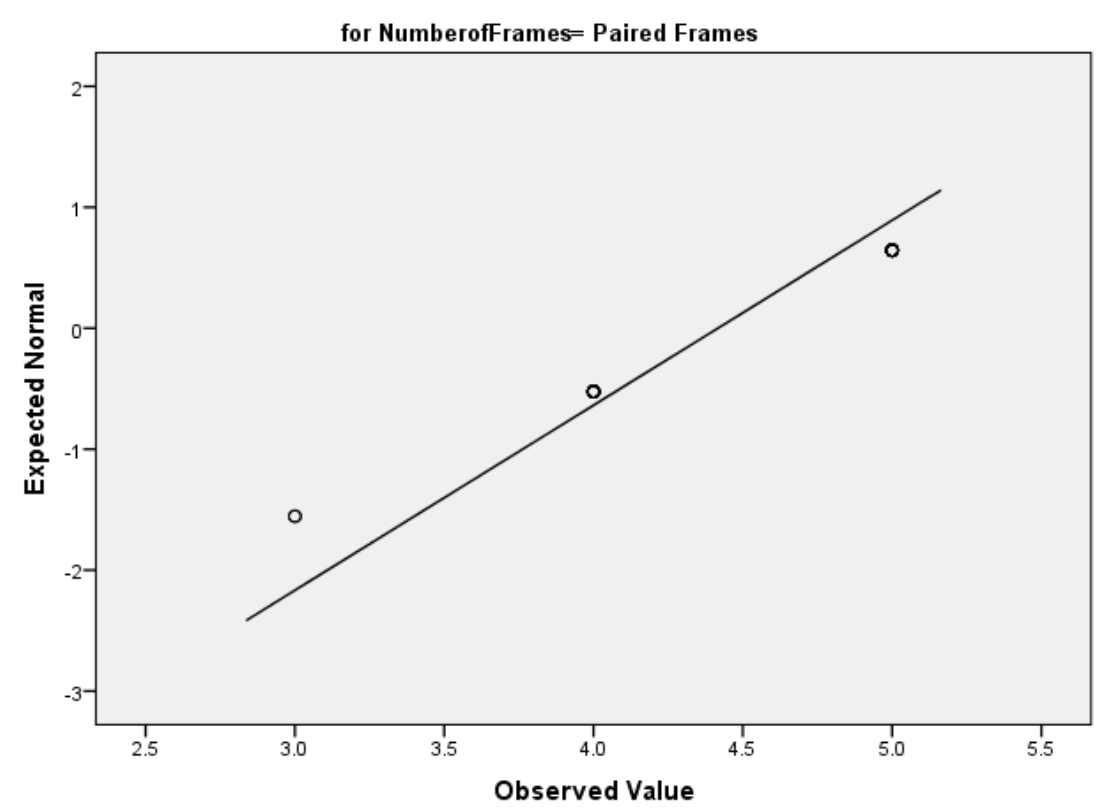

Figure 3. QQ plot for overall effectiveness as a leader - paired frames.

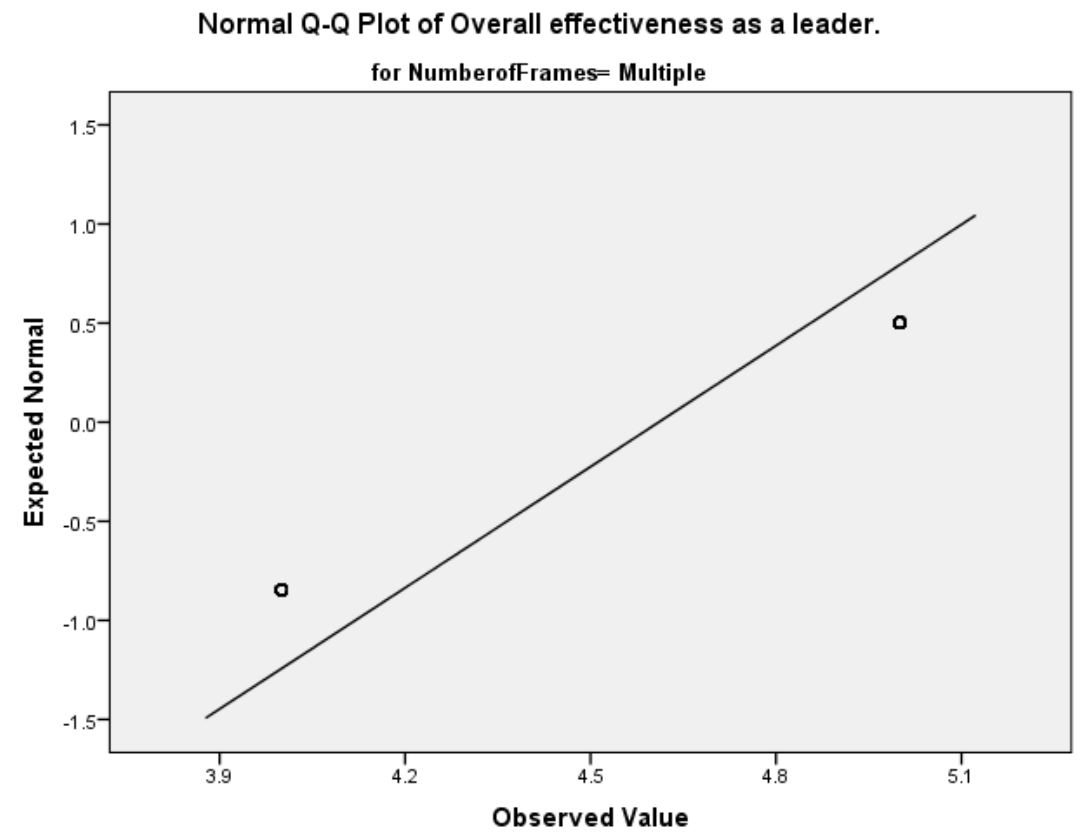

Figure 4. QQ plot for overall effectiveness as a leader - multiple frames. 
Table 4

Perceived Number of Leadership Frames Utilized

\begin{tabular}{lcc}
\hline Frames Utilized & Frequency & Valid Percent \\
\hline No Frames & 92 & 40.7 \\
Single Frame & 33 & 14.6 \\
Paired Frames & 24 & 10.6 \\
Multiple Frames & 77 & 34.1 \\
Total & 226 & 100.0 \\
\hline
\end{tabular}

Note: $n=226$

Table 5

Leadership Effectiveness Based on Number of Frames Used

95\% Confidence Interval for Mean

\begin{tabular}{lccccc} 
Number of Frames & $\begin{array}{c}\text { Size } \\
(n)\end{array}$ & Mean & Standard Deviation & Lower Bd. & Upper Bd. \\
\hline No Frames & 92 & 2.55 & 1.07 & 2.33 & 2.78 \\
Single Frame & 33 & 3.79 & 0.55 & 3.59 & 3.98 \\
Paired Frames & 24 & 4.42 & 0.65 & 4.14 & 4.69 \\
Multiple Frames & 77 & 4.61 & 0.49 & 4.50 & 4.72 \\
Total & 226 & 3.63 & 1.23 & 3.47 & 3.79
\end{tabular}

Note: $n=226$

Table 6

Differences in Perceived Leadership Effectiveness Based on Number of Frames Utilized

\begin{tabular}{lcrccc}
\hline & $\begin{array}{c}\text { Sum of } \\
\text { Squares }\end{array}$ & \multicolumn{1}{c}{ df } & $\begin{array}{c}\text { Mean } \\
\text { Square }\end{array}$ & $F$ & $p$ \\
\hline Between Groups & 196.13 & 3 & 65.38 & 101.93 & $.000^{*}$ \\
Within Groups & 142.39 & 222 & 0.64 & & \\
Total & 338.52 & 225 & & & \\
\hline
\end{tabular}

*Significant at .05

Note: $n=226$ 
Table 7

Tukey HSD for the Number of Frames Utilized Based on Perceived Leadership Effectiveness

\begin{tabular}{llccc} 
& & \multicolumn{3}{c}{ Subset for alpha $=0.05$} \\
\cline { 3 - 4 } Number of & $\mathrm{N}$ & 1 & 2 & 3 \\
Frames & 92 & 2.55 & \\
No Frames & 33 & & 3.79 & \\
Single Frame & 24 & & 4.42 \\
Paired Frames & 77 & & 4.61 \\
Multiple & Frames & & & \\
\hline
\end{tabular}

Note: $n=226$

To summarize, data from both Sections I and III of the LOI were used to determine if there were differences in the perceived leadership effectiveness based on the primary leadership frame used. The tests run showed no statistical significance in perceived leadership effectiveness based on primary leadership frame at the .05 level of significance.

Data from both Sections I and III were also used to determine if there were differences in the perceived leadership effectiveness based on the number of leadership frames utilized by aviation program leaders as stated by survey respondents. The tests run showed statistical significance within perceived leadership effectiveness based on the number of leadership frames at the .05 level of significance. A post-hoc (Tukey HSD) test was run to determine where the differences existed in the number of leadership frames used. There was no significant difference between the multiple and paired frames categories at the .05 level of significance. The perceived leadership effectiveness of the multiple frames, however, was significantly greater than the single and no frames groups. The mean for the paired frames group was significantly greater than the single, and no frames groups at the .05 level of significance. Lastly, the mean of the single frame group was significantly greater than the mean of the no frames group at the .05 level of significance.

\section{Conclusion, Discussion, and Recommendations}

\section{Conclusions}

The following conclusions are drawn from the data analysis and findings of the study:

1. Most aviation faculty and staff feel their leaders are being effective in their leadership roles.

2. Primary leadership frame does not affect perceived leadership effectiveness. 
3. Aviation program leaders who utilize two or more frames are perceived to be more effective leaders than those who use one or no leadership frames.

\section{Discussion}

In order to determine if differences existed in perceived leadership effectiveness based on primary leadership frame and number of frames used, a baseline measurement of perceived leadership effectiveness was first measured. Most aviation program leaders were ranked by respondents in the highest two categories of aviation program leaders. This indicates that the majority of the respondents felt that their leaders were in the 61$100 \%$ leadership effectiveness groupings with less than half of aviation program leaders falling in the 0-60\% leadership effectiveness groupings. Again, this may be explained by the difficult nature of aviation higher education. Effective leaders are needed to successfully deal with the unique challenges of the environment. It further follows that leaders who do not perform well may not be in leadership roles for extended periods of time or will have aviation programs that suffer and fail to continue.

With regard to the differences in perceived leadership effectiveness based on primary leadership frame, aviation program leaders did not receive higher leadership effectiveness scores based on their primary leadership frame. One possible reason for this could be the scoring method used. Again, for a leader to be counted as using a frame for research question two, they had to score a composite mean of 4.0 or higher for the given frame. Individuals below the cutoff were not counted. A 4.0 and higher score indicates strong leadership skills are present. Leaders may be stronger in one frame than others, but ultimately they still possess strong leadership abilities in at least one area (frame). Since they have strong foundational leadership skills, respondent followers may perceive them to be equally effective with regard to the success and happenings at their respective institutions. They may not be strong in the same frames, but to the respondent followers it does not matter to which frame they most strongly subscribe as long as they get the job done effectively. This finding may indicate that aviation program leaders who wish to be perceived as effective may not need to subscribe to one specific frame (symbolic for example), but must ensure that they are highly effective (4.0 or higher) in the leadership frame of their choosing.

Regarding the differences in perceived leadership effectiveness based on number of frames utilized, aviation program leaders score higher among respondents taking the survey in perceived leadership effectiveness if they subscribe to the paired frames or multiple frames approaches. Leaders who only utilize a single frame or no frames approach had lower perceived leadership effectiveness ratings. As previously mentioned, it is necessary for a leader in aviation higher education to accomplish a number of goals and objectives in a challenging environment. Bolman and Deal (2008) posited that is important for a leader to use all of the frames in differing combinations to be effective. The findings support this statement. The perceived effectiveness of a leader increased when paired or multiple frames were utilized. No significant difference was found between the effectiveness scores of leaders who utilize paired or multiple frames, but the effectiveness mean score increased as the number of frames used increased. 
Furthermore, leaders who wish to be perceived as effective must subscribe to and utilize multiple frames.

\section{Recommendations}

Aviation program leaders should subscribe to a paired or multiple frames approach. Leaders who did so in this study had higher perceived leadership effectiveness from followers. Aviation program leaders should make a point to implement more of Bolman and Deal's frames into their leadership practices to better lead in differing situations.

One possible way to improve survey response rate would be to offer a small incentive for survey participation. SurveyMonkey® offers some options to include as incentives such as coupons, instant win games, and sweepstakes. The possibility of a small reward could improve the response rate for future studies.

Aviation program leaders should study Bolman and Deal's leadership theory and understand the importance and role of each frame. Doing so will enable a leader to implement an appropriate frame to lead more effectively.

The current study only utilized the LOI-Other in order to prevent the loss of much needed samples. For future study, the implementation of the LOI-Self along with the LOI-Other is recommended to compare the self-perceptions of aviation program leaders to those of their followers. Doing so will provide a more in-depth picture of the leadership phenomenon in aviation higher education. Taking these actions would more closely mirror the studies of others who have used Bolman and Deal's frame theory (Beck-Frazier, 2005; Burks, 1992; Goldsmith, 2005; Tedesco, 2004).

Lastly, this study only posed one question pertaining to leadership effectiveness. Further study may be accomplished to measure leadership effectiveness more deeply and accurately as it relates to four frame leadership theory. 


\section{References}

Bass, B. M. (1985). Leadership and performance beyond expectations. New York, NY:

Free Press.

Beck-Frazier, S. G. (2005). Perceptions of selected university deans’leadership behavior. (Doctoral dissertation). Retrieved from ProQuest Digital Dissertations. (AAT 316293)

Bensimon, E. M., Neumann, A., \& Birnbaum, R. (1989). Making sense of administrative leadership. ASHE-ERIC Higher education report 1. ERIC Document Reproduction Service No. ED316074.

Bisignani, G. (2009). Remarks by Giovanni Bisignani: Director General and CEO International Air Transport Association (IATA). Comments presented at the International Aviation Club of Washington, DC. Retrieved from http://www.iata.org/pressroom/pr/Documents/Giovanni\%20Bisignani\%27s\%20r marks.p

Bolman, L. G., \& Deal, T. E. (1990). Leadership orientation instrument. San Francisco: Jossey-Bass.

Bolman, L. G., \& Deal, T. E. (1991). Leadership and management effectiveness: A multi frame, multi-sector analysis. Human Resource Management, 30(4), 509- 534.

Bolman, L. G., \& Deal, T. E. (1997). Reframing organizations: Artistry, choice, and leadership (2nd ed.). San Francisco, CA: Jossey-Bass.

Bolman, L. G., \& Deal, T. E. (2003). Reframing organizations: Artistry, choice, and leadership (3rd ed.). San Francisco, CA: Jossey-Bass.

Bolman, L. G., \& Deal, T. E. (2006). The Wizard and the warrior: Leading with passion and power. San Francisco: Jossey-Bass.

Bolman, L. G., \& Deal, T. E. (2008). Reframing organizations: Artistry, choice, and leadership (4th ed.). San Francisco, CA: Jossey-Bass.

Bolman, L. G., \& Deal, T. E. (2010). Reframing the path to school leadership: A guide for principals and teachers (2nd ed.). Thousand Oaks, CA: SAGE.

Burks, T. D. (1992). The use of organizational frames in leadership development. (Doctoral dissertation). Retrieved from ProQuest Digital Dissertations. (AAT 9224297) 
Cantu, D. A. (1997). The leadership frames of academic deans randomly selected and nominated as exceptionally effective at public colleges and universities. (Doctoral dissertation). Retrieved from ProQuest Digital Dissertations. (AAT DP18411)

Carlyle, T. (1840). Heroes, hero-worship and the heroic in history. London, UK: Chapman and Hall.

Chang, T. (2004). Leadership styles of department chairs and faculty utilization of instructional technology. (Doctoral dissertation). Retrieved from ProQuest Digital Dissertations. (AAT 3152254)

De-Frank Cole, L. M. (2003). An exploration of the differences in female and male selfperceptions of presidential leadership styles at colleges and universities in West Virginia. (Doctoral dissertation). Retrieved form ProQuest Digital Dissertations. (AAT 3117728)

Downton, J. V. (1973). Rebel leadership: Commitment and charisma in the revolutionary process. New York, NY: Free Press.

Englert, M. G. (2008). Leadership orientations of rural community college presidents serving appointed or elected independent governing boards: A four-frame analysis. (Doctoral dissertation). Retrieved form ProQuest Digital Dissertations. (AAT 3321274)

Federal Aviation Administration. (2009). 2009-2013 FAA flight plan: Charting the path for the next generation. Washington, DC: Government Printing Office. Retrieved from: http://www.faa.gov/about/plans_reports/media/flight_plan_2009-2013.pdf

Federal Aviation Administration. (2011). Federal Aviation Administration economic impact report of 2011. Washington, DC: Government Printing Office Retrieved from: http://www.faa.gov/air_traffic/publications/media/

FAA_Economic_Impact_Rpt_2011.p

Fiedler, F. E. (1964). A contingency model of leadership effectiveness. In L. Berkowitz (Ed.), Advances in experimental social psychology (Vol. 1, pp. 149-190). New York: Academic Press.

Freiberg, K., \& Freiberg, J. (1996). Nuts. New York, NY: Broadway Books.

Gmelch, W. H. (2000). Rites of passage: Transition to the deanship. Paper presented at the Annual Meeting of the American Association of Colleges for Teacher Education Conference, Chicago. (ED439094)

Goldsmith, C. S. (2005). Leadership for creating a learning college: A study of perceived leadership styles. (Doctoral dissertation). Retrieved form ProQuest Digital Dissertations. (AAT 3182820) 
Graham, S. W., Heiman, S., \& Williams, R. (2004). How department chairs are responding to budget cuts nationally. The Department Chair, 14(4), 3-5.

Griffin, M. S. (2005). A comparison of the leadership orientations of chairpersons of biology and English departments at baccalaureate and master's institutions in the southern region. (Doctoral dissertation). Retrieved form ProQuest Digital Dissertations. (AAT 3170917)

Guidry, T. C. (2007). Women deans' perceptions of their leadership styles: A study based on Bolman and Deal's four frame theory. (Doctoral dissertation). Retrieved form ProQuest Digital Dissertations. (AAT 3255414)

Hemphill, J. K. (1950). Leader behavior description. Columbus, OH: The Ohio State University Personnel Research Board.

Hersey, P., Blanchard, K.H., \& Johnson, D.E. (2007). Management of organizational behavior: Leading human resources (9th ed.). Upper Saddle River, NJ: Prentice Hall.

House, R. J. (1977). A 1976 theory of charismatic leadership. In J. G. Hunt \& L. L. Larson (Eds.), Leadership: The Cutting Edge (pp. 189-207). Carbondale: Southern Illinois University Press.

Kutz, M. N. (1998). Characteristics of successful aviation leaders of Oklahoma. (Doctoral dissertation). Retrieved from ProQuest Digital Dissertations. (AAT 9922557)

Lewin, K. \& Lippitt, R. (1938). An experimental approach to the study of autocracy and democracy: A preliminary note. Sociometry, 1(3/4), 292-300.

Lick, D. W. (2002). Leadership and change. In R.M. Diamond (Ed.), Field guide to academic leadership (pp. 27-49). San Francisco, CA: Jossey-Bass.

Little, S. D. (2010). Perceptions or reality? A frame analysis of leadership behavior, and effectiveness among selected community college administrators. (Doctoral dissertation). Retrieved form ProQuest Digital Dissertations. (AAT 3439268)

Maitra, A. (2007). An analysis of leadership styles and practices of university women in administrative vice presidencies. (Doctoral dissertation). Retrieved form ProQuest Digital Dissertations. (AAT 3260135)

Manning, G., and Curtis, K. (2011). The Art of Leadership, (4th ed.). New York, NY: McGraw-Hill. 
McArdle, M. M. (2008). Leadership orientations of community college presidents and the administrators who report to them: A frame analysis. (Doctoral dissertation). Retrieved from ProQuest Digital Dissertations. (AAT 3335355)

Middlehurst, R. (2010). Sustaining leadership in challenging times. Higher education management and policy, 22(3), 73-91.

Napier, N. K. (1996). Alice in Academia: The department chair role from both sides of the mirror. In Rhythms of academic life, ed. R J. Frost and M. S. Taylor, 313- 20. Thousand Oaks, CA: SAGE.

Parry, A. E. \& Horton, M. J. (1998) Finding, not looking, for leadership: a case study using the Bolman and Deal Model. Journal of Leadership Studies, (4)5, 122-130.

Phillips, E. D., Ruiz, J., \& Mehta, H. (2006). Industry members evaluate the strengths and weaknesses of aviation management graduates. Collegiate Aviation Review, 24(1), 120-131.

Phillips, R. S. (2012). Perceived leadership styles and effectiveness of aviation program leaders: A four-frame analysis. (Doctoral dissertation). Retrieved from ProQuest Dissertations and Theses. (1020617160)

Senko, K. A. (2010). Qualitative phenomenological study of leadership perspectives in commercial airlines. (Doctoral dissertation). Retrieved from Proquest Digital Dissertations. (AAT 3425619)

Stogdill, R. M. (1948). Personal factors associated with leadership: A survey of the literature. The Journal of Psychology, 25, 35-71.

Sypawka, W. (2008). A study of division deans' in the North Carolina community college system self-perceived leadership styles based on Bolman and Deal's four frame theory. (Doctoral dissertation). Retrieved form ProQuest Digital Dissertations. (AAT 3303589)

Tedesco, P. T. (2004). Leadership style comparison: Iowa community college presidents and superintendents and the ideal leadership style perceived by the board presidents of these organizations. (Doctoral dissertation). Retrieved form ProQuest Digital Dissertations. (AAT 3143865)

Tingey, K. M. (1997). College and university presidential leadership: Framed by leadership orientation and institution type. (Doctoral dissertation). Retrieved from ProQuest Digital Dissertations. (AAT 9717721)

University Aviation Association. (2012). UAA Homepage. Retrieved from: http://www.uaa.aero/ 
University of Texas. (2013). Instructional Assessment Resources Page. Retrieved from: http://www.utexas.edu/academic/ctl/assessment/iar/teaching/ gather/method/survey-Response.php

Vroom, V. H., \& Yetton, P. W. (1973). Leadership and decision-making. Pittsburgh, PA: University of Pittsburgh Press.

Wolverton, M., \& Ackerman, R. (2006). Cultivating possibilities: Prospective department chair professional development and why it matters. Planning for Higher Education, 34(4), 14-23.

Wolverton, M., Gmelch, W.H., Wolverton, M. L., \& Sarros, J. C. (1999). Stress in academic leadership: U.S. and Australian department chairs/heads. The Review of Higher Education, 22(2), 165-186. 


\title{
Economic Modeling to Improve Estimates of the Benefits of Safety Management Systems
}

\author{
Kelly Whealan George \\ Embry-Riddle Aeronautical University
}

\begin{abstract}
Safety Management Systems (SMS) in aviation have the potential to minimize costs, protect profits, and increase shareholder value. However, a gap exists in SMS research between the acknowledged safety benefits of SMS and the identified economic benefits. In the current competitive marketplace, SMS will need to demonstrate economic viability through modeling before industry leaders are likely to adopt a voluntary process. This paper reviews the literature related to a variety of possible economic models applicable to measuring the benefits of the application and implementation of SMS in aviation organizations. While the ultimate goal is to increase safety, the utilization of a model chosen based on the needs of the organization, could encourage voluntary adoption of SMS before regulations make it mandatory. The model will better inform the adopters of SMS of benefits and the processes themselves so that SMS does not degrade into a focus on following process steps rather than improving safety. Using good models that estimate the benefits of SMS would facilitate decision making as well as support the implementation of SMS.
\end{abstract}

\section{Introduction}

Incidents, accidents, and poor product and service quality due to safety challenges are part of the quantifiable costs of doing business. However, Roth (2004) questioned whether or not these are a required cost of doing business. Economist Milton Friedman maintained that the business of business is business (Davis, 2005). Combining Friedman's statement with Drucker's (1986) principle that the minimization of loss is the charge of business, are the costs associated with incidents, accidents and poor quality really a required cost of business? Cox and Flouris (2011) presented a simple spreadsheet tool to enable aviation safety officers to present their safety proposals with return on investment (ROI) measures in the language of Chief Financial Officers (CFO). As safety increasingly becomes a cost liability for businesses, it needs to be viewed as a value-producing center rather than a regulatory compliance center (Rosenkrans, 2011). Economic modeling of SMS implementation could increase the likelihood that organizations aggressively embrace SMS principles rather than just follow additional steps required by the regulators.

While not restricted solely to the aviation industry, studies show that $85-95 \%$ of accidents are caused by what employers or employees choose to do (Adebiyi, CharlesOwaba, \& Waheed, 2007). It is clear from the Federal Aviation Administration (FAA) and International Civil Aviation Organization (ICAO), SMS is quickly becoming a requirement in the aviation industry. Both the FAA Advisory Circular 120-92a and ICAO's Safety Management Manual provides guidance for the implementation of SMS from a regulatory frame of reference (FAA, 2010a; ICAO, 2009). The four components 
or pillars of SMS are policy, risk management, safety assurance, and safety promotion (FAA, 2010a; ICAO, 2009; Stolzer, Halford, \& Goglia, 2008). SMS is the continual process of formalized assessment of processes intended to identify issues prior to crisis, fix them and assuring they remain fixed in an effort to continually improve the safety of the aviation system. If accident costs can be mitigated or controlled through the implementation of Safety Management Systems (SMS), then the business of business would oblige leaders of these organizations to put a system into place that minimizes the cost of doing business and protects profits and increases shareholder value. Leaders would have a powerful economic incentive to implement SMS. The cost of employing SMS would be viewed as a source of profit management rather than a regulatory burden, gimmick, or fad program for those organizations that have not been early adopters of SMS (Lenz, 2012).

While the costs of implementation of an SMS can be transparent, the benefits of an SMS are not as readily available and quantifiable, nor is there one accepted approach or standard in the industry. An apparent gap exists in the SMS discipline where sound economic models can be applied to incentivize industry leaders to adopt SMS as a core operation within their organizations based on generally accepted economic valuation of the output (Stolzer, Halford, \& Goglia, 2008). Unfortunately, in the current competitive marketplace where every cost is scrutinized and many times safety isn't a problem until the accident happens to your company, safety officers need to demonstrate economic viability of safety improvements through modeling before industry leaders are likely to adopt a voluntary process that increases costs (Stolzer, Halford, \& Goglia, 2008). Esquer-Peralta, Velaquez, and Munguia (2008) found that $43 \%$ of their surveyed sustainability management system experts declared that having a clear understanding of the long-term economic benefits for the company is an important incentive for their implementation of a management system. In order to better illustrate the economic benefits of the application and implementation of SMS in aviation organizations, this paper reviews the literature related to a variety of possible economic models.

\section{Why Economic Principles?}

In the late 20th century, the discipline of economics evolved to include a branch that studied risk-based modeling including probabilities of events over time rather than pricebased modeling that simply weighed the costs against direct benefits. The study of risk views variations in values over time as more important than actual experienced price or cost. Using risk-return tradeoffs, better informed decisions can be made. SMS essentially strives to make informed decisions on risk-return trade-offs. Under SMS, risk is reduced to an acceptable level by engineering out presented hazards. By removing or significantly reducing the risk, costs are minimized and expenditures for adverse incidents can be more closely controlled. Financially, residual risk can be transferred to a third party through insurance contracts for a premium (Roth, 2004). Numerous studies exist and conclude that the financial performance of SMS adopters outperforms nonadopters (Bottani, Monica, \& Vignali, 2009). From these studies one can implicitly conclude that adoption of SMS is positively financially rewarded. Further, by using economic modeling to explicitly quantify benefits, businesses could be better 
incentivized to engage in processes under SMS to do the business of business. Moreover, as previously mentioned, the business of business is minimizing losses.

\section{Literature Review of Possible Economic Models}

Various measurement models of the benefits of safety programs have been employed within the aviation industry and in other industries. Each modeling framework has pros and cons depending on the specific situation. However, choosing the appropriate evaluation method should help focus the SMS effort from regulatory/compulsory adoption to voluntary industry adoption based on positive financial projections.

\section{Accounting Approach}

Friend (2011) and Skydel (2011) established a reactionary but basic direct accounting approach to estimate total business costs without SMS intervention. The direct accounting approach calculated the sum of possible losses (actual estimate of costs multiplied by the probability of occurrence) of the various activities under SMS using past recorded data of the organization or industry averages. They allowed that the possible loss calculation may also incorporate trend analysis and rates of growth of certain costs and incidents. This is a basic direct approach of estimating losses. However, it is backwards thinking or reactive in nature. It does not account for the constantly changing operations of the industry. It also does not include statistical concepts such as variability in probabilities of costs or risk used.

Some studies used cost estimates gathered by questionnaires from departments within an organization (Phelps, 1999). However, the cost estimates could be suboptimal as employees could inflate their estimates in an effort to increase their standing or importance in the organization. With those considerations in mind, using this method, objective estimates of costs should be used if the accounting approach is employed.

\section{Time-Driven Activity-Based Costing}

Time-driven activity-based costing (TABC) is a proprietary financial methodology developed by John Cox, CEO of Safety Operating Systems, and Triant Flouris, professor and Dean of Academic Affairs at Hellenic American University. The TABC aims to intentionally estimate an airline's organizational safety costs as an integrated organization using value-chain management. The accounting worksheet aims to identify or highlight variable and fixed costs for customization by safety officers who want to prototype their business. The developers claimed their model provides an accurate prediction of bottom line cost savings for safety proposals but no empirical justification was presented (Rosenkrans, 2011; Safety Operating Systems, 2012).

\section{Federal Aviation Administration's Return on Investment Simulator}

The Federal Aviation Administration (FAA) also developed an accounting worksheet and Microsoft PowerPoint training course designed to assist safety managers in communicating with their respective financial specialists about strategic safety decisions. 
The worksheet estimates benefits of expected expended costs and frequencies, and probability of safety events over six quarters. Each calculated ROI presents before-safety and after-safety measure values. The higher the ROI, the more money the airline would make from the safety investment (Rosenkrans, 2011). While basic and direct, the simulator can be manipulated with incorrect input data. The adage of garbage in, garbage out leads any model to calculate inaccurate estimates. However, the simplicity of the model would be attractive to self-directed safety officers intending to convey the benefits of investment in SMS in the organization as well as any perceived endorsement by a regulatory body.

\section{Cost-Benefit Analysis using Historical Data}

The FAA's initial regulatory evaluation estimated the benefits of implementing SMS on Part 121 operators using a cost-benefit approach that can be scaled down to a single organization. The FAA determined that in the past ten years, 172 accidents could have been prevented in whole or in part with SMS in place. The FAA used actual economic value from these accidents and then took $50 \%$ of the actual losses for 167 of the accidents and $5 \%$ of the remaining 5 more serious accidents that resulted in other policies and procedures changes. The FAA based their $50 \%$ reduction value from reductions in losses due to safety as a result of SMS implementation in non-aviation organizations. Organizations adopting Voluntary Protection Programs (VPP) typically experience a 10$20 \%$ reduction in losses. However, the FAA reasoned the more formalized and intensive nature of SMS warrants a higher expectation of reductions in losses due to safety issues. The FAA also delayed benefit accumulations until the third year after implementation (Federal Aviation Administration, 2010b). This approach is wholly reactive thinking as it uses past experience as a fair representation of future expectations in a constantly evolving industry.

\section{Cost-optimization Algorithms Combined with Probable Risk}

Cost optimization algorithms can be employed in a simulation including a budget constraint. Similar to the cause and effect diagram presented by Stolzer, Halford, and Goglia (2008), a fault tree analysis is combined with expectations of primary failure probabilities and cost parameters at the lowest level of the hierarchy of events in the fault tree. Minimizing lower level primary failures will minimize top level critical failures. Proactively, engineering solutions to predictive primary failures could be employed to lower the probability of failure to minimal accepted levels or limits. The entire system is subject to a budget constraint. Businesses can invest an enormous amount of resources in order to increase savings. By employing a cost sensitivity priority ranking of failures, this simulation informs management which failures are most costly, and which low level failures must be prevented in order to lower the probability of top level critical failures and the benefits of proactive SMS activities. Management could forecast where they would experience the biggest minimization of the failure cost and thus a lowering of the probability of a top level critical failure (Ben-Yair, 2004). These minimizing of cost failures are a proxy for the benefits of implementing SMS within the organization. A major drawback of this analysis is that it omits the human factor in quality escapes that 
are a critical piece of managing safety assurance that is different from a traditional quality assurance framework (Stolzer, 2012).

\section{Analytical Hierarchical Process}

Analytical hierarchical process (AHP) is not necessarily an economic model, but can be applied to economics as a technique that breaks down a complex process into subprocesses that include human decisions, and assigns numerical values that represent priority, weighting, or significance levels of each sub-process in the overall process. AHP as used in VPP can be extended as a rank-ordered cost-benefit quantitative measure of the inclusion of SMS to an organization which can then inform policy and priorities. Within this process, each element of the SMS is detailed into a pair of event options. One such element within SMS could be a hypothetical checklist that could include either checking air pressure on airplane's tires at each gate location, or alternatively, at the beginning of each day of service. Once all the elements in a process are detailed, an analyst must then prioritize the elements in order of desirability or importance. Each pair is then valued, once for the costs required to apply SMS principles to the element and once for the perceived benefit of application of SMS principles to the element. The element values can then be transformed into a benefit to cost ratio that was created using expert judgments and experience (Jervis \& Collins, 2001).

This process informs SMS in two ways. First, the estimate of benefits is determined by those who would be involved in the implementation of SMS. Hence, the importance of SMS buy-in, which is a difficult intangible cost and benefit to estimate, by those who would be affected are built into the analysis of proposed benefits of elements. Second, with budget constraints, the ranking of the benefit to cost ratios can inform management which elements of the SMS will have the maximum impact and thus be considered the easiest achievable targets that yield the greatest benefits. The resulting estimates of benefits would not necessarily result in an aggregate benefit of implementing SMS within an organization. The real illumination of benefits would be at the granular level of each process that was evaluated. A drawback of this method is that it would be involved and time consuming to tabulate the numerical values at each sub-process.

\section{Simulation Model Using System Dynamics and Data Mining}

The models presented thus far omit two important factors, organizational and management factors. The hierarchical decision making processes described above used as an indicator of savings from safety improvements assume accidents result from a chain of events or are limited to component failures. A simulation employing a system dynamics approach incorporates more complex relationships between the four pillars of SMS: policy, safety risk management, safety assurance, and safety promotion. System dynamics models would incorporate human decision making and system drift over time towards an accident (Charles-Owaba \& Adebiyi, 2006). Possibly more important to preventing accidents is identifying negative organizational behavior while submitting to cost-efficiencies in aggressive competitive environments (Ives, 2002; Rasmussen, 1997). Combining historical data of accidents that include management failures with systems 
dynamics models can yield estimates capturing both the human factors plus component failure values.

Applications of systems dynamics models are typically found in manufacturing industries. Since the FAA uses benefit gain estimates from adapting SMS from the manufacturing industry to evaluation of Part 121 operators, system dynamics estimates from manufacturing industries could also be transferrable (FAA, 2010b). Strengthening this model to evaluate the benefits of an SMS should include the incorporation of the human decision making factor or human-machine interaction that is often present in aviation accidents (Whealan George, 2012).

Using Forrester's (1973) conventional simulation model synthesis methodology, Charles-Owaba and Adebiyi (2006) used modeling to evaluate safety at a manufacturing bottling company. The simulation model was built on a pre-safety program period in the manufacturing company and then run for predictions and evaluated against a post-safety program implementation. Some assumptions were unrealistic, such as zero inflation and a stable government policy. Yet, the model still performed well and could assist the SMS planner to monitor and control SMS. Moreover, the model resulted in a good estimate of benefits of a safety implementation as there was no difference in the mean predicted benefit value and the actual benefit value.

One caution should be noted, this is not a perfect translation of methodology from one industry to another. Occupational safety is different than catastrophic aircraft accident risk where the aircraft accident risk has a low probability of occurrence making it particularly difficult to predict benefit values. Occupational safety accidents have, in general, a higher probability of occurrence and therefore predicting benefit values is less difficult.

\section{Baldrige Performance Excellence Model}

Recall that the very definition of SMS is a risk management system built on Quality management system (QMS) principles. The QMS principles are the policies and procedures used to improve the business processes that will result in improved organizational performance (Stolzer, Halford, \& Goglia, 2008). The Malcom Baldrige National Quality Improvement Act of 1987 sought to enhance U.S. business competitiveness by improving quality and productivity. The Baldrige performance excellence model (BPEM) estimates the net social value of improved quality performance. Benefits of safety improvements are beyond financial terms and include the value society receives by an improved, sustainable performing industry that has public confidence (Link \& Scott, 2011). If SMS is based on QMS principles, then estimating benefits using the BPEM would be appropriate. Researchers studied what the private sector would have to invest to achieve the same level of benefits provided through the publicly funded BPEM.

Benefits for organizations implementing a performance excellence program using the Baldrige criteria exceeded the quantifiable gains and losses on an organization's income statement. They included three categories of social benefits: gains to consumers from 
higher quality products, value created for the organization from the publicly funded Baldrige Performance Excellence Program, and macroeconomic gains by saving scarce resources. In 2010, the most inclusive and conservative BPEM benefit to cost ratio estimated that the social benefits are 820-to-1 and representative of most industry sectors. This means there was an $\$ 820$ dollar return on every $\$ 1$ spent in QMS using Baldrige criteria for Baldrige award applicants. It is important to note, this measure is not specified for the organizational gain but the entire economy's impact (Link \& Scott, 2011). While this is not an organizational bottom line estimate of benefits, it certainly makes the case for benefits of engagement in SMS using Baldrige Criteria that would result in cost advantages for the organization.

\section{Contrarian View of Safety at Any Cost and Modeling Benefits}

Vasign, Fleming, and Tacker (2008) seem to suggest that despite the various ways of measuring benefits, safety may have reached a long term economic equilibrium. The accident rate of commercial aircraft accidents per million departures in the United States decreased significantly from 1949 into the mid-1980s, stagnated, and then decreased further through 2009 (Moses \& Savage, 1990; NTSB, 2011). Conceivably, accidents could be reduced even further with SMS, but the costs of doing so would be higher than the benefits received and intangibles become difficult to measure. These intangibles could include passenger reaction, labor reaction, stock market effects, liability risks, and government enforcement (Kaplinski \& Levy, 2010). As an example, the FAA did not mandate child restraint seats on commercial airlines. With air travel and driving as substitutes, requiring families to purchase additional airline tickets increases the net number of fatalities as driving is more dangerous than flying and passengers would opt to drive (Coats, 2010).

In addition to questioning the cost-benefit of adopting SMS, Vasign, Fleming and Tacker (2008) remarked that these models may not be the best way to fairly evaluate the benefits of SMS. This statement is further justified as safety regulations are typically put into place without thorough economic consideration of unintended consequences despite regulatory impact assessments. Historically, some safety regulations are enacted due to potential threats in response to media-hyped passenger concerns that really do not affect safety. Others are just plain political processes. Even Stolzer, Halford, \& Goglia (2008) noted the purpose of the 1995 Aviation Safety Summit was to improve safety and increase public confidence. Public confidence is not a core value of SMS and clouds the economic valuation models, but it is a reality of the industry and government. Vasign, Fleming, \& Tacker (2008) cited the "Southwest rule" (p. 347) example or the regulation banning push-back until all passengers are seated. The authors state the rule was adopted because of political pressure from competitor airlines lobbying against Southwest's gate turn around and taxiing practices rather than a safety-inducing practice where financial benefits outweigh the costs. "It is probably true that, contrary to popular belief, aviation safety and security exceeds the levels that might be considered economically efficient" (Vasign et al., 2008, p. 347).

Robert Poole, head of the National Reason Foundation argued that measurement of the benefits of safety would be much more straightforward if regulations were privatized, 
similar to what Lenz (2012) proposed in an effort to remove the unintended effects of the punitive nature of safety data reporting (Andrade, 1987). A privatized regulatory system includes private third parties and insurers that have a vested interest in aviation safety. These third parties would be interested only in measures that improve safety and would charge lower premiums for organizations that meet a specific threshold for safety and higher premiums for those organizations that take on higher risks. In an effort to minimize costs, organizations would adopt SMS as a core operational business practice. Private regulators would not be able to demand any corrections where problems may exist. The market would incentivize undue risk and the entire model would take on a purely economic paradigm instead of being influenced by political or media interests. In theory, the private regulator that publishes records could be fired if they do an inadequate job. This model is unlikely to be politically attractive any time soon given the financial industry's recent experience with private monitors like S\&P or Moody's not properly examining and publishing data that reflected the true status of the banks, financial companies, and financial products that led to the subsequent collapse of 2008.

\section{Discussion and Recommendations}

It is clear from the FAA and International Civil Aviation Organization (ICAO;) SMS is quickly becoming a requirement in the aviation industry. Both the FAA Advisory Circular 120-92a and ICAO's Safety Management Manual provides guidance for the implementation of SMS from a regulatory frame of reference (FAA, 2010a; ICAO, 2009). Over time, perhaps clear financial benefits and resource savings will offer SMS greater acceptance by organizations as a beneficial proactive business practice instead of regulatory compliance. But, until that premise is widely accepted in the industry, commitments to safety as a core business operation will most likely be driven by regulatory requirements rather than financial rewards.

Regulations or government standards are often viewed as an unnecessary increase in an organization's costs (Charles-Owaba \& Adebiyi, 2006). However, if an acceptable model for estimating the benefits of adopting and implementing SMS were developed, then some of the peripheral perception of unnecessary increased costs by those in the field, and the leaders of the organizations themselves, could be overcome. As mentioned before, the business of business is business and undertaking the best processes to run a profitable, sustainable business that is also in compliance with current regulations should be the main goal of top management of an organization. Using good models that estimate the benefits of SMS would facilitate decision making as well as support the implementation of SMS. This could also serve as part of the metrics of the assessment of SMS (Charles-Owaba \& Adebiyi, 2006; Stolzer, Halford, \& Goglia, 2008).

All the models presented have advantages and disadvantages and review of the relevant literature has not yielded specific guidance on what model would be considered best. Some smaller organizations may want to initially employ the simple cost accounting or historical cost-benefit model in order to estimate the benefits. The understanding needs to be that the models are limited to event-chain measures. Other more complex organizations should employ the systems dynamics models to capture the interaction of human actions with systems and the resultant organizational drift to best 
estimate SMS's benefits. While the drawback to systems dynamics is that it is a complex model to run and certainly not a back-of-the-envelope or spreadsheet model, it incorporates the many human factors present in organizations utilizing both a historical and predictive perspective.

The functionality and user friendliness of any model may be the first criteria for selection of a model. The second criteria may be the model that speaks to the organization's management in their financial language. The FAA and the TABC - both commercial accounting models - intend to be user-friendly models that will deliver the positive, bottom-line message of a proactive SMS to Chief Executive Officers/Chief Financial Officers better and may be the best operational tool for estimating benefits in a competitive marketplace. The utilization of an economic model, whichever one is chosen based on the needs of the organization, would be a significant management tool to help reach the ultimate goal of improved safety. The model will better inform the adopters of SMS of benefits and the processes themselves so that SMS does not degrade into a focus on following process steps or managing a model rather than improving safety. Once organizations commit to using an economic model as part of their SMS implementation, they will need to decide which method of analysis is appropriate for their circumstances. The body of knowledge on this subject needs to be strengthened with a study that evaluates which model is the best for SMS estimations and deserves future research. 


\section{References}

Adebiyi, K. A., Charles-Owaba, O. E., \& Waheed, M. A. (2007). Safety performance evaluation models: A review. Disaster Prevention and Management, 16(2), 178-187. doi:10.1108/09653560710739504

Andrade, K. (1987). Next step in air deregulation: Sell air traffic control system. Pacific Business News, 24(51), A-A.

Ben-Yair, A. (2004). Cost-optimization heuristic algorithm in safety engineering. International Journal of Production Economics, 91(2), 149-164.

Bottani, E., Monica, L., \& Vignali, G. (2009). Safety management systems: Performance differences between adopters and non-adopters. Safety Science, 47(2), 155-162. doi:10.1016/j.ssci.2008.05.001

Charles-Owaba, O. E., \& Adebiyi, K. A. (2006). The development of manufacturing safety programme simulator. Journal of Modeling in Management, 1(3), 270-290. doi:10.1108/17465660610715249

Coats, M. (2010). Safety in the sky and safety on the highway [Web log post]. Retrieved from http://www.nicholls.edu/bastiatsbastions/2010/11/09/safety-in-the-sky-andsafety-on-the-highway/

Drucker, P. (1986). The practice of management. New York, NY: Harper-Collins.

Esquer-Peralta, J., Velazquez, L., \& Munguia, N. (2008). Perceptions of core elements for sustainability management systems (SMS). Management Decision, 46(7), 10271038. doi:10.1108/00251740810890195

Federal Aviation Administration. (2010a). Safety management systems for aviation service providers Washington, DC: Author.

Federal Aviation Administration. (2010b). Initial regulatory evaluation: Safety management system for domestic, flag, and supplemental operations. (Notice of Proposed Rulemaking). Washington, DC: Author.

Friend, M. (2011). Top management support. In A.J. Stolzer, C.D., Halford, \& J.J. Goglia, (Eds.), Implementing safety management systems in aviation (1st ed., p. 89). Burlington, VT: Ashgate Publishing.

International Civil Aviation Organization. (2009). Safety management manual (2nd ed.). Quebec, Montreal, Canada: Author.

Ives, S. (2002). Targeting specific accidents in workplace, Engineering Technology, July/August, 12-13. 
Jervis, S., \& Collins, T. R. (2001). Measuring safety's return on investment. Professional Safety, 46(9), 18-23.

Kaplanski, G., \& Levy, H. (2010). Sentiment and stock prices: The case of aviation disasters. Journal of Financial Economics, 95(2), 174.

Lenz, P. (2012). Impediments to data sharing. [Online forum comment] Retrieved from https://erau.blackboard.com/

Link, A. N., \& Scott, J. T. (2011). Economic evaluation of the Baldridge performance excellence program. (Planning Report No. 11-2). Washington, DC: National Institute of Standards and Technology.

Moses, L. N., \& Savage, I. (1990). Aviation deregulation and safety: Theory and evidence. Journal of Transport Economics and Policy, 24(2), 171-171.

National Transportation Safety Board (2011). Review of U.S. Civil Aviation Accidents, 2007-2009. Annual Review NTSB/ARA 11/01. Washington, DC: Author.

Phelps, G. R. (1999). Safety for managers. Farnham, UK: Gower.

Rasmussen, J. (1997). Risk management in a dynamic society. Journal of System Safety, 27(2/3), 21-3.

Rosenkrans, W. (2011). Financial SMS. Aerosafety World Magazine, December 2011 January 2012. Retrieved from http://flightsafety.org/aerosafety-worldmagazine/december-2011-january-2012/financial-sms.

Roth, C. L. (2004). The role of the ergonomist as a business management asset. Occupational Hazards, 66(9), 93-101.

Safety operating systems. (2012). Retrieved from http://www.safeopsys.com/.

Skydel, S. (2011). Collision avoidance: Measuring the benefits of onboard safety systems. Fleet Equipment, 37(8), 30-32.

Stolzer, A. J. (2012). Re: SA vs. QA - Ostrowski. [Online forum comment]. Retrieved from https://erau.blackboard.com/.

Stolzer, A. J. (Producer), (2008). Is SMS a safety program. [Video] Daytona Beach, FL: Embry Riddle Aeronautical University - Worldwide.

Stolzer, A. J., Halford, C. D., \& Goglia, J. J. (2008). Safety management systems in aviation. Burlington, VT: Ashgate.

Vasign, B., Fleming, K., \& Tacker, T. (2008). Introduction to air transport economics. Burlington, VT: Ashgate Publishing. 
Whealan-George, K. A. (2012). Standardization can omit critical information. [Online forum comment]. Retrieved from https://erau.blackboard.com/. 


\title{
Implementing Jet Aircraft Training in a University Setting: Instructor Perceptions and Lessons Learned
}

\author{
Scott R. Winter, Jennifer E. Kirschner, Steven M. Leib, and Richard O. Fanjoy \\ Purdue University
}

\begin{abstract}
This paper presents the findings of a phenomenological study of instructor pilot first-hand experiences when conducting training for collegiate flight students in a jet aircraft. While jet training has been conducted in simulators in the past, this was one of the first instances of training in an actual aircraft. A total of 22 students completed training in a very light jet aircraft during the spring semester of their junior year at the subject university. A group of four instructors conducted both simulator and flight training with the students. Surveys were used to collect data from instructors longitudinally throughout the length of the 16-week semester. At the conclusion of the training period, participants completed a structured interview. The results of those interviews suggested that students excelled in areas such as avionics programming, use of standardized operating procedures, and checklist usage. Students were challenged by the increased operating speeds of the jet aircraft, descent planning, and lesson preparedness. The instructors offered suggestions to enhance the course and provided a summary of the lessons learned.
\end{abstract}

Authors' Note:

A portion of this work was previously presented at the Human Factors and Ergonomics Society's 56th Annual Meeting in Boston, MA October 22-26, 2012, in the Student Conference Proceedings.

\section{Introduction}

Within university flight training programs, the use of jet aircraft has typically been limited by high operating costs. While some training programs provide ride along observations, few, if any, provide formal training in an actual aircraft. However, the subject university recently purchased a very light jet (VLJ) for use in the flight-training curriculum. For the first time, instructors are providing training to low-time pilots during a 4-year professional flight degree who recently completed their multi-engine commercial certificates with an instrument rating. The experiences and perceptions of these instructors provide valuable information as the first cohort of students' complete training. The researchers will report on four areas of findings: responses to surveys, internal training challenges, external training challenges, and areas of student strengths. Finally recommendations that might be used to modify and improve the curriculum will be provided. This paper provides a synthesis of the collected data and provides recommendations for future areas of research.

\section{Aim of the Study}

This study was grounded in a qualitative, phenomenological approach. The aim was to collect first-hand experiences from the instructor pilots conducting simultaneous 
training in both a jet simulator and a jet aircraft to gather their perceptions on the strengths and challenges of students completing this course. Students enrolled in the subject university's professional flight program completed a 10-hour training course in the aircraft. The 10-hour course consists of approximately: 3 hours practicing maneuvers, takeoffs, and landings; 2 hours practicing instrument approaches; 1 hour practicing single-engine procedures and a simulated emergency descent; 2 hours of copilot orientation to complete an SIC endorsement; and 2 hours completing a line orientated flight training lesson. At the completion of training, students earn a second-incommand endorsement for the Phenom 100 aircraft and a high altitude endorsement.

Of special interest are the issues and perceptions of the instructors as the training program unfolded, the level of student performance, and the preparedness of students completing the training. As a goal of the study was to gather data on the lived experiences of instructors who had all experienced the same training environment, along with this approach to civilian, university flight-training, a phenomenological study was deemed the most appropriate method of study to capture this data (Creswell, 2007).

\section{Literature Review}

The review of literature is broken down into two major sections. First, the authors will provide a review of recent legislation that may change the minimum training requirements of airline first officers. While the direct impact of this legislation is still to be seen, it is expected to have an impact on university aviation flight-training programs. The second section will provide information on jet training issues identified in previous literature, with a focus on very light jets and the ability of piston aircraft pilots to transition to larger transport category aircraft.

\section{Impetus for a Training Change}

In response to concerns over the standards of airline safety, specifically at the regional airline level, President Obama signed the Airline Safety and Federal Aviation Administration Act of 2010 into law on August $1^{\text {st }}, 2010$. The repercussions of this new legislation are yet to be seen. One of the more prominent items is the requirement for all airline first officers to hold airline transport pilot certificates (111th Congress, 2010). While the scope of this legislation lies outside the current research project, it will likely have an impact on how universities complete flight training. A debate has begun within in the industry on how "safe" pilots are produced - by attaining a certain quantity of flight hours or through the quality of the flight training received.

The Aviation Accreditation Board International (AABI) and the University Aviation Association (UAA) jointly undertook the task of identifying the characteristics of pilots who were most successful during regional airline pilot training. Smith, Bjerke, NewMyer, Niemczyk, and Hamilton (2010) studied characteristics of pilots hired by regional airlines from 2005 to 2009 and attempted to address how these characteristics related to their 
success at regional airlines. Six regional airlines were contacted to participate in the study and provide data for the researchers to review. However, because there is currently little standardization required in terms of employment record keeping, the researchers could only review outcomes common among all six airlines. The two main outcomes reviewed were "(a) how many times did the pilot need to repeat the elements of indoctrination training, and (b) whether the pilot completed the full training program at the airline" (Smith et al., 2010, p. 77). In the results of their study, Smith et al. (2010), reported that more than half of the pilots reviewed during their study had an aviation-related bachelors degree, were flight instructors who had less than 1,000 hours of flight time, and did not have any prior airline experience. Pilots who completed training in a university flight environment did comparatively better at airline training then counterparts who completed training at a non-university part 141 program or through part 61 training. Research has begun to examine the minimum experience necessary for first officers, and this study examines the practical issues that can arise when instructing collegiate students in a jet aircraft. It was also found that the group that was most successful were those pilots who had 501-1000 flight hours, compared to groups consisting of 178-500, 1001-1500, or greater than 1500 hours. While the study provides interesting information, the authors did note a small effect size. Recommendations for further research into this topic included a need to identify standardized parameters across the surveyed airlines to ensure simultaneous and similar data collection prior to the analysis.

\section{Jet Aircraft Training and Transition Issues}

The International Very Light Jet Training Stakeholders' Discussion Group surveyed 389 stakeholders about VLJ training practices currently used throughout the country (Barnes, 2008). Respondents expressed concern that "VLJs may experience a surge of early deliveries and rapid growth followed by a series of tragic and preventable humancaused accidents" (p. 2). Similarly, a review of National Transportation Research Board (NTSB) accident and incident reports found that VLJ pilots were more likely than pilots of other types of aircraft to have difficulty with landings, experience low fuel situations, be unfamiliar with aircraft avionics, not have flown recently, use poor crew (or single pilot) resource management, and lose situational awareness (Burian, 2007). Lack of experience in a particular aircraft is a common thread in all of these situations. Operating jets substantially increases the complexity and performance demands on pilots (Burian \& Dismukes, 2007). Despite this, VLJs are growing in popularity with little apparent change in the assessment and selection process of pilots.

While the European Joint Aviation Authority (JAA) is in the process of designing a required training program for all type ratings - VLJs included - the FAA has yet to establish a minimum experience level beyond that required to fly any multi-engine aircraft: a private pilot license with multi-engine rating (Barnes, 2008). The National Business Aviation Association (NBAA) has recommended that manufacturers conduct a "flight skills assessment" with each potential VLJ pilot, and consider an applicant's "experience and knowledge, recency of experience, background, and type of experience" 
to determine a candidate's likelihood of success in a training program (National Business Aviation Association, 2005, section 3.1).

Casner (2003) studied a sample of pilots during training to see how familiarization with a small aircraft GPS system would transfer to an airline style flight management system (FMS). Two experiments were completed. In the first, students who completed training on the GPS were able to complete $77 \%$ of the tasks on the FMS, a statistically significant improvement over the control group that received no prior instruction. In the second part of the study, participants were either given a self-study course or dual instruction on light piston aircraft automation. Participants that completed the self-study course did slightly better in the actual practice of those skills than did the participants in the dual instruction course. In a later study, Casner (2005) trained a group of participants to be proficient in a technologically advanced aircraft (TAA). The experimental group and an untrained control group then completed tasks in a jet transport aircraft simulator. The trained group was able to complete $83 \%$ of the tasks, compared to $54 \%$ of the control group (Casner, 2005). The findings of these two studies suggest that light piston aircraft automation may provide a positive transfer of learning to jet aircraft. The subject university of the current study utilizes a fleet of technologically advanced aircraft, with a similar avionics package to the VLJ, to complete primary training.

\section{Method}

\section{Participants}

All four instructor-pilots who volunteered to participate in the study served as training captains and completed training in both the simulator and jet aircraft. The participants consisted of one female and three males; all had prior experience in Part 121 operations. Study participants averaged 9,125 total flight hours - 7,600 hours in turbine operations, 1,260 hours of dual given, and four type ratings. The average age of participants was just under 45 years old. Three participants were trained in civilian flight programs and one participant had completed military flight training. Only instructors responsible for student training in both the simulator and jet aircraft were selected, excluding instructors who only supervise simulator training. Participants were solicited via an introductory e-mail and all volunteered to participate in the study. A limitation of this study was the small sample size, which may limit the generalizability of the findings.

\section{Materials}

The researchers distributed three paper surveys (at the beginning, middle, and end of the course) and conducted an in-person interview (at the end of the course). The surveys were administered electronically and participants' had the option of completing them online or by hand. At the conclusion of the project, interviews were conducted with all participants. Interviews were recorded, transcribed, and reviewed for accuracy by the 
researchers. The audio recordings were then deleted to preserve the anonymity of participants.

\section{Research Design and Procedure}

Interviews are typically the most common data collection tool within a phenomenological study (Creswell, 2007). However, because this was an exploratory study into a new experience, the researchers also decided to utilize survey instruments to collect data longitudinally to support the development of interview questions. The surveys were administered three times throughout the longitudinal study and given to participants at the beginning, middle, and end of the spring 2012 semester. Surveys attempted to capture the changing perceptions of instructors throughout the length of the training program. The survey instruments were constructed specifically for this research study. Content validity was obtained through analysis by aviation researchers with a background in providing training in jet aircraft. Participant surveys were examined longitudinally to examine responses for consistency and reliability. All survey items used open-ended, essay-style responses. Topics for response included perceptions of the training program, student strengths, student challenges, and overall program assessment. After all training was completed; interviews were conducted, ranging in length from 45 to 75 minutes. Interviews were semi-structured: all participants answered a series of approximately 20 questions, with follow-up questions added as deemed relevant, based on survey responses. All surveys were coded by hand. Interviews were coded both by hand and with the assistance of a qualitative software analysis tool. From the data analysis, the researchers grouped meaningful statements into larger themes. These themes are discussed in the results section and supported with statements from the participants. When coding the data, researchers used bracketing to account for their own experiences. Bracketing is the recognition that researchers have personal experiences, and it is an attempt to set aside those prior experiences to view the data with a fresh perspective (Creswell, 2007).

\section{Results and Discussion}

\section{Survey Responses}

The initial survey instrument was used to evaluate participants' concerns and issues regarding areas where students were likely to excel. Participants identified Garmin 1000 GPS operation, radio communications, standard operating procedures (SOP's), cockpit flows, checklist usage, and decision making as strong skills they expected the students to demonstrate during the training program. None of the four participants identified aircraft control as a skill at which the students were likely to excel. The participants stressed two major areas that may be problematic for new students: operating as part of a crew, and keeping up with the fast paced environment of the jet aircraft. 
When asked to express their concerns about students completing the training, the participants also focused on external issues. They agreed that the weather was a major concern and nearly all of them indicated aircraft availability (due to the number of students and the busy schedule of the aircraft) as factors that threated training completion and limit students' flight hours. Concern over descent planning and adjustment to the increased operating speed of jet aircraft were also expressed. Table 1 summarizes the strengths and challenges instructors anticipated for student performance from the first survey instrument.

Table 1

Initial Instructor Expectations for Student Performance

\begin{tabular}{|c|c|c|}
\hline Instrument & Anticipated Strengths & Anticipated Challenges \\
\hline Survey 1 & $\begin{array}{ll}\text { - } & \text { Avionics programming } \\
\text { - } & \text { Standard operating } \\
\text { procedures } \\
\text { - } & \text { Flow patterns and } \\
\text { checklist usage } \\
\text { - } & \text { Decision-making } \\
\end{array}$ & $\begin{array}{ll}\text { - } & \text { Adjusting to higher jet } \\
\text { airspeeds } \\
\text { - } & \text { Operating as a crew } \\
\text { - } & \text { Descent planning } \\
\text { - } & \text { Weather } \\
\text { - } & \text { Scheduling issues } \\
\end{array}$ \\
\hline
\end{tabular}

At the mid-point of the training program the participants indicated that students were performing checklists, standard operating procedures, and utilizing the Garmin avionics well; all items that participants anticipated students would be successful with completing. The anticipated challenge areas participants indicated on the initial survey were also observed. Instructors commented on how students were struggling to adjust to the faster speeds of operating the jet aircraft and the associated time management and prioritization required to accomplish tasks. Students were also challenged by some external factors such as the live air traffic control environment and busy airspace. These concepts will be discussed further in the external challenges section. The final area of note on the midpoint surveys was instructor concern with poor student preparation before flight and poor recall of memory items. Adequate time for pre- and post-flight briefings will be addressed in the internal challenges section.

Comments on the final survey indicated students continued to perform well using checklists, standard operating procedures, and avionics, although there was some lack of proficiency incorporating the auto flight control system (AFCS) with the avionics. Aircraft speed and descent planning were areas still challenging to students. Instructors also discussed issues students experienced when completing non-scripted items like the transition from en-route flight to traffic patterns with visual approaches. The instructors felt confident that the course provided a successful initial experience for students mastering the skills required to operate a jet aircraft in the national airspace system. A summary of the mid-point and final surveys is summarized in Table 2. 
Table 2

Observed Strengths and Challenges of Jet Students

\begin{tabular}{|c|c|c|}
\hline Instrument & Observed Strengths & Observed Challenges \\
\hline Survey 2 & $\begin{array}{ll}\text { - } & \text { Checklist usage } \\
\text { - } & \text { Standard operating } \\
\text { procedures } \\
\text { - } & \text { Avionics programming }\end{array}$ & 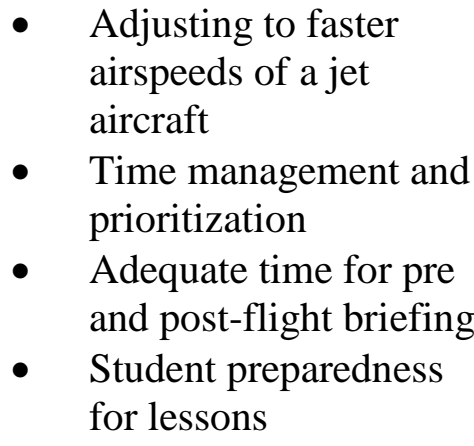 \\
\hline Survey 3 & $\begin{array}{l}\text { - } \quad \text { Checklist usage } \\
\text { - } \quad \text { Standard operating } \\
\text { procedures } \\
\text { - } \quad \text { Avionics programming }\end{array}$ & $\begin{array}{ll}\text { - } & \text { Aircraft speed } \\
\text { - } & \text { Descent planning } \\
\text { Dealing with non- } \\
\text { scripted items and } \\
\text { situation awareness }\end{array}$ \\
\hline
\end{tabular}

Survey responses were used to develop interview questions. Once the interviews were competed and transcribed, a search for common themes commenced. When addressing challenges faced by students, instructor pilots seemed to identify two themes: internal challenges and external challenges. The researchers defined internal challenges as those over which instructor pilots could exercise control, while external changes were those items caused by nature or other variables. The researchers also identified areas where students showed strength in the training program and provided suggestions for course improvement.

\section{Internal Challenges}

Internal challenges relate to items such as physical resources, time constraints for preand post-flight briefings, changing course objectives, and student preparedness. When developing the training schedule, there was a limit on physical resources: a single aircraft and four instructors. The aircraft was scheduled for two-hour time blocks, which copied the piston-training schedule at the subject university. However, an area of concern that arose from this type of scheduling was its limiting impact on pre- and post-flight briefing time. When instructors were scheduled with back-to-back lessons, it severely limited the amount of time for pre- and post-flight briefing time available for students because of the minimal time between flight lessons. All the instructors recognized this limitation and the need for more briefing time. Instructors recommended structuring the schedule to follow more of a Part 121 or military style of flight training, where 30-60 minutes of pre-flight briefing occur before flight and an additional 30-60 minutes of post-flight briefing upon 
return. The instructors felt that this change would allow time to discuss both the lesson objectives and the tasks to be completed during the lesson. One participant emphasized that as the one item he/she would change if it were possible to start the semester over, "I'd get more time for... briefing and debriefing the students." Another instructor commented, "If we had some pre-brief time ahead of time...the lessons would have been more productive too." A suggested change may be an attempt to alter the schedule of instructors in a way that would allow the aircraft to operate efficiently yet not force instructors in back-to-back training sessions, which limits the amount of pre- and postflight briefing time.

The "moving target" for course objectives was another challenge for the instructors. These objectives ranged from a basic familiarization course to possibly preparing some students for a type rating. "The objective of the course seems to be a moving target mostly because of the NPRM [notice of proposed rule making]," stated one participant. Understandably, the instructors had very limited goals for this first semester of training. Safety remained a prominent goal throughout the training program. "My approach, with no apologies, is I was going to be ultra conservative," explained one participant. As the program developed, it became clear that some students excelled faster than others. A suggestion of the instructors was to develop a tiered training program. An example of the tier system may require a certain letter grade in the ground school and simulator course before operating in the left seat of the jet, otherwise the student would be limited to the right seat. Instructors also encouraged an additional program that would allow the top percentage of students to complete an elective course in pursuit of a type rating. Students would have to be recommended by all or a majority of instructors to enroll in this course.

An internal challenge that was unanticipated was a lack of student preparedness. Instructors recounted how some students arrived unprepared for flights or without the necessary materials completed before the flight. One instructor commented, "I probably should have stressed some things more, of being more prepared when you show up." Some students also seemed to lack a thorough knowledge of cockpit memory items. A possible explanation for this is the difference in training environments between Part 121/military and university environments. In airline/military environments, the flight course is the primary responsibility of participants, whereas for university students, the flight-training course is just one of their responsibilities each semester. A participant commented, "It's the nature of the beast with the academic schedule to run that, unlike an airline training program, part 135 or part $91 \mathrm{~K}$ training facility, this isn't their only course." In the university environment, students are busy with other courses, projects, and activities. Instructors anticipated students would show up prepared for lessons, and it was somewhat surprising that some struggled in this role. A possible explanation may be the varying levels of maturity. College students may still be adjusting to their role as adult learners, and it may take some longer than others to accept the responsibility that accompanies operating a jet aircraft. Instructors have suggested the use of quizzes before certain flight lessons as a tool to motivate and confirm students are staying current on operating procedures, memory items, and limitations. 


\section{External Challenges}

External challenges identified by instructors were weather and situational awareness. The training program took place during the spring semester at the subject university, located in the Midwestern portion of the United States. This led to various weather situations from snow and ice to heat and humidity with thunderstorms. Instructors had to consider a number of factors when working to decide what weather minimums should be used for training because the jet could conduct training in situations that would normally ground a piston training aircraft. All instructors acknowledged the impact weather had on the training program. The instructors did feel that enough time was built into the program for student training completion as the weather improved later in the semester.

Situational awareness was an issue that instructors identified as challenging students - specifically involving external components such as air traffic control, other traffic, and situations that were not well scripted. This manifested most often during visual approaches to airports. In the simulator course completed prior to flying the jet, emphasis was placed on flying instrument approaches. Instrument approaches are standardized and very precisely timed, with the same tasks completed at the same points along every approach. However, when on a visual approach, these standardized procedures transition to the discretion of the student pilot. The student must decide when to slow down, how to enter the pattern (unless otherwise instructed), how long to make the pattern legs. Students would often wrestle with some of these decisions. Once the aircraft was maneuvered onto a leg of the pattern, students were able to resume the normal landing profile and comply with the standard operating procedures. However, the transition portion between the en-route phase of flight and entering the pattern was often haphazard. It was suggested that additional time be spent in the simulator conducting visual approaches to better prepare students for the aircraft.

Study participants suggested the training curriculum include line oriented flight training (LOFT) in the simulator phase, including visual approaches in an attempt to provide a more real-world experience with which students may have to deal during an actual flight. LOFT and scenario-based training provide real-world situations and put the student in situations where decisions must be executed using available information, as occurs in a real aircraft.

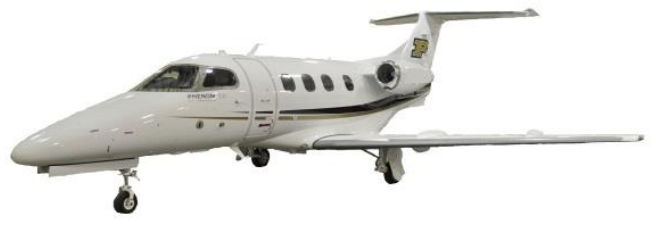

\section{Strengths}

A strength identified by the instructor pilots was the aircraft, an Embraer Phenom 100 aircraft depicted in Figure 1. This is aircraft is categorized as a very light jet (VLJ) and is certified for single-pilot operations. The aircraft is typically operated in five training slots, four days per

Figure 1. Phenom 100 Aircraft. 
week; at times, it completed up to 35 cycles per day. It was also used for select university trips, which necessitated the need to balance student training with official university business.

An area where instructors felt students excelled was in the use of the avionics. The Phenom uses a variation of the Garmin G1000 cockpit, called Prodigy. Before flying the Phenom 100, students completed primary training in a Garmin G1000 cockpit, called Perspective, found in a piston-training aircraft. It was anticipated that students' prior experience and familiarity with Garmin avionics would provide a positive transfer of learning into the jet aircraft. "I would say without Garmin experience there's no way they could do this course. There's absolutely no way," cited one participant. The instructors anticipated this strength, and it was observed throughout the training program. All the instructors felt students were able to program the avionics efficiently, however, a few expressed concern over whether the students fully comprehended how the programming functions actually linked with the other avionics, specifically the autopilot. One participant noted, "Well, every student was really competent on the Garmin... the difficulty they had was translating from the Garmin to the autopilot flight control system, the AFCS." Very few of the piston trainers with which students were familiar included autopilots. Instructors identified a learning curve as students became more familiar with the autopilot in the Phenom. A suggested improvement would be to have students gain more experience with the autopilot during the primary portions of training or at least prior to entering the Phenom aircraft to assist in learning transfer.

A final focus area of the instructors was the continued need for instructor standardization. While this initial semester only utilized four instructor pilots, as the program develops more instructors may be needed. It is also desired to provide a level of standardization that no matter which instructor completes training, it will be the same experience for the student. It should be noted that this program was unique to a university environment, and all members of the jet training team contributed to develop training and standardization materials, which are continually updated as more experiences are gained. Table 3 depicts a summary of student challenges, strengths, and suggestions for improvement that were derived from final participant interviews.

\section{Conclusions}

This study utilized a phenomenological approach to capture the first-hand experiences of four instructor pilots who trained a group of university students in a jet aircraft. Researchers completed a series of surveys with participants and a final interview to capture their perceptions on how students performed during the training. Instructors correctly anticipated that students would experience a positive transfer of learning in operating the Garmin avionics, standard operating procedures, flow patterns, and checklists. Instructors also accurately anticipated areas that would challenge students such as the increased operating speeds of the jet aircraft, descent planning, weather, and 
aircraft scheduling. After completing the interviews, the researchers identified both internal and external challenges for jet flight training.

Table 3

Summary of Student Challenges, Strengths, and Suggestions

\begin{tabular}{|c|c|c|c|c|}
\hline Instrument & $\begin{array}{c}\text { Internal } \\
\text { Challenges }\end{array}$ & $\begin{array}{c}\text { External } \\
\text { Challenges }\end{array}$ & Strengths & Suggestions \\
\hline Interview & 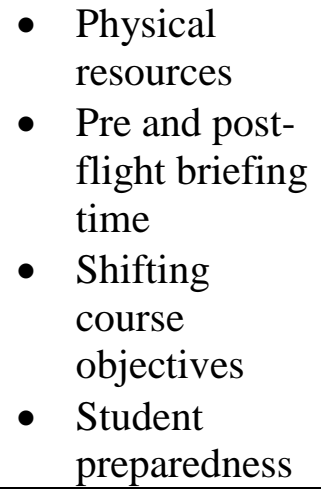 & $\begin{array}{l}\text { - Weather } \\
\text { - Situation } \\
\text { awareness }\end{array}$ & $\begin{array}{ll}\text { - } & \text { Aircraft } \\
\text { - } & \text { Avionics } \\
& \text { program } \\
& \text { ming }\end{array}$ & $\begin{array}{l}\text { - Use of Line } \\
\text { Oriented Flight } \\
\text { Training and } \\
\text { scenarios } \\
\text { - } \quad \text { Tiers of } \\
\text { training } \\
\text { - } \quad \text { Instructor } \\
\text { standardization }\end{array}$ \\
\hline
\end{tabular}

Internal challenges included availability of physical resources, pre- and post-flight briefing time, shifting course objectives, and student preparedness. Instructors expressed the need for sufficient pre- and post-flight briefing time to properly prepare students for flight lessons, yet also recognized limitations on physical resources such as instructor and aircraft scheduling demands. Concern was expressed that students needed to master procedural knowledge and arrive prepared for flights. Suggested improvements include increased briefing times and quizzes to verify knowledge retention and motivate students to keep studying. Instructors emphasized the need for students to arrive for lessons prepared, even though university environments demand student attention to other courses.

External challenges include those items over which the instructors were unable to exercise control. The weather impacted training early in the spring semester, but the instructors felt that there was enough time to make-up training later in the semester as the weather improved. Another item instructors identified was the difference between operating in a scripted environment, such as the simulator, versus the real world. External factors such as other aircraft and live air traffic control challenged students, especially when items required pilot discretion. Instructors have recommended increasing the number of visual approaches during simulator work to provide students with an opportunity to practice decision-making skills during transition from the en-route phase of flight to the traffic pattern with little or no help from air traffic control. Students were well prepared with their knowledge and understanding of programming the avionics, although some struggled with incorporating those avionics in conjunction with the automatic flight control system. Other suggestions include the use of scenarios in the training program and utilization of the principles from line oriented flight training. 
Tiers of training may address those students who are not as quick to catch on to the challenges of flying a jet or the lack the maturity level required to assume that responsibility. It may also offer the top percentage of students the chance to pursue advanced jet training. A possible limitation to a tiered system may be physical resources and time, and an additional cost to the student. Finally, standardization was recognized as needing further attention as additional groups of students complete training. Future research should focus on instructor perceptions of training cohorts, and trainee perceptions of their preparation and progress. 


\section{References}

$111^{\text {th }}$ Congress. (2010). Airline safety and federal aviation administration act of 2010. H.R 5900 .

Barnes, R. B. (2008). Ensuring VLJ safety: Learning to ask the right questions SAE Technical Publication Series 2008-01-2239. Wichita, KS: SEA.

Burian, B. (2007). Very light jets in the national airspace system. In Proceedings of The $14^{\text {th }}$ International Symposium on Aviation Psychology. Dayton, OH: Wright State University.

Burian, B. \& Dismukes, K. (2007). Training the VLJ Pilot. Mountain View, CA: NASA.

Casner, S. M. (2003). Learning about cockpit automation: From piston training to jet transport. National Aeronautics and Space Administration, Ames Research Center. Moffett Field: NASA.

Casner, S. M. (2005). Transfer of learning between a small technically advanced aircraft and a commercial jet transport simulator. International Journal of Applied Aviation Studies, 5(2), 307-319.

Creswell, J. W. (2007). Qualitative inquiry and research design: Choosing among five approaches. Thousand Oaks, Sage.

National Business Aviation Association. (2005). Very light jet training guidelines. Retrieved from http://www.nbaa.org/ops/safety/vlj/.

Smith, G. M., Bjerke, E., NewMyer, D. A., Niemczyk, M., \& Hamilton, R. A. (2010). Pilot source study: An analysis of pilot backgrounds and subsequent success in US regional airline training programs. International Journal of Applied Aviation Studies, 10(1), 73-96.

Winter, S. R., Kirschner, J.E., Leib, S. M., \& Fanjoy, R.O. (2012, October). Perceptions of instructors on student training in a jet aircraft: A preliminary qualitative analysis. Paper session presented at the Student Conference of the Human Factors and Ergonomics Society's $56^{\text {th }}$ Annual Meeting, Boston, MA. 